\title{
Biological applications and transmission electron microscopy investigation of mesoporous silica nanoparticles
}

by

Brian G. Trewyn

A dissertation submitted to the graduate faculty in partial

fulfillment of the requirements for the degree of DOCTOR OF PHILOSOPHY

\author{
Major: Inorganic Chemistry \\ Program of Study Committee: \\ Victor S.-Y. Lin, Major Professor \\ Robert J. Angelici \\ L. Keith Woo \\ Amy H. Andreotti \\ I. Scott Chumbiey
}

Iowa State University

Ames, Iowa

2006 
Graduate College

Iowa State University

This is to certify that the doctoral dissertation of

Brian G. Trewyn

has met the thesis requirements of Iowa State University.

Major Professor

For the Major Program 
iii

Imagination is more important than knowledge.

If we knew what it was we were doing, it would not be called research, would it?

- Albert Einstein 


\section{TABLE OF CONTENTS}

ABSTRACT

iv

CHAPTER 1. GENERAL INIRODUCTION

Dissertation Organization

1

Overview

Mesoporous Silica Material

1

Discovery

Synthesis and Mechanism

Characterization

Functionalization of MCM-41

Applications of MCM-41

References

Figures

CHAPTER 2. MORPHOLOGICAL CONIROL OF ROOM-TEMPERAIURE IONIC IIIUUID TEMMPIATED MESOPOROUS SIIITCA NANOPARTICIES FOR CONIROLTED REIFASE OF ANTIBACIERTAL ACHFINS

Abstract

35

References

Figures

CHAPTER 3. EHDOCYTOSIS OF TRI (ETHYLFNE GLYCOL) FUNCTIONALIZEID MESOPOROUS SIIICA NANOPARTICLES INTO CANCER AND PLANT CELTS

Abstract

Introduction

Experimental section

Results and Discussion

Figures

References

CHAPTER 4. TRANSMISSION ELECIRON MICROSCOPY AND IN VITRO TNVESTIGATION OF FLUORESCEIN IOADED, IRON OXIDE NANOPARTICLE CAPPED MESOPOROUS SILICA NANOPARTICLES.

Abstract 
Figures

110

References

CHAPTER 5. TRANSMISSION ETECTRON MICROSCOPY INVESTIGATION INIO MESOPOROUS MATERTAL AND REIATED STRUCTURES

Abstract

119

Introduction

119

Experimental

124

Results and Discussion

126

Figures

131

References

139

CHAPTER 6. GEHERAL CONCLUUSIONS

140

ACKNOWLEDGEMENTIS

144 
vi

\section{ABSTRACT}

The research presented and discussed within involves the development of novel biological applications of mesoporous silica nanoparticles (MSN) and an investigation of mesoporous material by transmission electron microscopy (TEM). Mesoporous silica nanoparticles organically functionalized shown to undergo endocytosis in cancer cells and drug release from the pores was controlled intracellularly and intercellularly. Transmission electron microscopy investigations demonstrated the variety of morphologies produced in this field of mesoporous silica nanomaterial synthesis.

A series of room-temperature ionic liquid (RTIL) containing mesoporous silica nanoparticle (MSN) materials with various particle morphologies, including spheres, ellipsoids, rods, and tubes, were synthesized. By changing the RTIL template, the pore morphology was tuned from the MCM-41 type of hexagonal mesopores to rotational moiré type of helical channels, and to wormhole-like porous structures. These materials were used as controlled release delivery nanodevices to deliver antibacterial ionic liquids against Escherichia coli K12. 
vii

The involvement of a specific organosiloxane function group, covalently attached to the exterior of fluorescein doped mesoporous silica nanoparticles (FITC-MSN), on the degree and kinetics of endocytosis in cancer and plant cells was investigated. The kinetics of endocystosis of TEG coated FITC-MSN is significantly quicker than EITC-MSN as determined by flow cytometry experiments. The fluorescence confocal microscopy investigation showed the endocytosis of TEG coated-FITC MSN triethylene glycol grafted fluorescein doped MSN (TEG coated-FITC MSN) into both HeIa cells and Tobacco root protoplasts.

Once the synthesis of a controlled-release delivery system based on MCM-41-type mesoporous silica nanorods capped by disulfide bonds with superparamagnetic iron oxide nanparticles was completed. The material was characterized by general methods and the dosage and kinetics of the antioxidant dependent release was measured. Finally, the biological interaction of the material was determined along with TEM measurements. An electron microscopy investigation proved that the pore openings of the MSN were indeed blocked by the $\mathrm{Fe}_{3} \mathrm{O}_{4}$ nanoparticles. The biological interaction investigation demonstrated $\mathrm{Fe}_{3} \mathrm{O}_{4}$-capped $\mathrm{MSN}$ endocytosis into HeLa cells. Not only does the material 


\section{viii}

enter the cells through endocytosis, but it seems that fluorescein was released from the pores, most probably caused by disulfide bond reducing molecules, antioxidants. In addition to endocytosis and release, the $\mathrm{Fe}_{3} \mathrm{O}_{4}$-capped $\mathrm{MSN}$ propelled the cells across a cuvette upon induction of a magnet force.

Finally, an important aspect of materials characterization is transmission electron microscopy. A TEM investigation demonstrated that incorporating different functional groups during the synthesis (co-condensation) changed the particle and pore morphologies. 


\section{CHAPTER 1. GENERAL INTRODUCTION}

\section{Dissertation Organization}

This dissertation begins with general information important in understanding the research presented within. The following three chapters are complete scientific manuscripts, while the fifth chapter is a transmission electron microscopy investigation on vaxious mesoporous materials that were produced in this laboratory. The sixth and final chapter contains general conclusions and points to directions of future projects.

\section{Overview}

Over the past two decades, the distinctions among material science, chemistry, and biology have become increasingly indistinguishable. Scientists in these fields have thus become ever more dependent upon one another's 
expertise. This fact is exemplified in research pertaining to mesoporous silica materials. In this chapter, an overview of mesoporous silica materials, including their discovery, synthesis and mechanism of formation, characterization, and applications in both the fields of catalysis and biology are presented and discussed.

\section{Mesoporous Silica Materials}

\section{Discovery}

Since the discovery of organic surfactant templating methods for preparing mesoporous silica materials such as MCM-41/48, ${ }^{1,2}$ SBA-15, ${ }^{3}$ MSU-n, ${ }^{4}$ KIT-1, ${ }^{5}$ and FSM-16, 6,7 the field of ordered materials has undergone extensive investigation regarding synthesis, characterization, and applications. Porous materials are broadly classified by IUPAC on the basis of pore diameter into three catagories: microporous $(<2 \mathrm{~nm})$, mesoporous $(2-50 \mathrm{~nm})$, and macroporous (>50 nm) materials. The best-known microporous materials are zeolites, which are natural or synthetic hydrated aluminosilicate with an open three-dimensional crystal structure. $^{8}$ Zeolites are used for separating mixtures by selective absorption, in sorption pumps for vacuum systems, and in ion exchange. Unfortunately, applications with 
zeolites are limited by the relatively small pore sizes available. Therefore, the research discussed herein focuses on mesoporous silica materials discovered in 1992 by researchers at the Mobil Research and Development Corporation. ${ }^{1,2}$ The researchers designated this family of materials MCM-4I (Mobile Composite of Matter) following the original reaction of aluminosilcate gels in the presence of a quaternary ammonium surfactant template. The MCM-41 family of mesoporous sieves consists of hexagonal array of uniform mesopores, varying from $15 \AA$ to greater than $100 \AA$ in diameter. The surface area of these materials is generally greater than $700 \mathrm{~m}^{2} / \mathrm{g}$ and have absorption capacities of $0.7 \mathrm{~cm}^{3} / \mathrm{g}$ and greater. Concurrently with the Mobil Researchers, an independent group from Japan developed another method for synthesis of mesoporous material, designated FSM-16 (Folded Sheet Materials). Inagaki et al. successfully synthesized a highly ordered mesoporous material derived from layered polysilicate kanemite by an ion exchange reaction. ${ }^{6,7}$ Though this material was synthesized by a different manner than the MCM-41 type, the pore size and surface area characteristics were similar, as were the powder X-ray diffraction patterns. 
The research presented, reported, and discussed henceforth is based on the self-organized cationic surfactant-templated MCM- 41 .

\section{Synthesis and Mechanism}

In a typical synthesis, a silica source (tetraethyl orthosilicate or tetramethyl orthosilicate) was added in a dropwise fashion to a clear alkaline solution of a micelleforming surfactant (generally long chain quaternary ammonium halides) at elevated temperature $(\sim 353 \mathrm{~K})$ under vigorous stirring. After stirring at this increased temperature $(\sim 2 \mathrm{~h})$ the as-synthesized $\mathrm{MCM}-41$ was filtered and washed with aqueous and organic phase solvents. Two methods are currently employed to remove the structuredirecting agents (surfactants). The first method for surfactant removal is calcination, which involves heating the as-synthesized MCM-41 to $2773 \mathrm{~K}$ for several hours under a flow of $\mathrm{N}_{2}, \mathrm{O}_{2}$, or air. The other common method for surfactant removal is acid extraction. This method employs a solution of methanol (100 mL) and hydrochloric acid (37\%, $1.0 \mathrm{~mL}$ ), with $1.0 \mathrm{~g}$ as-synthesized MCM-41. This suspension is stirred vigorously at elevated temperature (333 K) for 
several hours $(4-8 \mathrm{~h})$. The latter method of surfactant removal will be addressed further below.

A mechanism, coined as liquid crystal templating, for the formation of MCM-41 type materials was proposed in Mobile's Nature paper in $1992 .{ }^{1}$ In the liquid crystal templating mechanism, the formation of surfactant micelles, induced by the addition of silicate anions, and followed by polymerization, results in the generation of the MCM-41 structure (Figure 1). Later studies have shown that the synthesis of MCM-41 may occur with a surfactant template concentration below the critical micelle concentration; so the inorganic species, silicate in the case of silica MCM41, plays a key role in triggering the supramolecular selfassembly. This mechanism was proposed and further discussed by Stucky and coworkers (Figure 2). ${ }^{9}$ Additional evidence to corroborate this proposal is that shorter chain surfactants, such as $\left(\mathrm{C}_{12} \mathrm{H}_{25} \mathrm{~N}\left(\mathrm{CH}_{3}\right)_{3} \mathrm{Br}\right.$, which do not form rodlike micelles in water, templated mesoporous silica. In addition MCM-41 silicas are synthesized at temperatures above $70{ }^{\circ} \mathrm{C}$ where rod-like micelles are not stable. The mechanism is triggered by electrostatic interactions, which correspond to the displacement of the counteranions of the surfactant by polycharged and polydentate inorganic anions. 
This interaction leads to organic-inorganic ion pairs, which form pseudo-liquid crystal phases. This is followed by the base-catalyzed cross linking of the inorganic species and the formation of a rigid replica of the underlying liquid crystalline phase. ${ }^{10}$

\section{Characterization}

Following synthesis, the material must be characterized to determine particle and pore morphology, structure and surface details. The five main characterizing techniques used on most mesoporous materials are low angle powder X-ray diffraction (XRD), nitrogen adsorption/desorption, scanning electron microscopy (SEM), transmission electron microscopy (TEM), and, recently, solid state nuclear magnetic resonance (NMR). Adsorption analysis gives information about the porosity and surface area of the materials, while SEM gives particle size and morphology. Diffraction techniques and TEM supply insight to the degree of structural order. Finally, solid state NMR measurements provide details regarding the surfaces of MCM-41 materials. 


\section{a.) Powder X-ray Diffraction}

Despite long-range order, these materials are amorphous in nature, as demonstrated by solid state NMR and high angle $\mathrm{X}$-ray diffraction patterns. For this reason, $\mathrm{X}-$ ray diffraction analysis is generally measured at the low angle $\left(0.5-10^{\circ}\right)$. A typical example of a low angle powder XRD of silica MCM-41 is shown in figure 3a. The powder Xray diffraction is the most rapid method to determine the nature and degree of pore order in the material. Generally, three or four peaks of varying intensity are observed, which can be indexed in a hexagonal pattern characteristic of MCM-41 materials. ${ }^{2}$ These peaks observed in the low-angle 2-theta region can be indexed as $d_{100}, d_{110}$, $\mathrm{d}_{200}$, and $\mathrm{d}_{210}$. The simple hexagonal lattice is shown in figure 3b. The lattice parameter may also be obtained from the XRD via the equation: $a=2 d_{100} / \sqrt{3}$, which is the sum of pore diameter and wall thickness. Thus, by measuring the lattice parameter and pore diameter (see below) the wall thickness can be easily determined.

\section{b.) Nitrogen sorption analysis}

Nitrogen adsorption/desorption is an important aspect of material characterizing for the determination of pore size (diameter), pore volume, and surface area. Two 
calculation methods reported in the mid twentieth century facilitated the measurements of surface area and pore diameter/volume. Stephen Brunauer, P.H. Emmett, and Edward Teller developed a method employed to calculate the surface area. ${ }^{11}$ This calculation, known as Brunauer-Emmett-Teller (BET), determines the surface area by measuring the adsorption of nonpolar gases $\left(N_{2}, A r\right)$. The calculation is modeled on the physical adsorption of gas on the surface of the material as a function of pressure. ${ }^{12}$ Surface area determinations involve creating the conditions required to adsorb an average monolayer of gas molecules onto a sample. As pressure increases, the amount of gas adsorbed quickly rises due to the capillary condensation in mesopores. This gas condensation occurring in the mesopores allows the fine porous structure of the sample to be evaluated. The pressure is increased until saturation is reached when all mesopores are filled with liquid. The pressure is reduced incrementally, evaporating the condensed gas from the system. Upon desorption, a hysteresis is commonly observed in mesoporous materials. Hysteresis is the phenomenon in which the value of a physical property lags behind changes in the effect causing it. The hysteresis between the adsorption and desorption branches of the isotherm reveals 
information regarding pore size, volume, area, and shape. Hysteresis loops most likely arise from a combination of thermodynamic and network effects. The thermodynamic hysteresis may be due to capillary condensation and capillary evaporation occurring at higher and lower pressures, respectively. The network effect may be caused by a decrease in pore diameter at the mouths of the pores, much like a wine bottle. A typical isotherm produced by nonfunctional silica MCM-41 material can be seen in figure four, notice the hysteresis.

The pore diameter and pore volume calculations were developed by Elliot P. Barrett, Leslie G. Joyner, and Paul P. Halenda. ${ }^{13}$ This calculation, known as BJH, assumes a similar theory to the BET of the adsorption/desorption process. The BJH is calculated when saturation is reached and all mesopores are filled by the adsorptive gas. The BJH calculates a pore diameter distribution, outputs a histogram, and an average pore size is reported. It applies only to the mesopores and small macropore size range. This calculation assumes the approximate cylindrical pore geometry. ${ }^{12}$ 


\section{c.) Scanning and transmission electron microscopy}

The next characterization techniques employed on MCM41 type materials are scanning and transmission electron microscopy (SEM and TEM, respectively). Since low angle powder XRD provides insufficient information to draw definite conclusions on the structure of the materials, these two electron microscopy techniques are employed. Scanning electron microscopy utilizes a lower voltage electron beam $(<20 \mathrm{kV})$ and is useful for determining exterior particle morphology to about 50,000x magnification. The shape and size of the nanoparticles are readily observed by SEM (Figure 5a). Transmission electron microscopy utilizes a stronger electron beam $(\sim 300 \mathrm{kV})$, and allows for the visualization of pores. Transmission electron microscopy is not a substitute for XRD, since only a small sampling is obtained. The magnification achievable by TEM is in the order of $300,000 x$. Transmission electron microscopy gives evidence in support of the powder XRD regarding pore structure and order (Figure 5b). Chapter five provides further insight on TEM measurements of mesoporous materials.

\section{d.) Solid state nuclear magnetic resonance}


Solid state NMR, with new advances in ultrafast magic angle spinning (MAS), provides improved tools for the investigation of MCM-41 surfaces. With this technique, high-resolution ${ }^{1} \mathrm{H}$ spectra, ${ }^{1} \mathrm{H}-{ }^{13} \mathrm{C}$ heteronuclear, and ${ }^{1} \mathrm{H}^{29} \mathrm{Si}$ heteronuclear correlation spectra can be obtained quickly and with small sample quantities. ${ }^{14,15}$ The ${ }^{29} \mathrm{Si}$ NMR data allows for the estimation of the relative concentration of $Q^{2}$ and $Q^{3}$ silicon sites associated with geminal $(-\mathrm{O}-\rangle_{2} \mathrm{Si}(\mathrm{OH})_{2}$ and single $(-\mathrm{O}-)_{3} \mathrm{SiOH}$ silanol groups, respectively. When the MCM-41 material is covalently functionalized with organosilanes, functionalization of MCM-41 with organosilanes is detailed below, the MAS spectra can also estimate the relative concentration of $\mathrm{T}^{3}$ and $\mathrm{T}^{2}$ sites associated with (ESiO-) ${ }_{3} \mathrm{SiR}$ and $(\equiv \mathrm{SiO}-)_{2} \mathrm{Si}\left(\mathrm{OR}^{\prime}\right) \mathrm{R}$, respectively.

The first two characterizing methods, XRD and nitrogen adsoption, are the most frequently employed methods to characterize periodic mesoporous silica materials because of cost and technical availability. Electron microscopy and solid state NMR, while giving important data, have Iimits due to the cost of the instruments and the knowledge necessary to carry out such measurements. 


\section{Functionalization of MCM- 41}

The materials used in the following projects are modified through covalent linkage between functional groups (organosilanes) and silica framework. There are two wellknown methods for functionalizing the MCM-4I materials. These methods include grafting (post-synthesis) and cocondensation (direct incorporation).

The former method, grafting, involves introducing organic functional groups by direct reaction of organosilanes to the surface of the mesoporous material. One advantage of the grafting method of surface functionalization is that the as-synthesized material can be calcined before functionalizing to ensure the surfactant is completely removed. Functionalizing MCM-4l material through the grafting method has several disadvantages. The distribution and concentration of functional groups are influenced by the reactivity of the organosilane and the accessibility of surface silanols, which are limited by diffusion and steric factors. Essentially, grafting organosilanes allows, almost exclusively, for coverage on the exterior and at the ends of the pores.

The latter method, co-condensation, ìnvolves hydrolytically condensing organosilanes with conventional 
silica sources such as tetraethyl orthosilicate. ${ }^{16,17}$ The co-condensation method has advantages over the grafting method in that it offers a short, one-pot preparation, which yields a mesoporous silica material with a homogeneous distribution of functional groups, in high loading. In 2002, Ozin and coworkers reported very high functional group loading, up to $62 \%$, in mesoporous silica material through the co-condensation method. ${ }^{1.8}$ The incorporation of the organosilanes in the synthesis does lead to interesting, unique particle morphologies. ${ }^{19,20}$ The various organosilanes interact with the template-directing surfactants in a different manner than the silanols or silicates of MCM-41, giving rise to these different morphologies.

\section{Applications of MCM-41}

The unique characteristics of the MCM-41 family of materials -- including high surface area, well-defined pore shape, narrow pore size distribution, large pore volume, and high stability -- are conducive to a wide variety of noteworthy applications. These applications include, but are not limited to, heterogeneous catalysis and catalyst support, ${ }^{21-38}$ heterogenization of homogeneous catalysts, ${ }^{39-44}$ 
separation and adsorption processes, ${ }^{32,45-50}$ drug delivery and controlled release, ${ }^{51-62}$ and sensors. ${ }^{56,63-75}$

Heterogeneous catalysis systems display advantages over similar homogeneous systems, such as the ease of recovery and recycling of the active species. Heterogeneous catalysts are obviously attractive from environmental and economical points of view. The high surface area, large pore volume, and structure diversity allows for the selective adsorption of a variety of gases, liquids, and solids. One application of heterogeneous catalysis has been the development of a hetexogeneous solid acid catalyst. This is advantageous over traditional homogeneous acid catalysts, since traditional homogenous acid catalysts necessitate the handling of hazardous chemicals. In 2002, Klier and coworkers reported the synthesis of propylsulfonic acid-functionalized SBA-15. ${ }^{76}$ This material catalyzed coupling reactions of alcohols to ethers with high selectivity.

Organic functionality is not the only type of chemical functionality to be incorportated into mesoporous materials. The incorporation of organic ligand groups are often used for the entrapment of metal components in MCM41. Recently, Thiel and coworkers covalently 
functionalized $\quad$ MCM-41 with 3-(2-pyridyl)-1pyrazoylacetamide ligands via a co-condensation method. ${ }^{77}$ By adding a solution of oxodiperoxomolybdenum, a heterogeneous $\mathrm{MoO}\left(\mathrm{O}_{2}\right)$ complex formed with all chemically accessible ligands. This catalyst worked as a highly active catalyst for the epoxidation of cyclooctene with tbutyl hydroperoxides, with minimal leaching.

Another important Eunction of MCM-41 type material involves their interaction with biomolecules and biological. systems. Various publications document the use of MCM-41 as solid supports for enzymes -- by covalent attachment, electrostatic interactions, and hydrogen bonding. Immobilized enzymes are being increasingly used as catalysts in many commercial applications, owing to their ease of separation and enhanced thermal and $\mathrm{pH}$ stability. In 2003, Choudary and coworkers reported the preparation of immobilized $\alpha$-chymotrypsin on MCM-41, with a significant protein loading of $170 \mathrm{mg}^{-1}$. In this case, the enzyme was stirred with MCM-41 in aqueous tris-HCl buffer (pH 7.2), where the a-chymotrypsin is immobilized via a simple electrostatic interaction. ${ }^{78}$ More recently, in 2004, Duan and coworkers immobilized lipase in the pores of MCM-41 through hydrogen bonding interactions between the weakly 
acidic hydroxyl groups of the support and the enzyme. By treating the immobilized enzyme with vinyltrimethoxysilane, the activity of triacetylglycerol hydrolysis remained constant over five cycles. ${ }^{79}$

Recently, researchers have demonstrated endocytosis of MCM-41 material into various cellular systems. In 2005, Mou et al. synthesized functionalized nanosized mesoporous silicas to be used as fluorescence cell tags in both fibroblast and human masenchymal stem cells. ${ }^{32,80}$ Earlier, Radu et al. showed the endocytosis of MCM-41 that was covalently capped with PAMAM dendrimer and complexed with plasmid DNA. ${ }^{81}$ Also, in 2005 Lin et al. demonstrated the synthesis of a controlled-release delivery system that is based on MCM-41 capped with superparamagnetic iron oxide nanoparticles and was stimuli-responsive and chemically inert to guest molecules entrapped in the pores. ${ }^{82}$

This review shows that a vast field of new and exciting periodic mesoporous materials are rapidly emerging from research institutes around the world. Diverse applications of periodic mesoporous materials continue to stimulate interest in many fields including chemistry, material science, and biology. The mesoporous silica nanoparticle (MSN) materials developed in our labs possess 
a variety of properties to make them potentially useful at the cellular level. our goal was to investigate the potential applications of MSNs as antibacterial agents, vehicles for animal and plant cell endocytosis, and stimuli-responsive controlled release material. In addition, a final goal was the investigation of various mesoporous materials using transmission electron microscopy. 


\section{References}

(1) Kresge, C. T.; Leonowicz, M. E.; Roth, W. J.; Vartuli, J. C.; Beck, J. S. Nature (London, United Kingdom) $1992,359,710-12$.

(2) Beck, J. S.; Vartuli, J. C.; Roth, W. J.; Leonowicz, M. E.; Kresge, C. T.; Schmitt, K. D.; Chu, C. T. W.; Olson, D. H.; Sheppard, E. W.; et al. Journal of the American Chemical Society 1992, 114, 10834-43.

(3) Zhao, D.; Feng, J.; Huo, Q.; Melosh, N.; Frederickson, G. H.; Chmelka, B. F.; Stucky, G. D. Science (Washington, D. C.) 1998, 279, 548-552.

(4) Bagshaw, S. A.; Prouzet, E.; Pinnavaia, T. J. Science (Washington, D. C.) 1995, 269, 1242-4.

(5) Ryoo, R.; Kim, J. M.; Ko, C. H.; Shin, C. H. Journal of Physical Chemistry 1996, 100, 17718-17721.

(6) Inagaki, S.; Fukushima, Y.; Kuroda, K. Journal of the Chemical Society, Chemical Communications 1993, 680-2.

(7) Inagaki, S.; Koiwai, A.; Suzuki, N.; Fukushima, Y.; Kuroda, K. Bulletin of the Chemical Society of Japan $1996,69,1449-1457$.

(8) Daintith, J. A Dictionary of Chemistry; 3 ed.; Oxford University Press: New York, 1996. 
(9) Firouzi, A.; Kumar, D.; Bull, L. M.; Besier, T.; Sieger, P.; Huo, Q.; Walker, S. A.; Zasadzinski, J. A.; Glinka, C.; Nicol, J.; Margolese, D.; Stucky, G. D.; Chmelka, B. F. Science (Washington, D. C.) 1995, $267,1138-1143$.

(10) Yang, P.; Editor The Chemistry of Nanostructured Materials, 2003.

(11) Brunauer, S.; Emmett, P. H.; Teller, E. Journal of the American Chemical Society 1938, 60, 309-19.

(12) Kruk, M.; Jaroniec, M. Chemistry of Materials 2001, $13,3169-3183$

(13) Joyner, L. G.; Barrett, E. P.; Skold, R. Journal of the American Chemical Society 1951, 73, 3155-8.

(14) Trebosc, J.; Wiench, J. W.; Huh, S.; Lin, V. S. Y.; Pruski, M. Journal of the American Chemical Society $2005,127,7587-7593$.

(15) Trebosc, J.; Wiench, J. W.; Huh, S.; Lin, V. S. Y.; Pruski, M. Journal of the American Chemical Society $2005,127,3057-3068$.

(16) Burkett, S. L.; Sims, S. D.; Mann, S. Chemical Communications (Cambridge) 1996, 1367-1368.

(17) Macquarrie, D. J. Chemical Communications (Cambridge) $1996,1961-1962$. 
(18) Kruk, M.; Asefa, T.; Jaroniec, M.; Ozin Geoffrey, A. Journal of the American Chemical Society 2002, 124, $6383-92$.

(19) Huh, S.; Wiench, J. W.; Trewyn, B. G.; Song, S.; Pruski, M.; Lin, V. S. Y. Chemical Communications (Cambridge, United Kingdom) 2003, 2364-2365.

(20) Huh, S.; Wiench, J. W.; Yoo, J.-C.; Pruski, M.; Lin, V. S. Y. Chemistry of Materials 2003, 15, 4247-4256.

(21) Aprile, C.; Abad, A.; Garcia, H.; Corma, A. Journal of Materials Chemistry 2005, 15, 4408-4413.

(22) Brunel, D.; Blanc, A. C.; Galarneau, A.; Fajula, F. Catalysis Today 2002, 73, 139-152.

(23) Chai, G. S.; Shin, I. S.; Yu, J.-S. Advanced Materials (Weinheim, Germany) 2004, 16, 2057-2061.

(24) Cho, Y. S.; Park, J. C.; Lee, B.; Kim, Y.; Yi, J. Catalysis Letters 2002, 81, 89-96.

(25) Corma, A. Chemical Reviews (Washington, D. C.) 1997, $97,2373-2419$.

(26) Dubey, A.; Choi, M.; Ryoo, R. Green Chemistry 2006, 8, $144-146$.

(27) Huh, S.; Chen, H.-T.; Wiench, J. W.; Pruski, M.; Lin, V. S. Y. Angewandte Chemie, International Edition $2005,44,1826-1830$ 
(28) Li, Z.; Gao, L.; Zheng, S. Applied Catalysis, A: General 2002, 236, 163-171.

(29) Lin, V. S. Y.; Radu, D. R.; Han, M.-K.; Deng, W.; Kuroki, S.; Shanks, B. H.; Pruski, M. Journal of the American Chemical Society 2002, 124, 9040-9041.

(30) Patra, C. R.; Ghosh, A.; Mukherjee, P.; Sastry, M.; Kumar, R. Studies in Surface Science and Catalysis $2002,141,641-646$.

(31) Rac, B.; Molnar, A.; Forgo, P.; Mohai, M.; Bertoti, I. Journal of Molecular Catalysis A: Chemical 2006, 244, $46-57$.

(32) Radu, D. R.; Lai, C.-Y.; Huang, J.; Shu, X.; Lin, V. S. Y. Chemical Communications (Cambridge, United Kingdom) 2005, 1264-1266.

(33) Thomas, J. M. Journal of Molecular Catalysis A: Chemical 1999, 146, 77-85.

(34) Wang, X.; Tseng, Y.-H.; Chan, J. C. C.; Cheng, S. Microporous and Mesoporous Materials 2005, 85, 241251.

(35) Xiang, S.; Zhang, Y.; Xin, Q.; Li, C. Angewandte Chemie, International Edition 2002, 41, 821-824.

(36) Xiao, F.-S. Topics in Catalysis 2005, 35, 9-24. 
(37) Zhang, J.-L.; Liu, Y.-L.; Che, C.-M. Chemical Communications (Cambridge, United Kingdom) 2002, 29062907.

(38) Zheng, Y.; Su, X.; Zhang, X.; Wei, W.; Sun, Y. Studies in Surface Science and Catalysis 2005, 156, 205-212.

(39) Kureshy, R. I.; Ahmad, I.; Khan, N.-u. H.; Abdi, S. H. R.; Pathak, K.; Jasra, R. V. Tetrahedron: Asymmetry $2005,16,3562-3569$.

(40) Fuerte, A.; Corma, A.; Sanchez, F. Catalysis Today $2005,107-108,404-409$.

(41) Gonzalez-Arellano, C.; Corma, A.; Iglesias, M.; Sanchez, F. Advanced Synthesis \& Catalysis 2004, 346, $1316-1328$.

(42) Peng, Q.; Yang, Y.; Yuan, Y. Journal of Molecular Catalysis A: Chemical 2004, 219, 175-181.

(43) Kucherov, A. V.; Kramareva, N. V.; Finashina, E. D.; Koklin, A. E.; Kustov, L. M. Journal of Moleculax Catalysis $A$ : Chemical 2003, 198, 377-389.

(44) Alcon, M. J.; Corma, A.; Iglesias, M.; Sanchez, F. Journal of Organometallic Chemistry 2002, 655, 134145. 
(45) Ernst, S.; Hartmann, M.; Munsch, S.; Thiel, H. Studies in Surface Science and Catalysis 2004, 154B, 20202026.

(46) Mehraban, Z.; Farzaneh, F. Microporous and Mesoporous Materials 2006, 88, 84-90.

(47) Shiraishi, Y.; Nishimura, G.; Hirai, T.; Komasawa, I. Industrial \& Engineering Chemistry Research 2002, 41, $5065-5070$.

(48) Song, C.; Xu, X.; Andresen, J. M.; Miller, B. G.; Scaroni, A. W. Studies in Surface Science and Catalysis 2004, 153, 411-416.

(49) Xu, X.; Song, C.; Andresen, J. M.; Miller, B. G.; Scaroni, A. W. International Journal of Environmental Technology and Management 2004, 4, 32-52.

(50) Zhao, Y. X.; Ding, M. Y.; Chen, D. P. Analytica Chimica Acta 2005, 542, 193-198.

(51) Andersson, J.; Rosenholm, J.; Areva, S.; Linden, M. Chemistry of Materials 2004, 16, 4160-4167.

(52) Casasus, R.; Marcos, M. D.; Martinez-Manez, R.; RosLis, J. V.; Soto, J.; Villaescusa, L. A.; Amoros, P.; Beltran, D.; Guillem, C.; Latorre, J. Journal of the American Chemical Society 2004, 126, 8612-8613. 
(53) Fornasieri, G.; Badaire, S.; Backov, R.; MondainMonval, 0.; Zakri, C.; Poulin, P. Advanced Materials (Weinheim, Germany) 2004, 16, 1094-1097.

(54) Gruenhagen, J. A.; Lai, C.-Y.; Radu, D. R.; Lin, V. S. Y.; Yeung, E. S. Applied Spectroscopy 2005, 59, 424431.

(55) Mal, N. K.; Fujiwara, M.; Tanaka, Y. Nature (London, United Kingdom) 2003, 421, 350-353.

(56) Ostafin, A. E.; Burgess, J. P.; Mizukami, H. Tissue Engineering and Novel Delivery Systems 2004, 483-503.

(57) Sayari, A. Chemistry of Nanostructured Materials 2003, $39-68$.

(58) Tourne-Peteilh, C.; Lerner, D. A.; Chamay, C.; Nicole, L.; Begu, S.; Devoisselle, J.-M. ChemPhysChem 2003, 4, $281-286$.

(59) Tozuka, Y.; Oguchi, T.; Yamamoto, K. Pharmaceutical Research 2003, 20, 926-930.

(60) Trewyn, B. G.; Whitman, C. M.; Lin, V. S. Y. Nano Letters 2004, 4, 2139-2143.

(61) Vallet-Regi, M.; Doadrio, J. C.; Doadrio, A. L.; Izquierdo-Barba, I.; Perez-Pariente, J. Solid State Ionics 2004, 172, 435-439. 
(62) Zhu, Y.; Shi, J.; Shen, W.; Chen, H.; Dong, X.; Ruan, M. Nanotechnology 2005, 16, 2633-2638.

(63) Balaji, T.; Sasidharan, M.; Matsunaga, H. Analytical and Bioanalytical Chemistry 2006, 384, 488-494.

(64) Cabot, A.; Arbiol, J.; Cornet, A.; Morante, J. R.; Chen, F.; Liu, M. Thin Solid Films 2003, 436, 64-69.

(65) Descalzo, A. B.; Marcos, M. D.; Martinez-Manez, R.; Soto, J.; Beltran, D.; Amoros, P. Journal of Materials Chemistry 2005, 15, 2721-2731.

(66) Feng, Y.; Yao, R.; Zhang, L. Materials Chemistry and Physics 2004, 89, 312-315.

(67) Konorov, S. O.; Mitrokhin, V. P.; Smirnova, I. V.; Fedotov, A. B.; Sidorov-Biryukov, D. A.; Zheltikov, A. M. Chemical Physics Letters 2004, 394, 1-4.

(68) Metivier, R.; Leray, I.; Lebeau, B.; Valeur, B. Journal of Materials Chemistry 2005, 15, 2965-2973.

(69) Onida, B.; Borello, L.; Fiorilli, S.; Bonelli, B.; Arean, C. O.; Garrone, E. Chemical Communications (Cambxidge, United Kingdom) 2004, 2496-2497.

(70) Radu, D. R.; Lai, C.-Y.; Wiench, J. W.; Pruski, M.; Lin, V. S. Y. Journal of the American Chemical Society $2004,126,1640-1641$. 
(71) Sasahara, T.; Kido, A.; Ishihara, H.; Sunayama, T.; Egashira, M. Sensors and Actuators, B: Chemical 2005, $B 108,478-483$.

(72) Wirnsberger, G.; Scott, B. J.; Stucky, G. D. Chemical Communications (Cambridge) 2001, 119-120.

(73) Yantasee, W.; Fryxell, G. E.; Conner, M. M.; Iin, Y. Journal of Nanoscience and Nanotechnology 2005, 5, $1537-1540$.

(74) Yantasee, W.; Lin, Y.; Fryxell, G. E.; Wang, Z. Electroanalysis $2004,16,870-873$

(75) Zhang, H.; Sun, Y.; Ye, K.; Zhang, P.; Wang, Y. Journal of Materials Chemistry 2005, 15, 3181-3186.

(76) Shen, J. G. C.; Herman, R. G.; Klier, K. Journal of Physical Chemistry B 2002, 106, 9975-9978.

(77) Jia, M.; Seifext, A.; Berger, M.; Giegengack, H.; Schulze, S.; Thiel, W. R. Chemistry of Matexials 2004, $16,877-882$

(78) Fadnavis, N. W.; Bhaskar, V.; Kantam, M. L.; Choudary, B. M. Biotechnology Progress 2003, 19, 346-351.

(79) Ma, H.; He, J.; Evans, D. G.; Duan, X. Journal of Molecular Catalysis B: Enzymatic 2004, 30, 209-217. 
(80) Lin, Y.-S.; Tsai, C.-P.; Huang, H.-Y.; Kuo, C.-T.; Hung, Y.; Huang, D.-M.; Chen, Y.-C.; Mou, C.-Y. Chemistry of Materials 2005, 17, 4570-4573.

(81) Radu, D. R.; Lai, C.-Y.; Jeftinija, K.; Rowe, E. W.; Jeftinija, S.; Lin, V. S. Y. Journal of the American Chemical Society 2004, 126, 13216-13217.

(82) Giri, S.; Trewyn, B. G.; Stellmaker, M. P.; Lin, V. S. Y. Angewandte Chemie, International Edition 2005, 44, $5038-5044$ 


\section{FIGURE LEGENDS}

Figure 1. Liquid Crystal templating mechanism for the formation of MCM-41. [2].

Figure 2. Cooperative inorganic-surfactant templating mechanism [8].

Figure 3. (a) Typical low angle powder X-ray diffraction for MCM-41. (b) Simple hexagonal lattice index.

Figure 4. Typical nitrogen adsorption/desorption isotherm and pore diameter distribution (inset) calculated by BJH.

Figure 5. Typical SEM (a) and TEM (b) micrographs of nonfunctional MCM-41 silica. 
Figure 1.

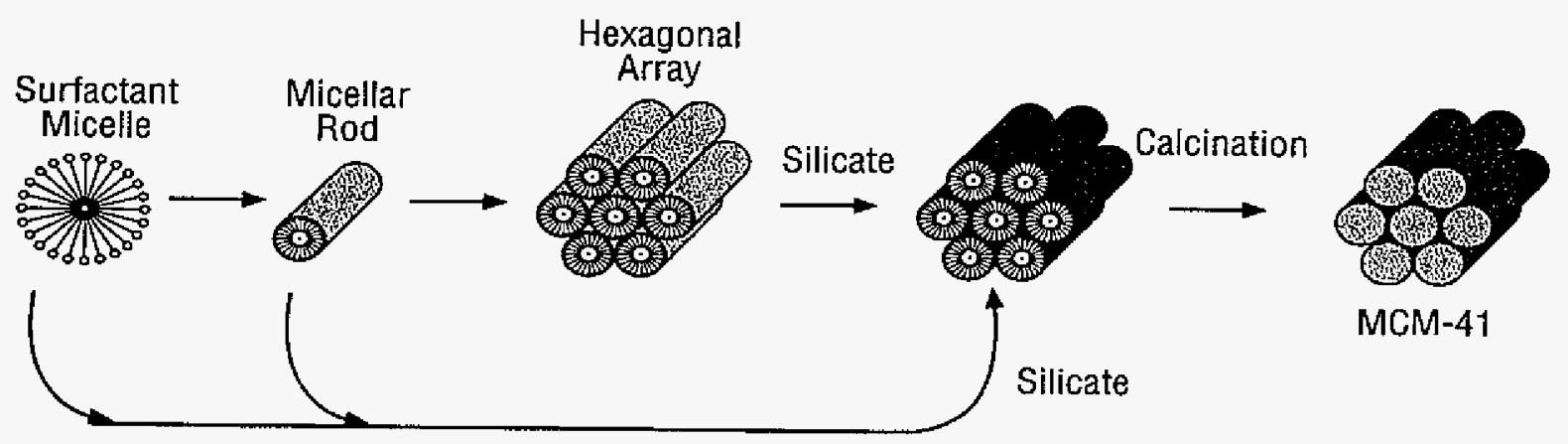


Figure 2 .

A Precursor solutions

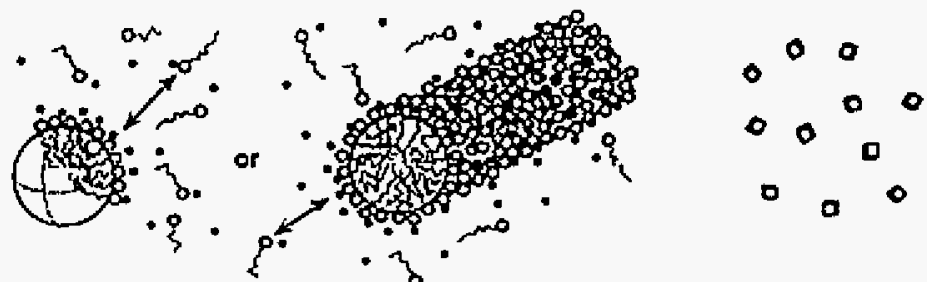

Micelles and isolated cationic Inorganic silicate anions

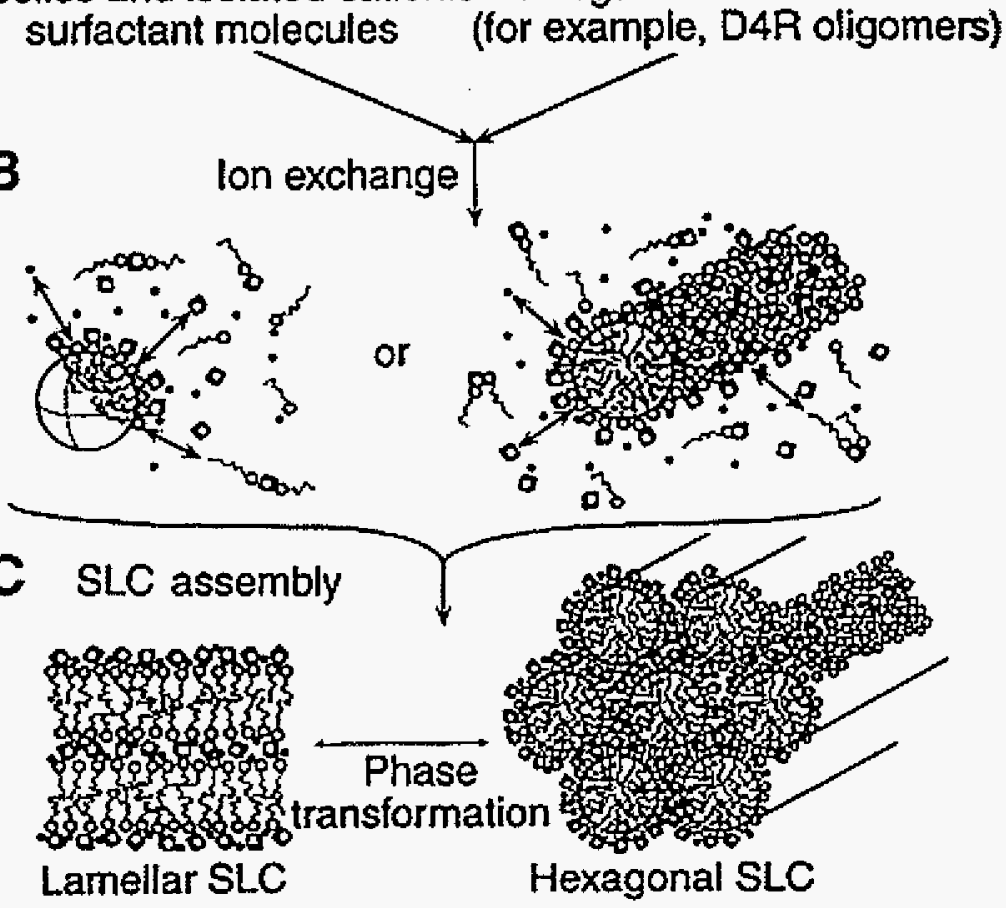


Figure $3 a$.

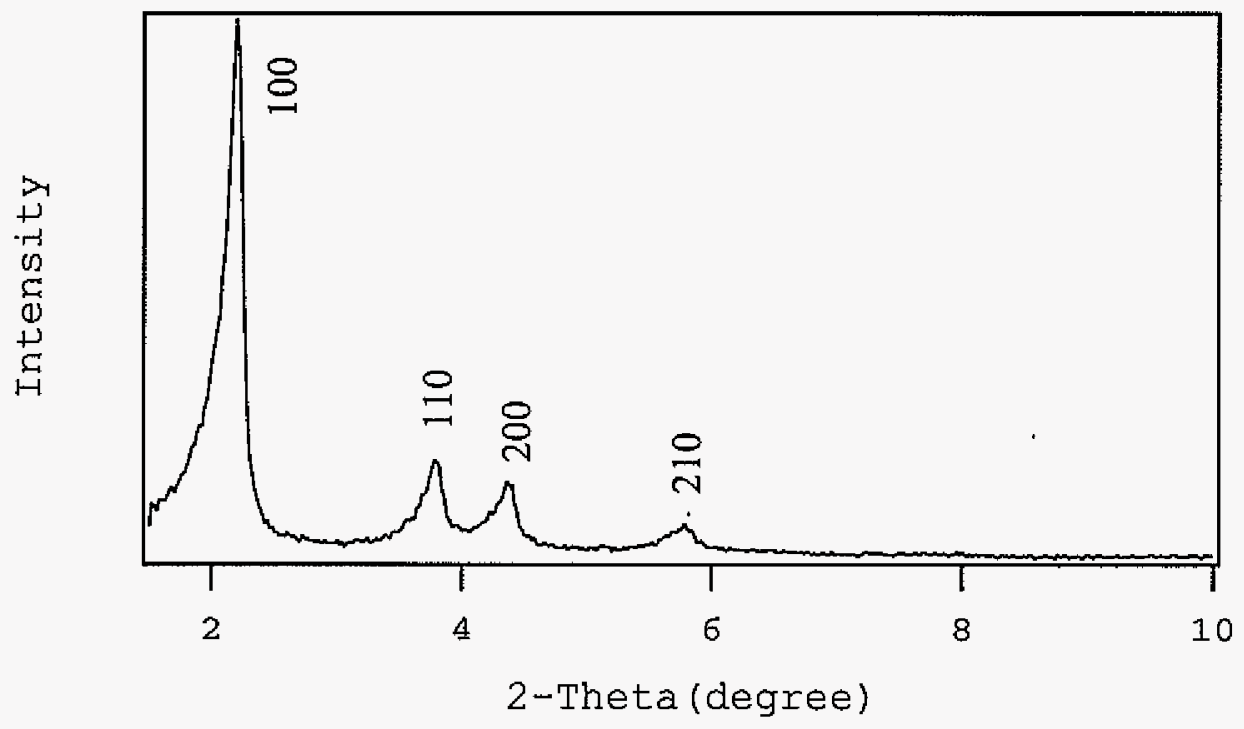


Figure 3b.

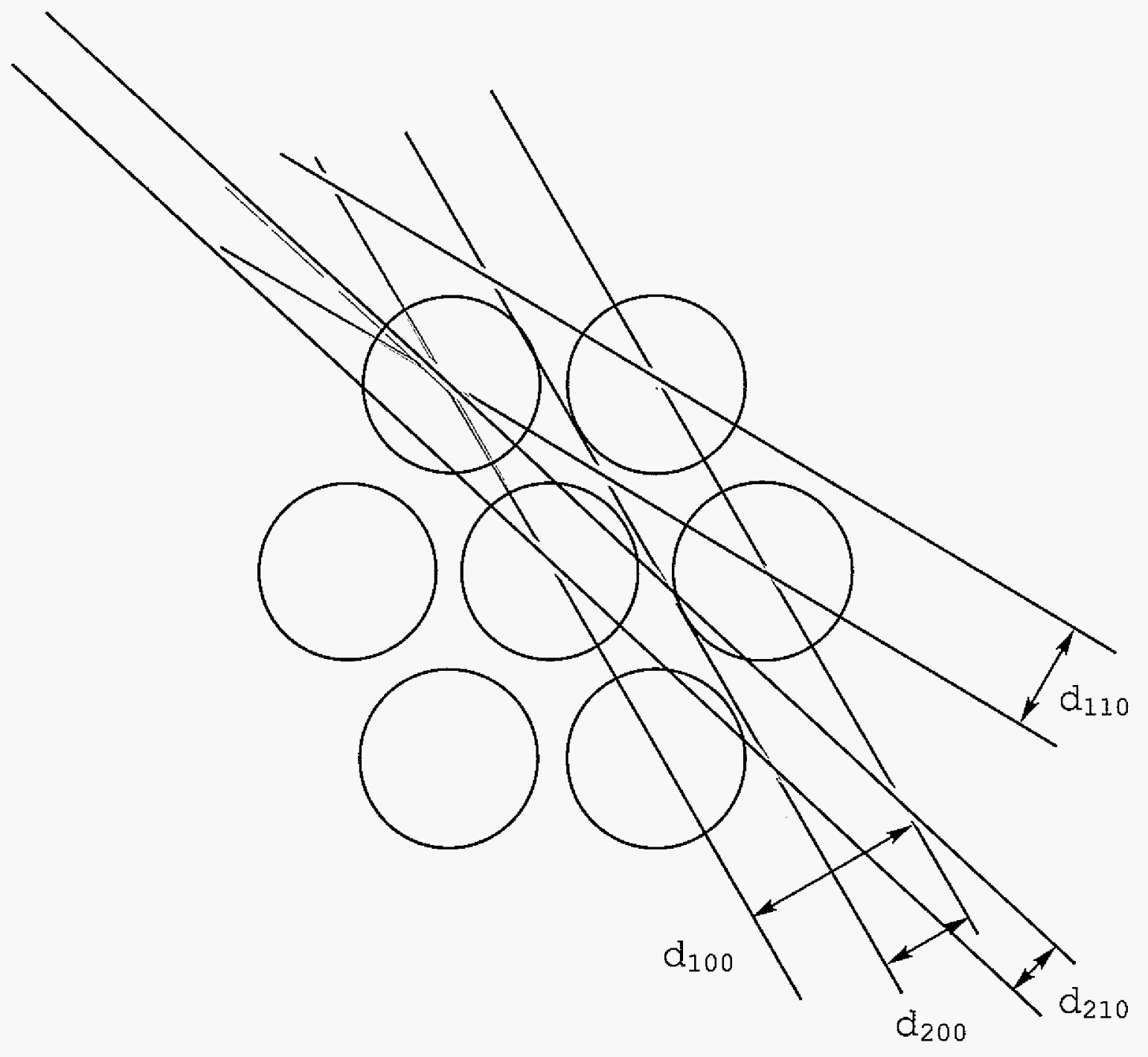


Figure 4.

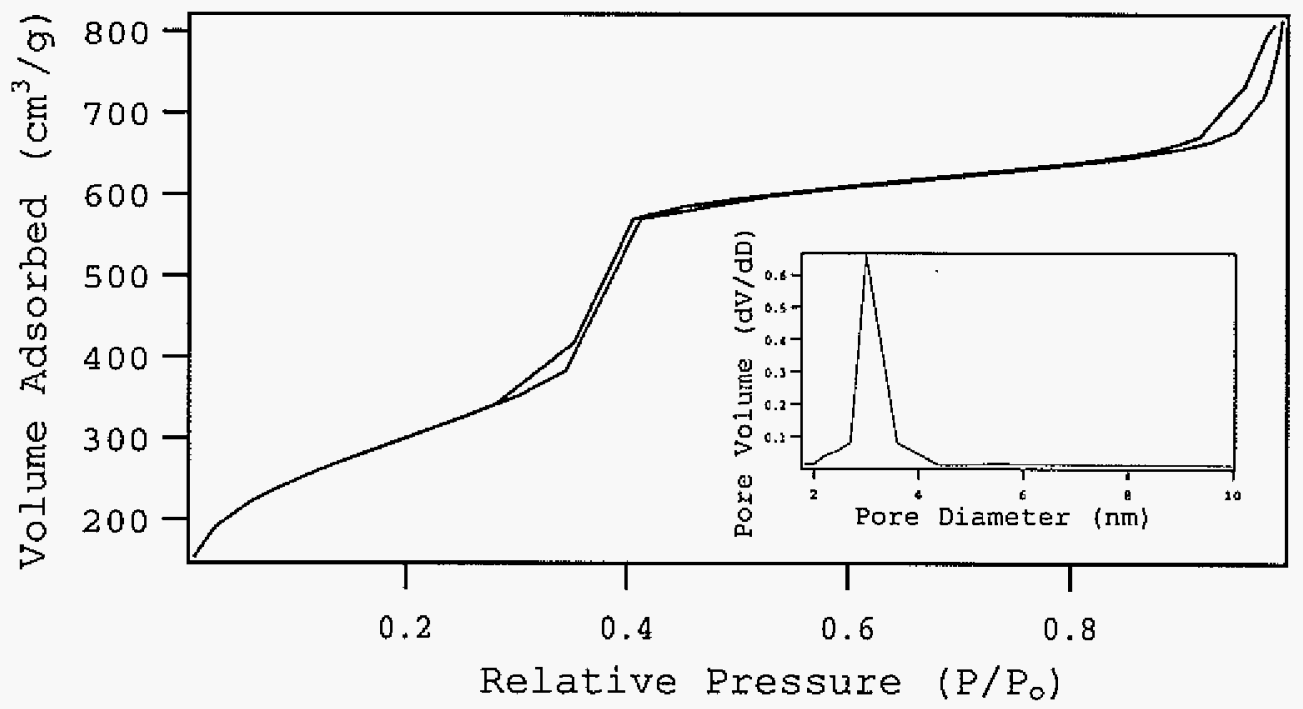


Figure 5.
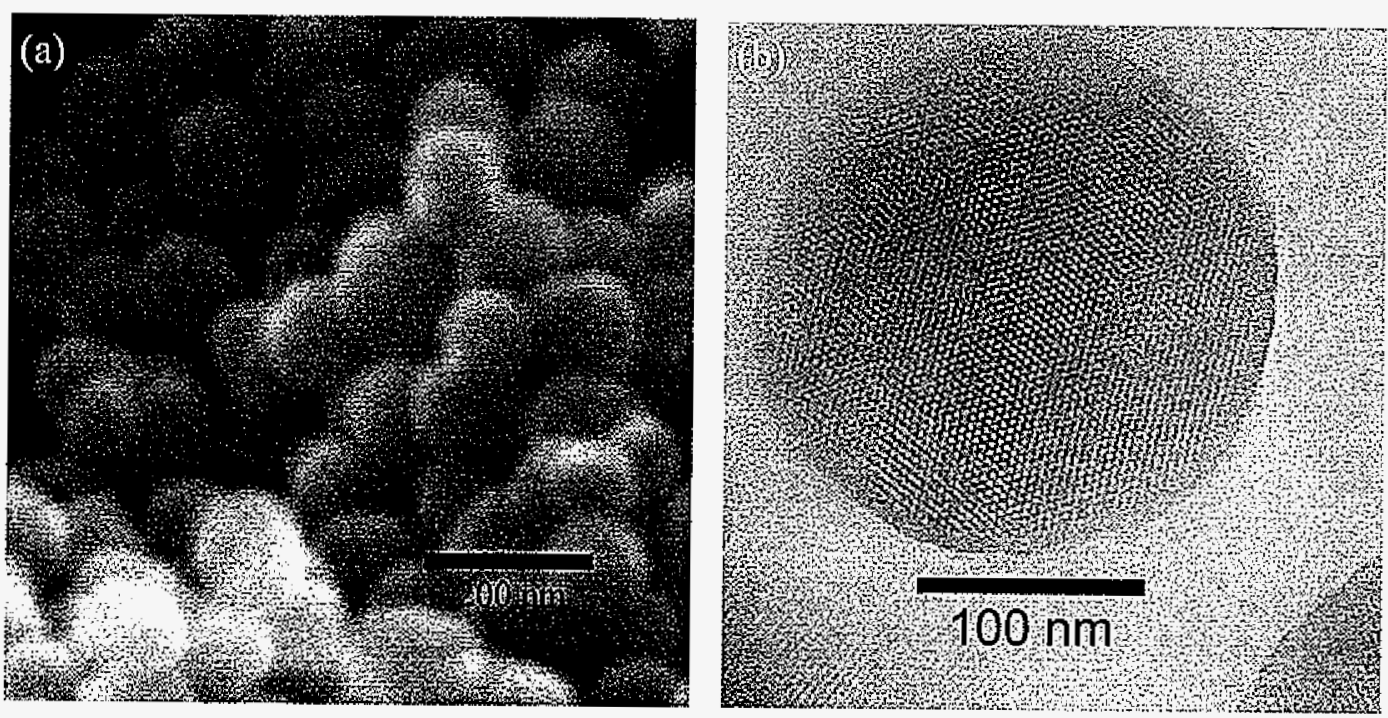


\title{
CHAPTER 2. MORPHOLOGICAL CONTROL OF ROOM- TEMPERATURE IONIC LIQUID TEMPIATED MESOPOROUS SILICA NANOPARTICLES FOR CONTROLLED RELEASE OF ANTIBACTERIAL AGENTS
}

A paper published in NanoLetters 2004, 11, 2139-2143.

\author{
Brian G. Trewyn*, Chad M. Whitman, Victor S. $-Y$. Lin
}

*Primary researcher and author

ABSTRACT. A series of room-temperature ionic liquid (RTIL) containing mesoporous silica nanoparticle (MSN) materials with various particle morphologies, including spheres, ellipsoids, rods, and tubes, were synthesized. By changing the RTIL template, the pore morphology was tuned from the MCM-41 type of hexagonal mesopores to rotational moiré type of helical channels, and to wormhole-like porous structures. These materials were used as controlled release delivery nanodevices to release antibacterial ionic liquids against Escherichia coli K12. 
Structurally well-defined mesoporous silica materials, such as MCM-41/48, ${ }^{1}$ SBA- $15,{ }^{2}$ MSU- $n,{ }^{3}$ KIT-1, ${ }^{4}$ and FSM-16, ${ }^{5}$ have recently attracted much attention for their potential applications in sensing, ${ }^{6}$ catalysis, ${ }^{7}$ and drug delivery. ${ }^{8}$ These materials are typically synthesized by utilizing organic surfactants or block copolymers as structuredirecting templates in acid- or base-catalyzed condensation of alkoxysilanes. Obviously, the realization of the aforementioned applications for mesoporous silica materials greatly depends on the ability of controlling not only the intra-particle, but also the inter-particle mass-transport processes. Therefore, it is important to develop methods to regulate both the pore and particle morphology of these materials. ${ }^{9}$

To this goal, several recent reports ${ }^{10}$ have focused on the utilization of other amphiphilic molecules, such as roomtemperature ionic liquids (RTILs), as templates for the synthesis of mesoporous silica materials. For example, Zhou et. al. ${ }^{10 a-c}$ have demonstrated that monolithic mesoporous silicas with either wormlike pores or lamellar super-microporous structures could be prepared by using 1alkyl-3-methylimidazolium $\left(\mathrm{C}_{\mathrm{n}} \mathrm{MIM}, \mathrm{n}=\right.$ the number of carbons 
in the alkyl chain) chloride or tetrafluoroborate, respectively, as templates. Also, Dai and co-workers ${ }^{10 d}$ have successfully synthesized periodic mesoporous organosilica (PMO) materials by using two different $C_{n} M I M$ bromide templates in the condensation reaction of bis(triethoxysilyl)ethane. Despite these recent advancements, no study has been reported on how the particle morphology (size and shape) could be regulated by these RTILs. Herein, we report on the synthesis and characterization of a series of mesoporous silica nanoparticle (MSN) materials with various porous structures and particle shapes, such as spheres, ellipsoids, rods, and tubes, by using different RTIL templates, such as 1tetradecyl-3-methylimidazolium bromide (C $\left.{ }_{14} \mathrm{MIMBr}\right), \quad 1-$ hexadecyl-3-methylimidazolium bromide $\left(\mathrm{C}_{16} \mathrm{MIMBr}\right), \quad 1-$ octadecyl-3-methylimidazolium bromide ( $\left.\mathrm{C}_{18} \mathrm{MIMBr}\right)$, and 1tetradecyloxymethyl-3-methylimidazolium chloride $\left(C_{14}\right.$ OCMIMCl), respectively (Figure 1$)$. To study the masstransport properties of the $\mathrm{C}_{\mathrm{n}}$ MIM-MSN materials, we investigated the controlled release profiles of these materials by utilizing the RTIL templates as antibacterial agents against the Gram (-) microbe Escherichia coli $K 12$ as 
depicted in Figure 2. Our results indicated that the rates of RTIL release from the MSN materials are governed by the particle and pore morphology leading to different antibacterial activities.

First, we synthesized the $\mathrm{C}_{14} \mathrm{MIMBr}, \mathrm{C}_{16} \mathrm{MIMBr}$, and $\mathrm{C}_{18} \mathrm{MIMBr}$ RTIJs by reacting 1 -methylimidazole (50 mol) with 50 mol of 1-bromotetradecane, 1-bromohexadecane, and 1bromooctadecane, respectively, at $90^{\circ} \mathrm{C}$ for $48 \mathrm{~h}$. The products were purified by recrystallization in THF. The resulting white crystals were collected by filtration, and dried under vacuum at room temperature. The $\mathrm{C}_{14}$ OCMIMCl was prepared via a literature procedure. ${ }^{11}$ In a typical procedure for the synthesis of the $\mathrm{C}_{\mathrm{n}} \mathrm{MIM}$-MSN materials, a selected $C_{n} M I M$ RTIL $(2.74 \mathrm{mmol})$ was first dissolved in 480 $\mathrm{mL}$ of $15 \mathrm{mM} \mathrm{NaOH}(\mathrm{aq})$. The solution was heated to $80^{\circ} \mathrm{C}$, followed by a dropwise addition of tetraethyl orthosilicate (22. 4 mmol) and stirred for 2 h to yield the desired C MIMMSN material.

To characterize the mesoporous structures of the $C_{n} M I M-M S N$ materials, the $C_{n}$ MIM RTILs were extracted from the mesopores by refluxing the as-synthesized $\mathrm{C}_{\mathrm{n}}$ MIM-MSN (500 $\mathrm{mg}$ ) in $200 \mathrm{~mL}$ of methanolic solution of $\mathrm{HCl}(520 \mathrm{mM})$ for $48 \mathrm{~h}$. As 
revealed by the transmission electron micrographs (TEM) in Figure 3, $\mathrm{C}_{n}$ MIM-MSNs synthesized with the four different RTIL templates exhibited different particle morphologies. For example, the $C_{14}$ MIM-MSN material showed spherical particles with diameters ranging from 100 to $300 \mathrm{~nm}$, as depicted in Figure 3a. Interestingly, upon replacing the $\mathrm{C}_{14} \mathrm{MIMBr}$ with other structurally similar RTILs with longer alkyl chains, such as $C_{16} M I M B r$, and $C_{18} M I M B r$ (Figure 3b, c), the shapes of the MSN materials transformed into ellipsoids and rods, respectively. Furthermore, substituting the $C_{16}$ MIM template with a similar sized $C_{14}$ OCMIM RTIL gave rise to the $\mathrm{C}_{14}$ OCMIM-MSN material (Eigure $3 \mathrm{~d}$ ) consisted of tubular shaped particles.

The pore morphologies of the C $\mathrm{n}$ MIM-templated MSNs were determined by nitrogen adsorption-desorption surface analysis (BET isotherms and BJH pore size distributions), TEM (Figure 3), and powder X-ray diffraction (XRD) spectroscopy (Figure 4). All four $C_{n}$ MIM-MSN materials exhibited type IV BET isotherms. Also, the BJH average pore diameters of these materials increased as the organic regions of the RTILs lengthened (Table 1). Hexagonally packed mesoporous channels were clearly observed in the TEM 
micrographs of the $\mathrm{C}_{1\lfloor\mathrm{MIM}-}$ and $\mathrm{C}_{16} \mathrm{MIM}$-MSNs (Figure $3 a$, b). In addition, both materials exhibited diffraction patterns characteristic of hexagonal MCM-41 silicas, including (100), (110), (200), and (210) peaks as depicted in Figure $4 a, b$.

Interestingly, a pseudo-moiré rotational pattern of mesopores was observed in the TEM micrograph of the $\mathrm{C}_{18} \mathrm{MIM}-$ MSN material (Eigure 3c), where parallel mesopores are twisted in a helical nature along the long axis of the nanorods. This pore morphology is structurally similar to a chiral mesoporous silica material recently reported by Tatsumi and co-workers. ${ }^{12}$ In contrast to Tatsumi's material, which was synthesized in the presence of a chiral surfactant template, the $\mathrm{C}_{18}$ MIM-MSN material was prepared by using an achiral surfactant ( $\left.\mathrm{C}_{18} \mathrm{MIMBr}\right)$ as the structuredirecting agent. As indicated by the arrow-pointed areas in Figure 3c, each visible fringe represents the (100) interplanar spacing. The distance between two fringes is one-sixth of a pitch or a $60^{\circ}$ rotation through the center of the long axis. It is noteworthy that all the particles shown in Figure $3 c$ appeared to have rotations of approximately $120^{\circ}$ regardless of particle size. The powder 
XRD analysis (Figure $4 \mathrm{C}$ ) of the $\mathrm{C}_{18}$ MIM-MSN material further confirmed the twisted hexagonal ordering of the mesopores as evidenced by the diffraction pattern of an intense (100) peak along with a well-resolved (110) and a broadened (200) peaks. The handedness of the rotation (right- or lefthanded) could not be determined from the TEM analysis. As discussed in Tatsumi's report, ${ }^{12}$ the ratio of the left- and right-handedness of their chiral mesoporous silica material (65/35, left/right) was not entirely governed by the intrinsic chirality of the surfactant template since only the L-enantiomer of the chiral surfactant was employed. In our case, we hypothesized that, as the alkyl chain lengths of the $C_{n} M I M B r$ increases from $C_{14}$ to $C_{18}$, tighter intermolecular packing between the methylimidazolium head groups of the achiral $\mathrm{C}_{18} \mathrm{MIMBr}$ molecules might have occurred. Given the planar structure of the imidazolium group, such tight packing would perhaps cause a staggered wadding of the $\mathrm{C}_{18} \mathrm{MIMBr}$ molecules and twisted the micelles into a helical structure.

This assumption was further investigated by the TEM and XRD analyses of the $C_{24}$ OCMIM-MSN material that was synthesized with $\mathrm{C}_{14}$ OCMIMCl, which is a similarly sized 
molecule in comparison with the $\mathrm{C}_{16} \mathrm{MIMBr}$ that gave rise to a MCM-41 type mesoporous structure. The mesoporous structure of the $\mathrm{C}_{14}$ OCMIM-MSN material appeared to be disordered as indicated by a broad XRD diffraction peak at $4.22^{\circ}$ representing superimposed (110) and (200) peaks (Figure 4d). The TEM micrograph shown in Figure $3 \mathrm{~d}$ is also consistent with this observation. Given that the hydrophilic polar region of $\mathrm{C}_{14}$ OCMIM, with the ether moiety close to the methylimidazolium head group, is significantly larger of that of $\mathrm{C}_{16} \mathrm{MIM}$, the results support our theory that the micellar structure and packing is strongly influenced by the alkyl chain length of the alkylimidazolium template.

It is widely known that cationic surfactants possess antibacterial properties, several can be found in household soaps and detergents. ${ }^{1.3}$ A recent report ${ }^{11}$ in the literature has demonstrated the antibacterial activity of $\mathrm{C}_{14}$ OCMIMCl on both Gram (+) and Gram (-) microbes. The mechanism of the antibacterial activity of $\mathrm{C}_{14}$ OCMIMCl was attributed to the electrostatic interaction of phosphate groups on the microbial cell wall and the cationic methylimidazolium head group of the RTIL. Also, the organic tail region embeds 
itself in the lipid bilayer. This in turn leads to the free flow of electrolytes out of the microbe and causes the cell death. This is believed to be the mechanism of cell death for the other RTIL as well.

The antibacterial activities of the $\mathrm{C}_{16} \mathrm{MIMBr}$ and $\mathrm{C}_{14} \mathrm{OCMIMCl}$ were measured by three methods: disk diffusion assay, minimal inhibitory concentration (MIC), and minimal bactericidal concentration (MBC). The disk diffusion assay was determined by placing a $25 \mathrm{~mm}$ cellulose disk saturated with $15 \mathrm{mM}$ of $\mathrm{C}_{16} \mathrm{MIMBr}$ and $\mathrm{C}_{14} \mathrm{OCMIMCl}$ in $100 \mathrm{mM}$ phosphate buffer (pH 7.4) onto agar plates seeded with E. Coli K12. As depicted in Figure 5, the results of the disk diffusion assay showed an average of $35 \mathrm{~mm}$ of microbial clearing for $\mathrm{C}_{16} \mathrm{MIMBr}$ and $\mathrm{C}_{14} \mathrm{OCMIMCl}$. The control (a cellulose disk saturated with $100 \mathrm{mM}$ phosphate buffer $\mathrm{pH}$ 7.4) showed no antibacterial activity (Figure 5c). The MIC and MBC concentrations were determined by dissolving ten different concentrations ( 10 to $100 \mathrm{mM}$ ) of $\mathrm{C}_{16} \mathrm{MIMBr}$ and $\mathrm{C}_{14} \mathrm{OCMIMCl}$ in broth media, inoculated in a $1: 1$ ratio with stock $E$. coli K12 culture, and visually determining the lowest concentration that lacked bacteria growth for the MIC. The MBC was measured by spreading one loopful from each 
dilution onto the agar plates and visually determining the lowest concentration of RTIL that supported no colony formation. The MIC of both RTILs was $30 \mathrm{\mu M}$. The MBC of the RTILs deviated slightly from one another. The MBC of $\mathrm{C}_{16} \mathrm{MIMBr}$ was $100 \mu \mathrm{M}$ and the $\mathrm{MBC}$ of $\mathrm{C}_{14}$ OCMIMCl was $70 \mu \mathrm{M}$.

The antibacterial activities of $\mathrm{C}_{16}$ MIM-MSN and $\mathrm{C}_{14}$ OCMIM-MSN were measured by series dilution for $24 \mathrm{~h}$ at $25{ }^{\circ} \mathrm{C}$ and $48 \mathrm{~h}$ at $37^{\circ} \mathrm{C}$ as shown in Figure $6 \mathrm{a}$ and $\mathrm{b}$, respectively. The two MSNs were suspended in $6 \mathrm{~mL}$ of tryptic soy broth with $0.6 \%$ yeast extract and inoculated with $1 \mathrm{~mL}$ of 18 hour stock culture of $E$. coli K12. At various times, aliquots of each sample were diluted and plated on tryptic soy agar with $0.6 \%$ yeast extract. The plates were incubated for 18 h. Colonies were counted and recorded for dilutions containing between 30 and 300 colonies. In contrast to the similar MBC values for the free RTILs, C16MIM-MSN exhibited a superior antibacterial activity than that of $\mathrm{C}_{14}$ OCMIM-MSN by a thousand fold. The diffusion of both RTIL from the pores slowed down at $25^{\circ} \mathrm{C}$. The pronounced difference in antibacterial activity between the two RTIL-MSN materials could be attributed to the different release profiles of the pore-encapsulated RTIL molecules. According to the 
aforementioned TEM analyses, the pore morphologies of these two samples are very different. $C_{66}$ MIM-MSN has a hexagonal array ordered pores that all line up parallel, while $\mathrm{C}_{14}$ OCMIM-MSN has a disordered pore arrangement. It is plausible that the rate of RTIL release via diffusion from the parallel hexagonal channels of $\mathrm{C}_{16} \mathrm{MIM}$ MSN would be faster than that of the disordered pores of $\mathrm{C}_{14}$ OCMIM-MSN. In addition to pore morphology, the mass transfer of RTIL from the tubular particles $\left(\mathrm{C}_{14}\right.$ OCMIM-MSN $)$ will be considerably slower than the spherical particle $\left(\mathrm{C}_{16} \mathrm{MIM}-\right.$ MSN). The antibacterial activity of as-synthesized MCM-41 synthesized with conventional methods (CTAB as template) was measured by the same method and found to have similar activity as $\mathrm{C}_{16} \mathrm{MIM}$-MSN (see Supporting Information Figure S1).

The dependence of ionic strength on template release was measured by ${ }^{1} \mathrm{H}$ NMR. It seems that there is a base $10 \mathrm{log}$ dependence of ionic strength on the template release.

In conclusion, we have demonstrated that the particle and pore morphology of mesoporous silica nanoparticle materials could be tuned by using various room temperature ionic liquids as synthetic templates. The antibacterial 
activities of two RTIL-MSNs have been measured against $E$. coli K12. The antibacterial activity was dependent on the rate of diffusional release of the pore-encapsulated RTIL, which was governed by the particle and pore morphology of the MSN materials. By further functionalizing the surface of these RTIL-MSN materials with various organic moieties, we envision that these materials could serve as a new generation of controlled release delivery nanodevices for various applications.

ACKNOWLEDGMENT. This research was supported by NSE (CHE0239570). The authors thank Dr. M. J. Kramex and Dr. L. S. Chumbley for experimental assistance in TEM measurements of the materials and helpful discussions. 


\section{REFERENCES}

(1) (a) Beck, J. S.; Vartuli, J. C.; Roth, W. J.; Leonowicz, M. E.; Kresge, C. T.; Schmitt, K. D.; Chu, C. T. W.; Olson, D. H.; Sheppard, E. W. J. Am. Chem. Soc. 1992, 114, 10834-10843. (b) Kresge, C. T.; Leonowicz, M. E.; Roth, W. J.; Vartuli, J. C.; Beck, J. S. Nature (London) $1992,359,710-712$.

(2) Zhao, D.; Feng, J.; Huo, Q.; Melosh, N.; Frederickson, G. H.; Chmelka, B. F.; Stucky, G. D. Science (Washington, D. C.) 1998, 279, 548-552.

(3) Bagshaw, S. A.; Prouzet, E.; Pinnavaia, T. J. Science (Washington, D. C.) 1995, 269, 1242-1244.

(4) Ryoo, R.; Kim, J. M.; Ko, C. H.; Shin, C. H. J. Phys. Chem. 1996, 100, 17718-17721.

(5) Inagaki, S.; Koiwai, A.; Suzuki, N.; Fukushima, Y.; Kuroda, K. Bull. Chem. Soc. Jpn. 1996, 69, $1449-1457$.

(6) (a) Lin, V. S. Y.; Lai, C.-Y.; Huang, J.; Song, S.-A.; Xu, S. J. Am. Chem. Soc. 2001, 123, 11510-11511. Radu, D. R.; Lai, C.-Y.; Wiench, J. W.; Pruski, M.; Lin, V. S. Y. J. Am. Chem. Soc. 2004, 126, 1640-1641. (c) 
Casasus, R.; Marcos, M. D.; Martinez-Manez, R.; Ros-Lis, J. V.; Soto, J.; Villaescusa, L. A.; Amoros, P.; Beltran, D.; Guillem, C.; Latorre, J. J. Am. Chem. Soc. $2004,126,8612-8613$.

(7) (a) Huh, S.; Chen, H.-T.; Wiench, J. W.; Pruski, M.; Lin, V. S. Y. J. Am. Chem. Soc. 2004, 126, 1010-1011. (b) Lin, V. S. Y.; Radu, D. R.; Han, M.-K.; Deng, W.; Kuroki, S.; Shanks, B. H.; Pruski, M. J. Am. Chem. Soc. 2002, 124, 9040-9041. (C) Corma, A. Chem. Rev. 1997, 97, 2373-2419 and references therein. (d) Thomas, J. M. J. Mol. Catal. A 1999, 146, 77-85. (e) Brunel, D.; Blanc, A. C.; Galarneau, A.; Fajula, F. Catal. Today $2002,73,139-152$.

(8) (a) Lai, C.-Y.; Trewyn, B. G.; Jeftinija, D. M.; Jeftinija, K.; Xu, S.; Jeftinija, S.; Lin, V. S. Y. J. Am. Chem. Soc. 2003, 125, 4451-4459. (b) Mal, N. K.; Fujiwara, M.; Tanaka, Y.; Taguchi, T.; Matsukata, M. Chem. Mater. 2003, 15, 3385-3394. (c) Vallet-Regi, M.; Ramila, A.; del Real, R. P.; Perez-Pariente, J. Chem. Mater. 2001, 13, 308-311. (d) Tourne-Peteilh, C.; Brunel, D.; Begu, S.; Chiche, B.; Fajula, E.; Lerner, D. A.; Devoisselle, J.-M. New J. Chem. 2003, 27, 1415-1418. 
(9) (a) Huh, S.; Wiench, J. W.; Yoo, J.-C.; Pruski, M.; Lin, V. S. Y. Chem. Mater. 2003, 15, 4247-4256. (b) Huh, S.; Wiench, J. W.; Trewyn, B. G.; Song, S.; Pruski, M.; Lin, V. S. Y. Chem. Commun. (Cambridge) 2003, 2364-2365.

(10) (a) Zhou, Y.; Antonietti, M. Adv. Mater. (Weinheim, Ger.) 2003, 15, 1452-1455. (b) Zhou, Y.; Schattka, J. H.; Antonietti, M. Nano Lett. 2004, 4, 477-481. (c) Zhou, Y.; Antonietti, M. Chem. Mater. 2004, 16, 544-550. (d) Lee, B.; Luo, H.; Yuan, C. Y.; Lin, J. S.; Daj, S. Chem. Commun. 2004, 240-241.

(11) Pernak, J.; Sobaszkiewicz, K.; Mirska, I. Green Chem. $2003,5,52-56$.

(12) Che, S.; Liu, Z.; Ohsuna, T.; Sakamoto, K.; Terasaki, o.; Tatsumi, T. Nature (London) 2004, 429, 281-284.

(13) Davis, B.; Jordan, P. An Overview of the Biocidal Activity of Cationics and Ampholities. In Ind. Appl. Surfactants II; Karsa, D. R., Ed.; Royal Society of Chemistry; Cambridge, 1990; Vol. 77, pp 195-210. 


\section{FIGURE CAPTIONS}

Figure 1. Chemical structures of 1-tetradecyl-3methylimidazolium bromide (C 14 MIMBr), 1hexadecyl-3-methylimidazolium bromide $\left(\mathrm{C}_{16} \mathrm{MIMBr}\right), \quad$ 1-octadecyl-3-methylimidazolium bromide $\left(\mathrm{C}_{18} \mathrm{MIMBr}\right)$, and 1-tetradecyloxymethyl-3methylimidazolium chloride ( $\left.\mathrm{C}_{14} \mathrm{OCMIMCl}\right)$.

Figure 2. Schematic representation of the controlled release process of $C_{n}$ MIM-MSN and its antibacterial activity against $E$. coli.

Figure 3. Transmission electron micrographs of $C_{n} M I M-M S N$ materials. (a) $\mathrm{C}_{14} \mathrm{MIM}-\mathrm{MSN}$, (b) $\mathrm{C}_{16} \mathrm{MIM}-\mathrm{MSN}$, (c) $\mathrm{C}_{18}$ MIM-MSN, and (d) $\mathrm{C}_{14}$ OCMIM-MSN. These micrographs wexe obtained from a Phillips CM30 TEM operated at $300 \mathrm{kV}$.

Figure 4. Low angle powder X-ray diffraction patterns of RTIL-removed $C_{n}$ MIM-MSN materials. (a) $C_{14}$ MIM-

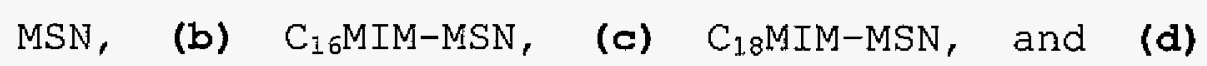
C140CMIM-MSN. The diffraction data were collected on a Scintag XRD 2000 X-ray diffractometer using $\mathrm{Cu} K \alpha$ radiation. The 
samples were scanned from $1.5^{\circ}$ to $10^{\circ}(2 \theta)$ with a step size of $0.02^{\circ}$ and a count time of $0.5 \mathrm{~s}$ at each point.

Figure 5. Disk diffusion assay of $15 \mathrm{mM} \mathrm{C}_{16} \mathrm{MIM}-\mathrm{MSN}$ (a), $\mathrm{C}_{14}$ OCMIM-MSN (b), and phosphate buffer (c) on a lawn of E. coli $K 12$. The red arrow points to an area of microbial lawn and the blue arrow points to the zone of clearing caused by the diffusion of RTIL.

Figure 6. Histogram of the antibacterial activity of $C_{n}$ MIM-MSNs against $E$. coli $K 12$ at $25^{\circ} \mathrm{C}$ (a) and $37{ }^{\circ} \mathrm{C}$ (b). Four samples were measured at each temperature: C 16 MIM-MSN (black bars), C $_{14}$ OCMIMMSN (green bars), RTIL-removed C 16 MIM-MSN (blue bars), and blank control (no silica material) (red bars). 
Table 1. Nitrogen sorption data of $\mathrm{C}_{n} \mathrm{MIM}-\mathrm{MSN}$ material.

\begin{tabular}{cccc}
\hline & $\begin{array}{c}\text { BET surface } \\
\text { area }\left(\mathrm{m}^{2} / \mathrm{g}\right)\end{array}$ & $\begin{array}{c}\text { Pore } \\
\text { volume } \\
\left(\mathrm{cm}^{3} / \mathrm{g}\right)\end{array}$ & $\begin{array}{c}\text { BJH } \\
\text { Average } \\
\text { Pore } \\
\text { Diameter } \\
(\AA)\end{array}$ \\
\hline $\mathrm{C}_{14}$ MIM-MSN & 729 & 0.664 & 27.1 \\
$\mathrm{C}_{16}$ MIM-MSN & 924 & 0.950 & 30.3 \\
$\mathrm{C}_{18}$ MIM-MSN & 893 & 0.995 & 32.7 \\
$\mathrm{C}_{14}$ OCMIM- & 639 & 0.695 & 26.1 \\
\hline MSN & & & \\
\hline
\end{tabular}


Figure 1.

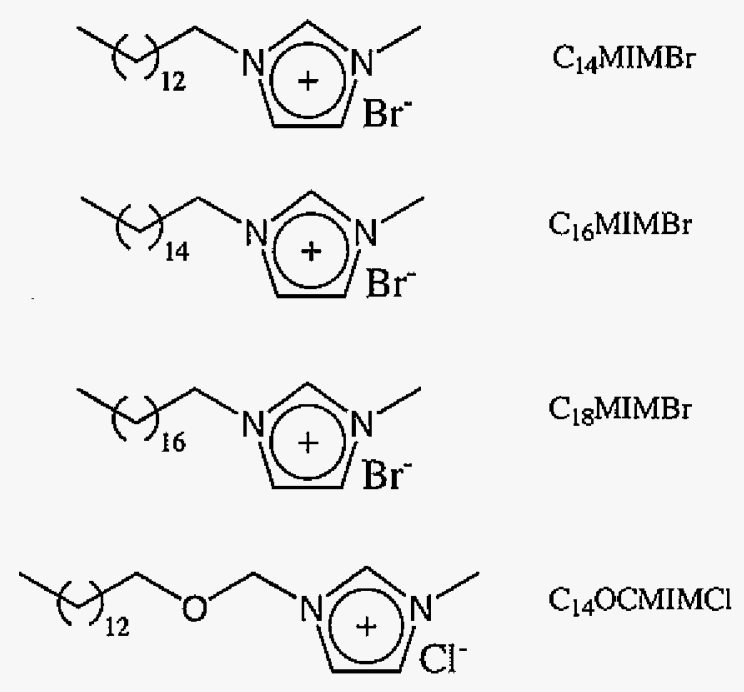


Figure 2 .
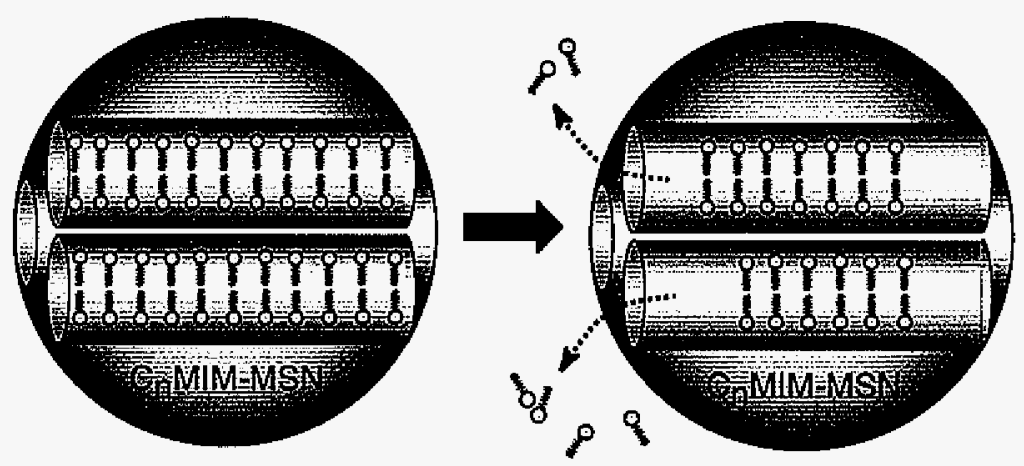

Fmm = RTIL

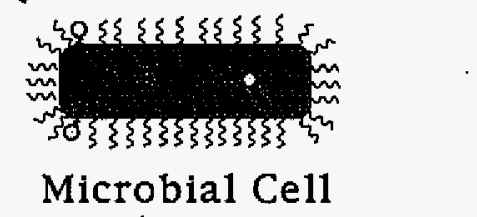


Figure 3.
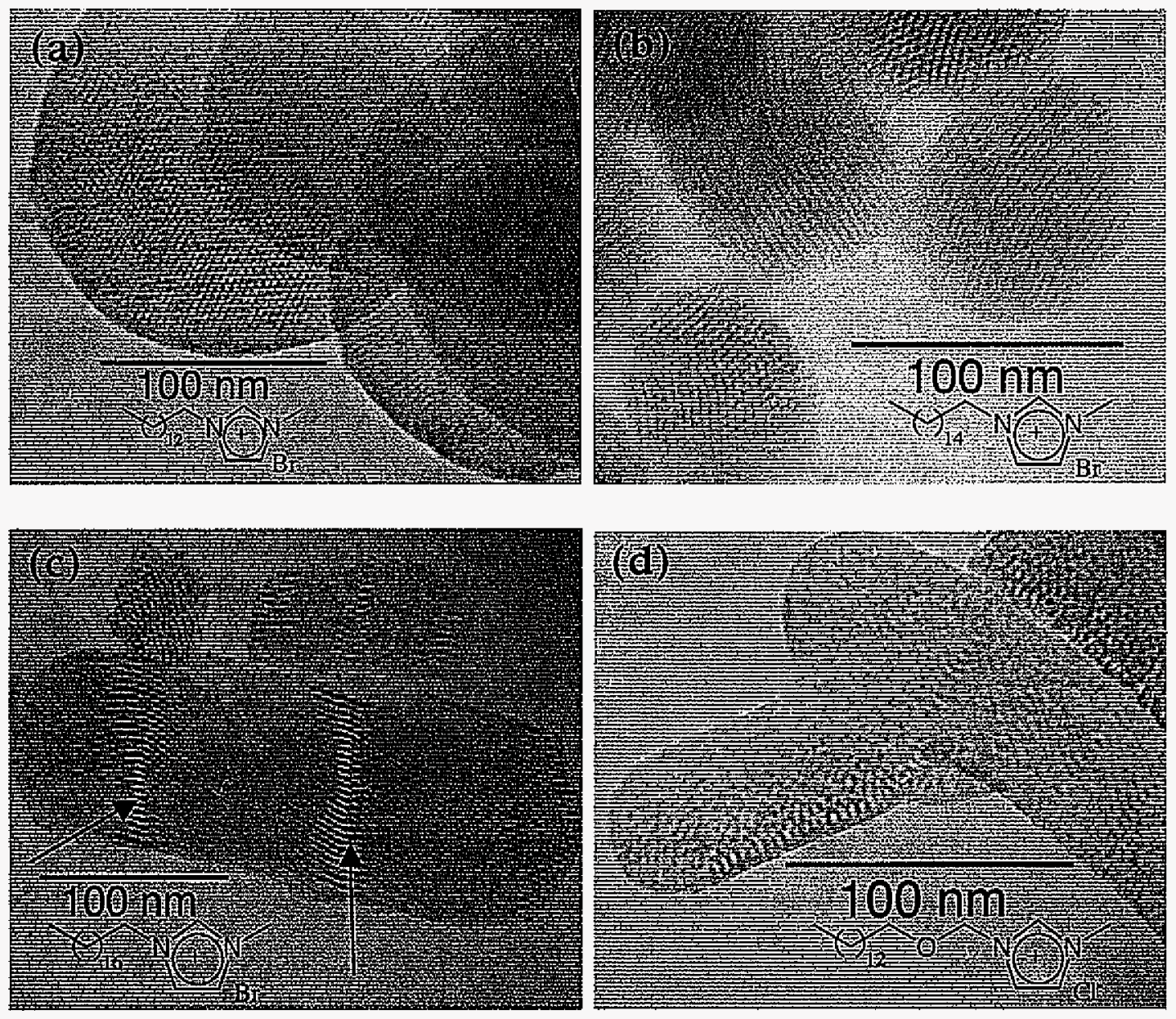
Figure 4.

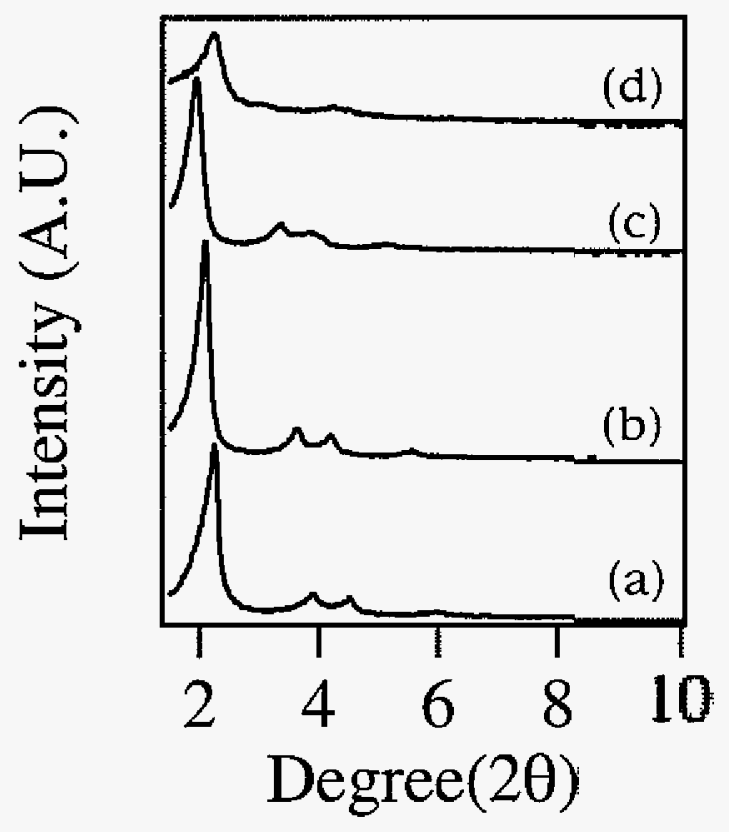


Figure 5.
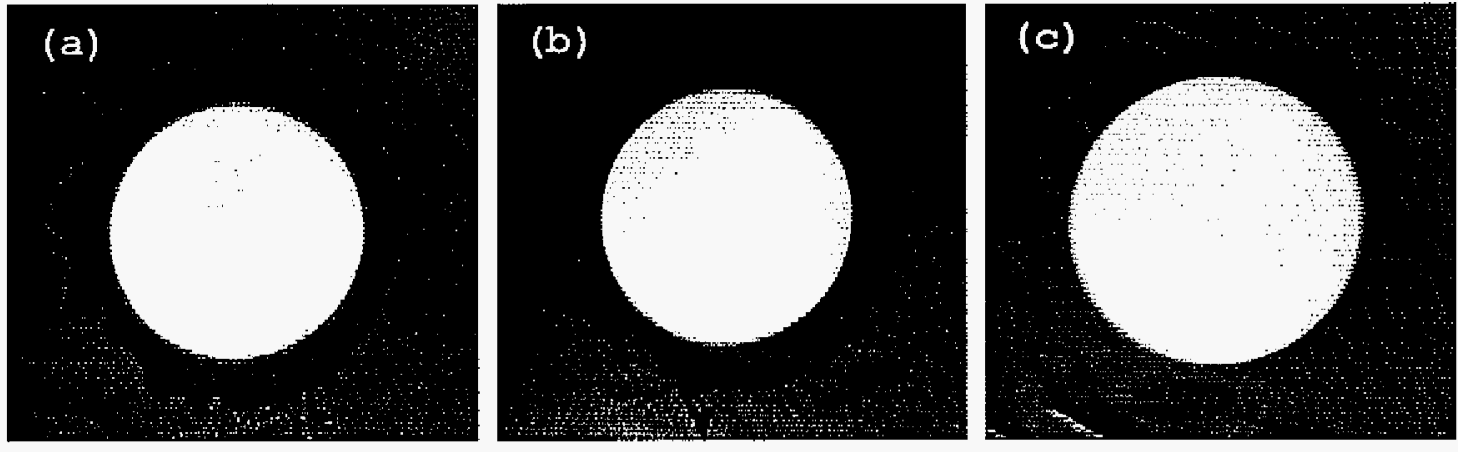
Figure 6.

(a)

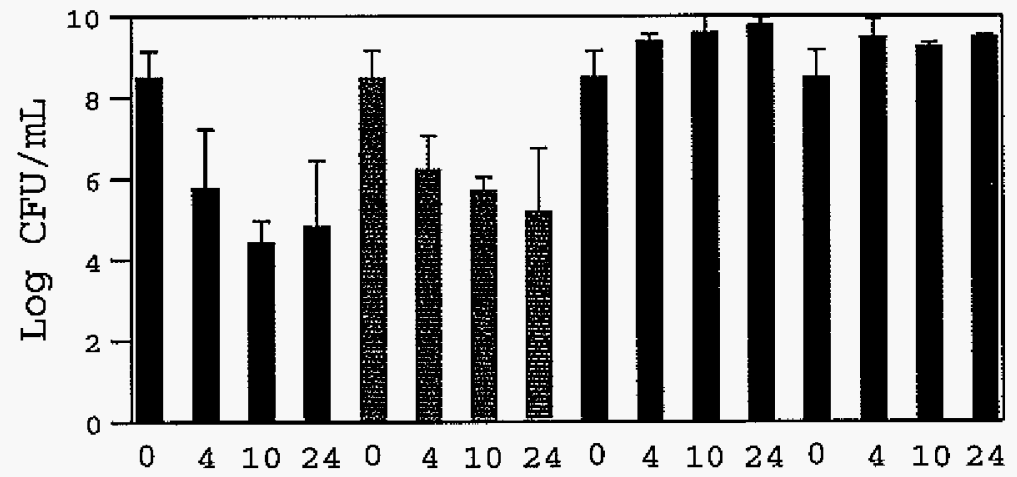

Hours after inoculation

(b)

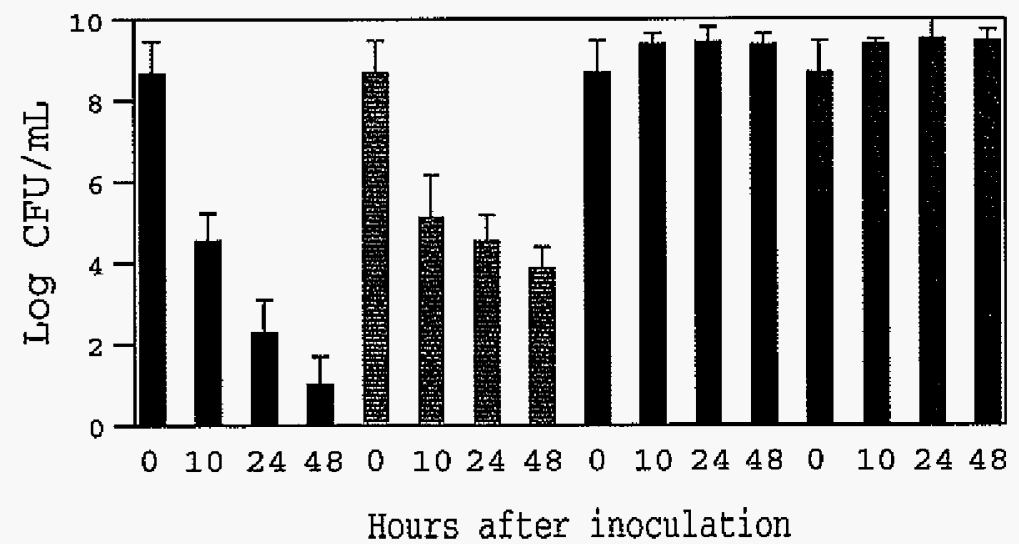


APPENDIX 1 
Figure s1. Histogram of the antibacterial activity of CTAB-MSNs against E. coli $K 12$ at $37^{\circ} \mathrm{C}$. Two samples were measured: CTAB-MSN (black bars) and blank control (no silica material) (red bars) .

Figure s2. Dependence ionjc strength has on the release of

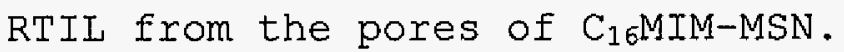


Figure $\mathrm{s} 1$.

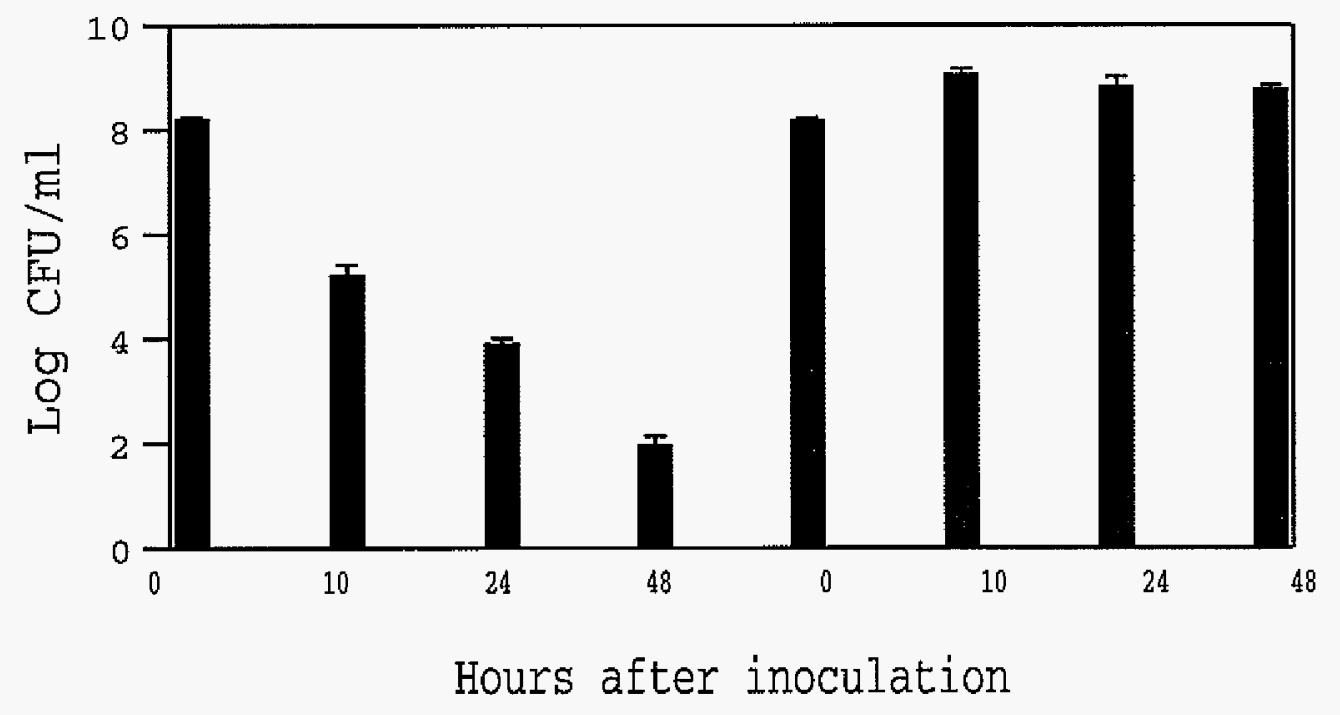


Figure s2.

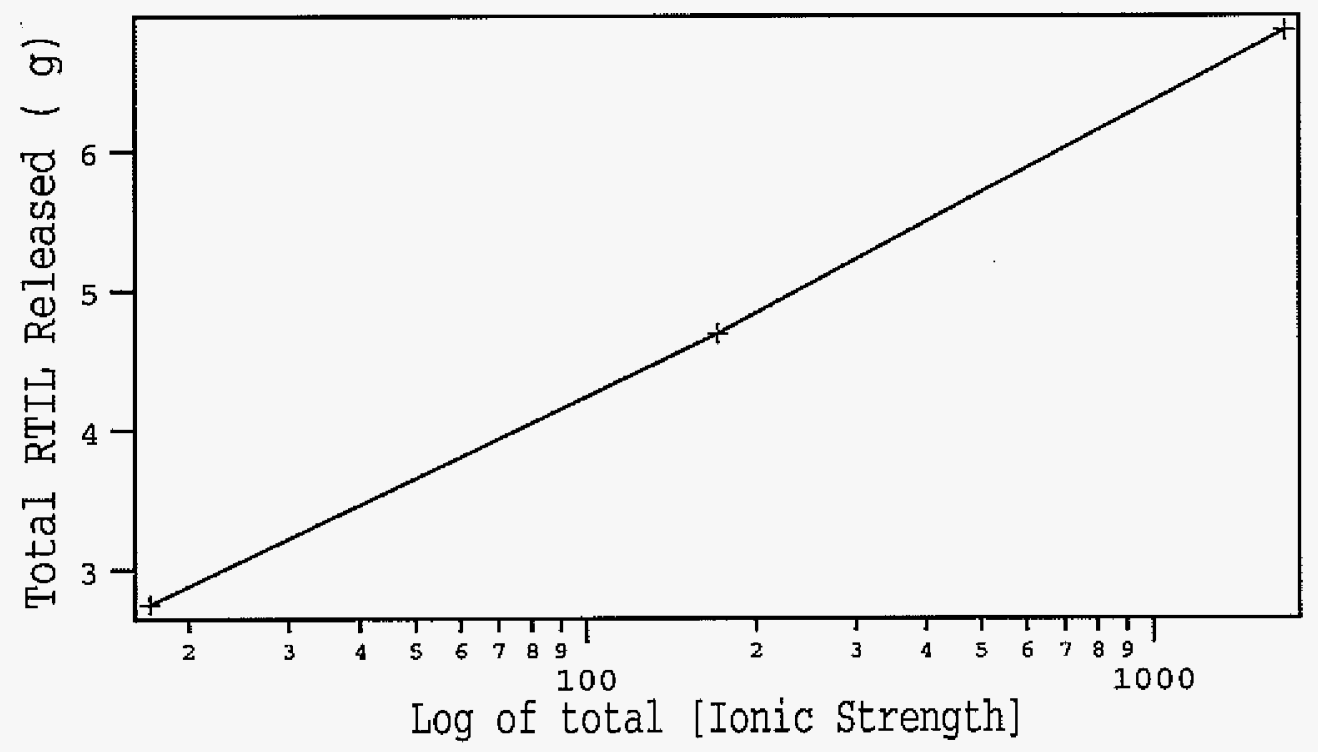




\title{
CHAPTER 3. ENDOCYTOSIS OF TRI (ETHYLENE GLYCOL) FUNCTIONALIZED MESOPOROUS SILICA NANOPARTICLES INTO CANCER AND PLANT CELLS
}

\author{
Brian G. Trewyn*, Francios Terney, Jennifer $A$. Nieweg, \\ Joseph D. Buss, Kan Wang, and Victor S.-Y. Lin \\ *Primary researcher and author \\ To be submitted to NanoLetters
}

\begin{abstract}
The involvement of a specific organosiloxane functional group covalently attached to the exterior of fluorescein doped mesoporous silica nanoparticles on the degree and kinetics of endocytosis in cancer and plant cells was investigated. The kinetics of endocystosis of tri(ethylene glycol) functionalized fluorescein doped mesoporous silica nanoparticles (TEG coated FITC-MSNs) are significantly quicker than nonfunctional FITC-MSNs as determined by flow cytometry experiments. Fluorescence confocal microscopy investigation showed the endocytosis of TEG coated FITC-MSN into both HeLa cells and Tobacco protoplasts.
\end{abstract}




\section{INTRODUCTION}

In recent years, the use of mesoporous nanoparticles has spanned many divisions of the biological field, including sensors, drug delivery, and clinical diagnosis.1-8 Mesoporous silica nanoparticles have many unique properties, such as an ordered pore structure, high surface area $\left(\sim 1000 \mathrm{~m}^{2} \mathrm{~g}^{-1}\right)$, large pore volume $\left(\sim 0.9 \mathrm{~cm}^{3} \mathrm{~g}^{-1}\right)$, tunable pore size with a narrow distribution $(2.0-10 \mathrm{~nm})$, and biocompatibility that makes them suitable for use in biological applications. Several active research groups have shown that mesoporous nanoparticles can act as reservoirs for drugs and biomolecules. Two groups have shown the ability to produce stimuli-responsive controlled release vehicles in MCM-41, both chemical and photocontrolled release were demonstrated. ${ }^{4,8,9}$

Concurrently, with the study of controlled release, the endocytosis of these mesoporous nanoparticles is being investigated. Endocytosis is the process of the internalization of molecules, particles, and nutrients from the plasma membrane and extracellular environment. It is an essential process of eukaryotic cells, which are cells that contain genetic DNA in the form of chromosomes within a distinct nucleus. Recent reports in the literature have 
demonstrated that mesoporous silica nanoparticles can undergo endocytosis into various animal cell types. ${ }^{10-12}$ Mou and coworkers functionalized nanosized mesoporous silcas that, upon internalization, can be used as fluorescence cell tags. ${ }^{12}$ with the ability of cell internalization and the fact that endocytosis and endocytic proteins are linked closely with human cancer, ${ }^{13,14}$ research in this field is novel and important to study.

The study of endocytosis in higher order plants remained inactive for a long period of time because it was thought that plant endocytosis could not occur against the high turgor pressure in plant cells. However, recent publications contradict this former belief. ${ }^{15-22}$ Volkmann and coworkers demonstrated the internalization of the fluorescent dye Lucifer Yellow presumably by endocytosis, as evidenced by light and electron microscopy. ${ }^{23}$ Paciorek and coworkers demonstrated that auxin, a major regulator of plant development inhibits plant endocytosis. ${ }^{24}$ Despite the doubts based on turgor pressure, endocytosis is possible in intact plant cells and evidence supporting this notion are continually being discovered.

In this paper, we functionalized mesoporous silica nanoparticles (MSNs), which were internalized by animal and 
plant cells. The fluorescein doped MSNs developed in our laboratory are easily prepared, and have strong fluorescence intensity, excellent photostability, and no fluorescein leaching.

\section{EXPERIMENTAL SECTION}

Reagents and Materials for Material Synthesis: Fluorescein isothiocyanate, isomer 1 (90\%) (FITC), 3-aminopropyltrimethoxysilane (97\%) (APTMS), n-cetyltrimethylammonium bromide (CTAB), phosphorus tribromide (99\%), pyridine, tri(ethylene glycol) monomethyl ether (95응 were all purchased from Aldrich and used as received. Tetraethoxysilane (TEOS) was purchased from Gelest and used as received.

Synthesis of Fluorescein-doped MSNs (FITC-MSN): The MSN material was prepared by the following procedures: First, $1.0 \mathrm{mg}$ fluorescein isothiocyanate was stirred overnight at room temperature with $500 \mu \mathrm{L}$ 3-aminopropyltrimethoxysilane (APTMS) in $500 \mu \mathrm{L}$ anhydrous DMF. Next, n-cetyltrimethylammonium bromide (CTAB, $1.00 \mathrm{~g}, 2.74 \times 10^{-3}$ mol) was dissolved in $480 \mathrm{~mL}$ nanopure water. This solution was made basic by the addition of $3.5 \mathrm{~mL} 2.00 \mathrm{M} \mathrm{NaOH}$, followed by adjusting the solution temperature to $353 \mathrm{~K}$. TEOS $(5.00$ $\left.\mathrm{mL}, 2.57 \times 10^{-3} \mathrm{~mol}\right)$ was first introduced dropwise to the 
template solution, followed by the dropwise addition of the EITC-APTMS/DMF solution. The mixture was stirred for $2 \mathrm{~h}$ at $353 \mathrm{~K}$ to give rise to orange precipitates (as synthesized FITC-MSNs). The solid product was filtered, washed with deionized water and methanol, and dried in under high vacuum at $353 \mathrm{~K}$. To remove the surfactant template (CTAB), $1.0 \mathrm{~g}$ of as-synthesized FITC-MSNs were refluxed for $18 \mathrm{~h}$ in a solution of $1.0 \mathrm{~mL}$ of $\mathrm{HCl}$ (37.4\%) and $100.0 \mathrm{~mL}$ of methanol, followed by washing with methanol and water. The yellow surfactant removed FITC-MSNs (washed FITC-MSNS) were placed under high vacuum to remove solvent from the mesopores.

Synthesis of Tri(ethylene glycol) Trimethoxysilane Molecules (TEG): This molecule was synthesized by a modified technique developed by zheng et. al. ${ }^{25}$ Phosphorous tribromide $\left(9.0 \mathrm{~g}, 3.3 \times 10^{-2} \mathrm{~mol}\right)$ was added dropwise to a stirred mixture of tri(ethylene glycol) monomethyl ether $\left(7.7 \mathrm{~g}, 4.8 \times 10^{-2} \mathrm{~mol}\right)$ and pyridine $\left(2.0 \mathrm{~g}, 2.5 \times 10^{-2} \mathrm{~mol}\right)$ at $0^{\circ} \mathrm{C}$. The orange solution was stirred at room temperature for $48 \mathrm{~h}$. Reaction was quenched with $10 \mathrm{~mL}$ water, and the product was extracted three times with $40 \mathrm{~mL}$ carbon tetrachloride. The combined organic extracts were washed successively with $25 \mathrm{~mL}$ of each $10 \%$ sodium 
carbonate, 5\% sulfuric acid, and water, followed by drying with anhydrous magnesium sulfate. The carbon tetrachloride was removed under reduced pressure and the crude product was dried under high vacuum. The crude product $(2.7 \mathrm{~g})$ was dissolved in $10 \mathrm{~mL}$ ethanol. While this was stirred, 3aminopropyltrimethoxysilane $\left(2.10 \mathrm{~g}, 1.17 \mathrm{x} 10^{-2} \mathrm{~mol}\right)$ was added dropwise to form tri(ethylene glycol) propyltrimethoxysilane (EG $\mathrm{E}_{3} \mathrm{TMS}$ ). This was heated for $24 \mathrm{~h}$ at $90^{\circ} \mathrm{C}$. Synthesis of TEG coated Fluorescein-doped Mesoporous Silica Nanoparticles (TEG coated FITC-MSN): To coat the FITCMSNs, $200 \mathrm{mg}$ was first suspended in $20 \mathrm{~mL}$ chloroform by sonicating for $30 \mathrm{~min}$. Following sonication, $220 \mathrm{mg}$ EG 3 TMS was dissolved in $5 \mathrm{~mL}$ chloroform and added to the suspension. The solution was refluxed for $24 \mathrm{~h}$, after which the TEG-FITC MSNs were filtered, and washed with chloroform, methanol and water.

Instrumental Methods, Conditions, and Parameters for the Structure Characterizations of FITC-MSN and TEG-coated FITC MSN : Powder XRD diffraction data was collected on a Scintag XRD $2000 \mathrm{X}$-ray diffractometer using $\mathrm{Cu} \mathrm{K \alpha}$ radiation. Nitrogen adsorption and desorption isotherms, surface areas, and median pore diameters were measured using a Micromeritics ASAP2000 sorptometer. Sample 
preparation included degassing at $90{ }^{\circ} \mathrm{C}$ for $6 \mathrm{~h}$. Nitrogen adsoption and desorption isotherms of these materials were obtained at $-196^{\circ} \mathrm{C}$. Specific surface areas and pore size distributions were calculated using the Brunauer-EmmettTeller (BET) and Barrett-Joyner-Halenda (BJH) method, respectively. Particle morphology of these materials was determined by scanning electron microscopy (SEM) using a JEOL 840A scanning electron microscope with $20 \mathrm{kV}$ accelerating voltage and $0.005 \mathrm{nA}$ of beam current for imaging. For SEM analysis the sample was spread on a carbon stub and sputter coated with $20 \AA$ of gold. For transmission electron microscopy (TEM) investigations, a small aliquot was suspended in methanol and a drop was placed on a lacey carbon film on a 400 mesh copper grid, the methanol was allowed to evaporate. The sample was examined with a Philips model CM-30 TEM operating at 300 $\mathrm{kV}$.

Infrared spectroscopy was measured on a Nicolet Nexus 470 (Madison, WI), equipped with a cooled MCT/A detector and an Ever-Glo source. Omnic 5.2 software was used to collect the data and to perform data analysis. Dry air was purged through the optical bench to reduce IR absorbance 
due to water. Samples were prepared by mixing nanoparticles with $\mathrm{KBr}(\sim 5 \% \mathrm{w} / \mathrm{w})$.

For fluorescence confocal microscopy measurements, Hela cells were grown on cover slips as reported below. Fluorescence confocal examinations were completed on a Leica TCS NT confocal microscope with UV, argon, and krypton lasers with excitation wavelengths at $340-458 \mathrm{~nm}$, $488 \mathrm{~nm}$, and $568 \mathrm{~nm}$, respectively.

Reagents and Materials for Biological Studies: Human cervical cancer (HeLa), Chinese Hamster Ovarian (CHO) and Human vascular Endothelium cell lines were obtained from American Tissue Culture Collection (ATCC). Formaldehyde solution (37\% $\mathrm{w} / \mathrm{w})$ was purchased from Fisher. 4,6diamidino-2-phenylindole, dihydrochloride (DAPI) and trypan blue were purchased from Sigma-Aldxich. Trypsin (1x, 0.25) in $0.1 \%$ EDTA-2Na without calcium and magnesium was purchased from Fisher Scientific.

Cell Line Maintenance: HeLa and $\mathrm{CHO}$ cells were maintained in T75 flasks using DMEM (Dulbucco's modified Eagle's medium) supplemented with $10 \%$ equine serum, $2 \mathrm{mM}$ Lglutamine, $100 \mathrm{U} \mathrm{mL}^{-1}$ penicillin, $100 \mathrm{mg} \mathrm{mL^{-1 }}$ streptomycin, and $1 \mathrm{mg} \mathrm{mL}^{-1}$ gentamycin. HeLa and CHO cells were split every 2-3 days. Endothelial cells were maintained in T75 
flasks using Kaighn's F12K medium supplemented with $0.1 \mathrm{mg}$ $\mathrm{mL}^{-1}$ heparin, $0.04 \mathrm{mg} \mathrm{mL}^{-1}$ endothelial cell growth supplement (ECGS), and 10\% fetal bovine serum. Endothelial cells were split every $7-10$ days.

Measuring the Dosage of FITC-MSN and TEG-coated FITC-MSN: To investigate the maximum amount of material that can be incorporated by HeLa and CHO cells, a dosage experiment was designed. The cells were grown in 6-well plates for 24, hours or until visual confluency developed; the cells were then treated with incremental amounts of FITC-MSNs and TEGcoated FITC-MSNs suspended in media. Experiments were designed for both FITC-MSNs and TEG coated FITC-MSNs with concentrations of $0,0.01,0.05,0.10,0.15$, and $0.20 \mathrm{mg}$ $\mathrm{mL}^{-1}$. The cells were incubated with the varying concentrations of MSNs for $12 \mathrm{~h}$ at $37{ }^{\circ} \mathrm{C}$ in $5 \% \mathrm{CO}_{2}$. After $12 \mathrm{~h}$, the cells were washed two times with PBS (phosphatebuffered saline) and trypsinized. The cells were incubated in $830 \mathrm{mM}$ trypan blue for $10 \mathrm{~min}$ to quench the fluorescence of any MSNs adhered to the exterior of the cells. The MSN uptake was measured by flow cytometry.

Measuring the Kinetics of FITC-MSN and TEG-coated FITC-MSN Uptake: To investigate the rate of MSN uptake into HeLa and CHO cells, a kinetic experiment study was concieved. 
The cells were grown in 6 -well plates for $24 \mathrm{~h}$, or until visual confluency developed. The cells were incubated with a uniform amount of MSNs $\left(0.10 \mathrm{mg} \mathrm{mL}^{-1}\right)$ for varying amounts of time. Uptake was measured at $0,0.5,1.0,1.5,2.0,4.0$, and 6.0 time intervals. After the pre-determined amount of time, the cells were washed twice with PBS, and incubated in standard growth media. Fourteen hours after initial inoculation, the cells were trypsinized, and the MSN uptake was measured by flow cytometry.

Fluorescence Confocal Microscopy Measurements: To visually investigate the endocytosis of FITC-MSNs and TEG-coated FITC-MSNs, fluorescence confocal microscopy was employed. Coverslips (22 $\left.\mathrm{mm}^{2}\right)$ were cleaned with $1 \mathrm{M} \mathrm{HCl,} \mathrm{nanopure}$ water $(3 x), 50 \frac{\circ}{\circ}$ ethanol, $70 \%$ ethanol, and $100 \%$ ethanol, and dried overnight at $60{ }^{\circ} \mathrm{C}$. Following cleaning, the coverslips were placed on the bottom of the wells of 6-well plates and covered with $3 \mathrm{~mL}$ of standard growth media. HeLa and CHO cells ( $1 \times 10^{5}$ cells $\mathrm{mL}^{-1}$ ) were grown for $24 \mathrm{~h}$ on the coverslips. After $24 \mathrm{~h}$, the cells were inoculated with $0.1 \mathrm{mg} \mathrm{mL}-1$ MSNs, and grown for an additional $12 \mathrm{~h}$. Afterwards, the growth media was removed, the cells were washed with PBS $(2 x)$, and the cells were then reincubated with a PBS solution of $3.7 \%$ formaldehyde and $57 \mathrm{mM}$ DAPI for 
30 min. These coverslips were removed from the PBS solution and fixed to glass slides with liquid adesive.

Tobacco Protoplasts Isolation: Nicotiana tabacum $I$. cV. Petite Havana SRI was grown aseptically on MS solid media for 6 weeks. Mesophyll protoplasts were isolated by modified processes previously described. ${ }^{26}$ Briefly, pieces of tobacco leaves were incubated overnight at room temperature, in K4 medium with $1.2 \%$ cellulase onozuka $\mathrm{R}-10$ and $0.6 \%$ macerozyme $\mathrm{R}-10$ under continuous gentle orbital shaking. After filtration, the digestion mixture was overlayed with w5 media and centrifuged for 15 minutes at 80g. The intact protoplasts form a ring at the interphase. Purified protoplasts were washed 3 times in W5 and adjusted to $1 \times 10^{6}$ cells $\mathrm{mL}^{-1}$.

Protoplast Treatment: Protoplasts were incubated in w5 media with FITC-doped MSNs and TEG coated FITC-MSNs. The ratio used was $1 \times 10^{6}$ cell for $0.1 \mathrm{mg}$ of MSN. The protoplasts were incubated in the dark, overnight at room temperate. After incubation, the protoplasts were separated from unincorporated MSN by centrifugation on a K4 medium cushion for 15 minutes at $80 \mathrm{~g}$.

Protoplasts Confocal Microscopy: All cells were observed alive with a Leica TCS/NT confocal microscope. For FITC the 
Ar laser for excitation (488nm) was used and $\mathrm{Kr}$ laser (568nm) for the TRITC. $10 \mu \mathrm{L}$ of the purified protoplasts were mounted on a glass slide and covered with a coverslip. Autofluorescence of chlorophyll is visible in all channels.

\section{RESULTS AND DISCUSSION}

To prepare TEG functional MSNs for the endocytosis studies, (Figure 1) fluorescein doped MSNs were first synthesized via a modified synthesis of our previously published synthesis. The synthesis was modified by first synthesizing a trimethoxysilane derivatized fluorescein molecule. Following this, the fluorescein derivative was added to the MSNs during addition of the silica monomer. After the mesoporous materials were synthesized, the previously synthesized tri(ethylene glycol) propyltrimethoxysilane was grafted to the exterior of the MSNs via reflux in toluene. Once the ethylene glycol group was grafted to the exterior of the MSNs the surfactant was removed from the pores via hydrochloric acid wash.

The material was fully characterized after the synthesis was complete and prior to cell studies. As depicted in figure 2a, the spherical morphology and the hexagonal pore structure of the TEG-grafted MSNs is readily observable by scanning (a) and transmission (b) electron 
microscopy investigation (SEM and TEM, respectively). The arrows in figure $2 \mathrm{~b}$ point to the pores formed during the synthesis of the FITC-doped MSNs. Clearly the addition of the TEG-TMS did not change the particle or pore morphology.

The nitrogen adsorption/desorption isotherms are further evidence for MCM-41 type material with a typical BET isotherm (type IV) (Figure 3a). The surface area of the material was determined to be $1048 \mathrm{~m}^{2} \mathrm{~g}^{-1}$, with an average pore diameter of $27.4 \AA$ before the TEG-TMS was grafted onto the surface. After grafting, the surface area decreased to $712.7 \mathrm{~m}^{2} \mathrm{~g}^{-1}$ with an average pore diameter below $20 \AA$. The pore size was determined by BJH calculation and had a narrow size distribution (Table 1 and Figure 3b).

The powder $x$-ray diffraction (XRD) demonstrated more conclusively the MCM-41 type porous structure. Before the TEG-TMS was grafted, the hexagonal array of pores is easily distinguishable, as shown in the XRD in figure 4. Notice peaks representing the $d_{100}, d_{110}, d_{200}$, and $d_{210}$ Miller indices are clearly present and labeled as such in figure 4a. After the TEG-TMS group was grafted some of the resolution was lost due to coverage of the organic functional groups. The $d_{100}$ peak is still clearly present 
but decreased in intensity, again due to the presence of the TEG-TMS groups grafted to the exterior.

Finally, the evidence for the grafting of TEG-TMS was investigated by infrared spectroscopy (Figure 4b). Peaks are visible after the organic group was grafted above 2900 $\mathrm{cm}^{-1}$ (data not shown). These peaks represent $\mathrm{C}-\mathrm{H}$ bond stretches and are not present before grafting.

Following complete material characterization, the interaction of the TEG coated FITC-MSNs with biological systems was investigated and compared to that of the uncoated FITC-MSNs. First, the uptake of both MSNs was measured as a function of the concentration in both $\mathrm{CHO}$ (Chinese Hamster Ovarian cancer) and HeLa (Human Cervical Cancer) cells. Endocytosis is staturated (>95\%) for both cell lines with the addition of just $0.05 \mathrm{mg} \mathrm{mL}^{-1}$ TEG coated FITC-MSNs (Figures $5 \& 6$ ). At the same concentration, FITC- MSNs showed endocytosis of only $\sim 10-15 \%$ into the cells. Following the dosage dependent study, the kinetics of endocytosis was measured in both cell lines. The rate at which cell internalization occurred for the TEG coated FITC-MSN exceeded that of the FITC-MSN by a significant amount for both cell lines (Figure $7 \& 8$ ). After just 30 minutes, over $90 \%$ of the recorded cells contained TEG 
coated FITC-MSNs, while just 5-7\% of the cells internalized the FITC-MSNs.

Fluorescence confocal images showed that the TEG coated FITC-MSNs crossed the cell membrane and were internalized into the cells, most likely through endocytosis (Figure 9a-c). The green fluorescence of the fluorescien can be seen in the cytoplasm especially around the nucleus upon excitation at $494 \mathrm{~nm}$ (Figure 9a). To visualize the locations of the nuclei, the cells were excited at $358 \mathrm{~nm}$ (Figure 9b). The appearance of healthy intact nuclei and the visibility of fully grown cells by pseudo-brightfield suggested that the TEG coated FITC-MSN are biocompatible with HeLa cells under experimental conditions (Figure 9c). A series of fluorescence images of different cross-sections of TEG coated FITC-MSN containing Hela cells were obtained by changing the focal depth by 1.2 $\mu m$ vertically (Figure 10a-f)

Finally, the TEG coated FITC-MSNs were internalized by tobacco protoplasts (Figure $11 a-1)$. The arrows indicate a cluster of TEG coated FITC-MSNs that are excited by the Ar laser. The round artifacts clustered just inside the protoplast are chloroplasts, and are excited at $488 \mathrm{~nm}$ and $568 \mathrm{~nm}$ by $\mathrm{Ar}$ and $\mathrm{Kr}$ lasers, respectively. In contrast, the 
TEG coated FITC-MSNs are not visible when excited at 568 $\mathrm{nm}$, which allows for the differentation of the nanoparticles from the chloroplasts. The nanoparticles without the organic functionality were not internalized by the tobacco protoplasts.

The mechanism by which the tri(ethylene glycol) functional group increases the cellular internalization ability is not completely clear. However, a recent publication and personal experimental observations gives some theories. To begin with, the ethylene glycol is a very hydrophilic molecule and, as observed in our laboratory, make the MSN suspend in aqueous solution for a much longer time and at a wider range of temperatures than non-functional MSN. In 2003, it was reported that tetra(ethylene glycol) protected gold nanoparticles had great stability in aqueous solutions with a high concentration of electrolytes. It was also reported that these gold nanoparticles with hydrophilic surfaces have complete resistance to protein nonspecific interactions. ${ }^{25}$ This prevention of nonspecific protein interaction, plus the increased suspension stability, may be the reasons for increased cell uptake. 
In summary, tri(ethylene glycol) functionalized fluorescein doped mesoporous silica nanoparticles were synthesized and extensively characterized. Internalization of the nanoparticles into HeLa and CHO cells, and accumulation in the cytoplasm was demonstrated. For the first time, the internalization of mesoporous silica nanoparticles was demonstrated in protoplasts. The MSNs appear to have no cytotoxic effects on both, animal and plant cell types. 


\section{FIGURE LEGENDS}

Table 1. Nitrogen sorption data of FITC-MSN and TEG coated FITC-MSN.

Figure 1. Schematic representation of the TEG coated FITC doped MSNs, used to measure endocytosis into cancer and plant cells.

Figure 2. Electron micrographs of TEG coated FITC doped MSNs: (a) Scanning electron micrographs (b) Transmission electron micrographs.

Figure 3. (a) BET isotherm of surfactant-removed FITCdoped MSNs (red) and TEG grafted FITC-doped MSNs (blue). (b) BJH pore diameter distribution of surfactant-removed FITC-doped MSNs (red) and TEG grafted EITC-doped MSNs (blue) .

Figure 4. XRD spectra of surfactant-removed FITC-doped MSNS (a) and TEG grafted FITC-doped MSNs (b). 
Figure 5. Uptake of FITC-doped MSNs (a) and TEG grafted FITC doped MSNs (b) by HeLa cells after $12 \mathrm{~h}$ incubation at $37{ }^{\circ} \mathrm{C}$ as a function of nanoparticle concentration.

Figure 6. Uptake of FITC-doped MSNs (a) and TEG grafted FITC doped MSNs (b) by CHO cells after $12 \mathrm{~h}$ incubation at $37{ }^{\circ} \mathrm{C}$ as a function of nanoparticle concentration.

Figure 7. Uptake of FITC-doped MSNs (a) and TEG grafted FITC doped MSNs (b) by HeLa cells at $37^{\circ} \mathrm{C}$ as a function of varying incubation time. The dosing concentration was $100 \mu \mathrm{g} \mathrm{mL} \mathrm{m}^{-1}$.

Figure 8. Uptake of FITC-doped MSNS (a) and TEG grafted FITC doped MSNs (b) by CHO cells at $37^{\circ} \mathrm{C}$ as a function of varying incubation time. The dosing concentration was $100 \mu \mathrm{g} \mathrm{mL} \mathrm{m}^{-1}$.

Figure 9. Fluorescence confocal micrographs of HeLa cells incubated with $100 \mu \mathrm{g} \mathrm{mL}^{-1}$ of TEG coated FITCdoped MSNs for $12 \mathrm{~h}$ at $37^{\circ} \mathrm{C}$ : a.) cells 
excited in the UV region; b.) cells excited at 494 nm; c.) a pseudo-brightfield image.

Figure 10. Flourescence confocal micrographs of HeLa cells after $12 \mathrm{~h}$ incubation demonstrating endocytosis of TEG coated FITC-MSNs (a)-(f). Each frame represents a focal point with $1.2 \mu \mathrm{m}$ vertical difference.

Figure 11. Fluorescence confocal micrograph images of Tobacco protoplasts, demonstrating the endocytosis of TEG coated ETTC-MSNs after incubation at room temperature overnight (a)(1) . 
Table one.

\begin{tabular}{|c|c|c|c|}
\hline & $\begin{array}{c}\text { BET surface area } \\
\left(\mathrm{m}^{2} \mathrm{~g}^{-1}\right)\end{array}$ & $\begin{array}{c}\text { Pore volume } \\
\left(\mathrm{cm}^{3} \mathrm{~g}^{-1}\right)\end{array}$ & $\begin{array}{c}\text { BJH Average } \\
\text { Pore Diameter } \\
(\AA)\end{array}$ \\
\hline FITC-MSN & 1048 & 0.914 & 27.4 \\
\hline $\begin{array}{c}\text { TEG coated } \\
\text { FITC-MSN }\end{array}$ & 713 & 0.367 & $\geq 20$ \\
\hline
\end{tabular}




\section{FIGURES}

Figure 1.

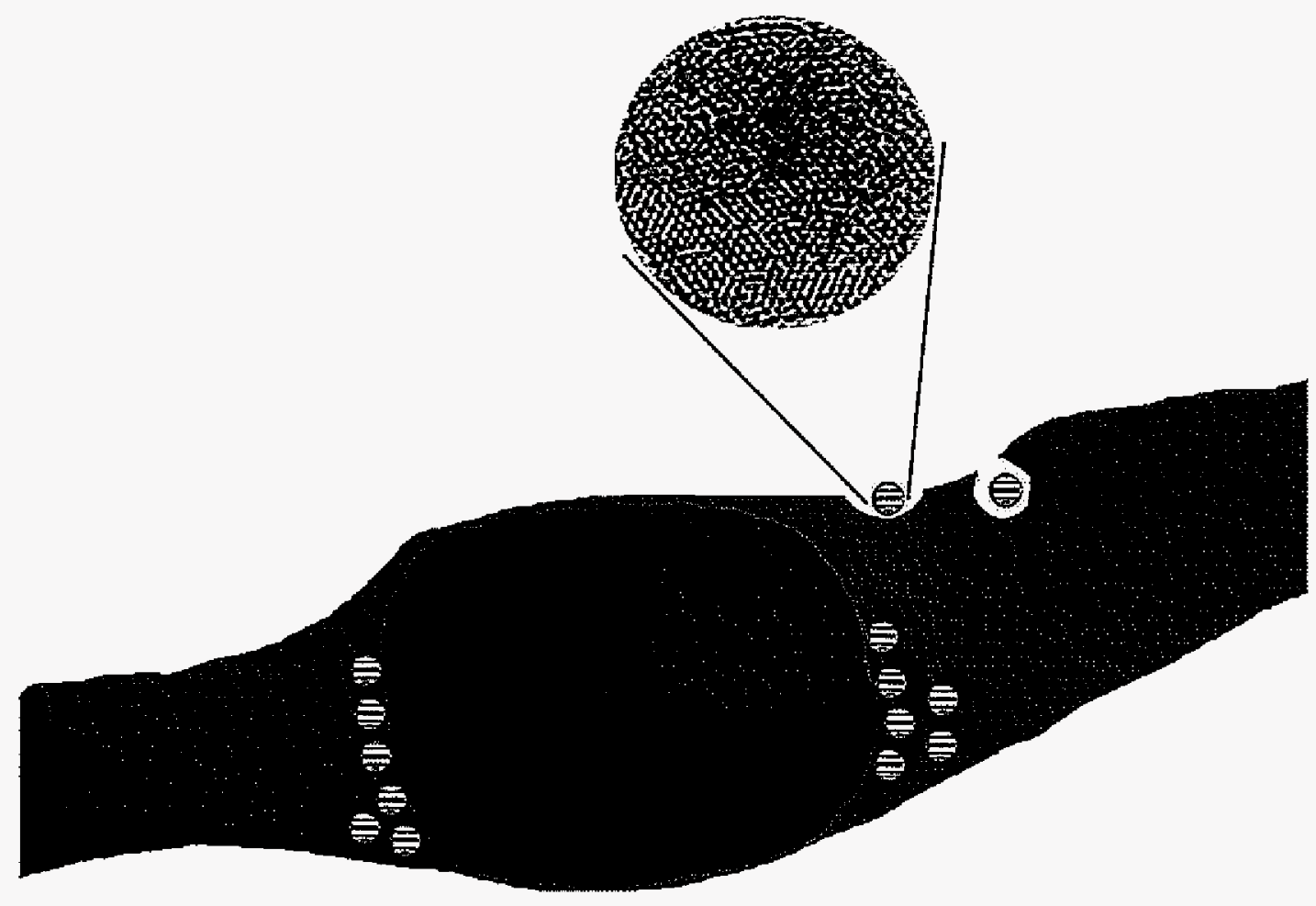


Figure 2a.

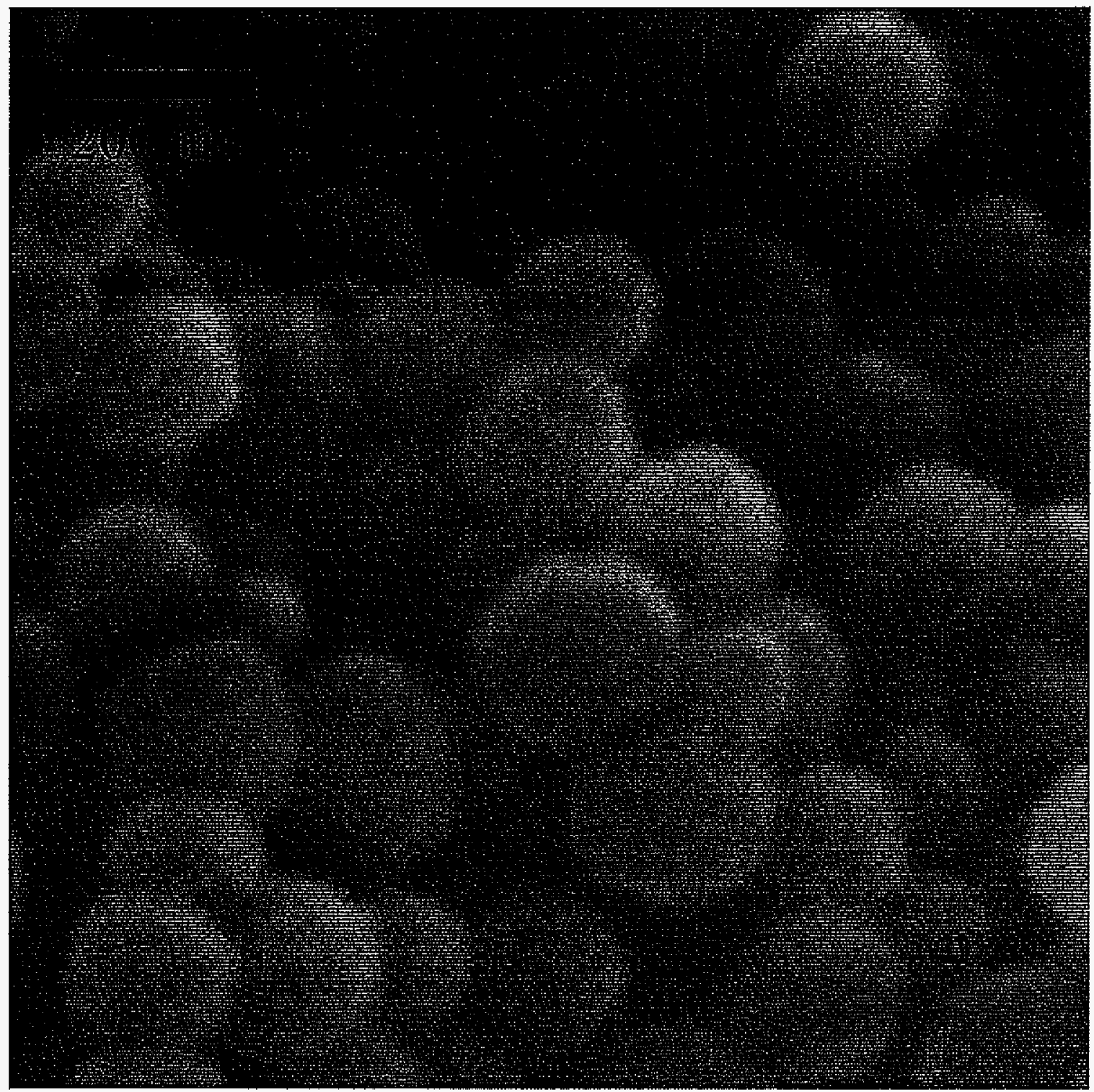




\section{Figure 2b.}

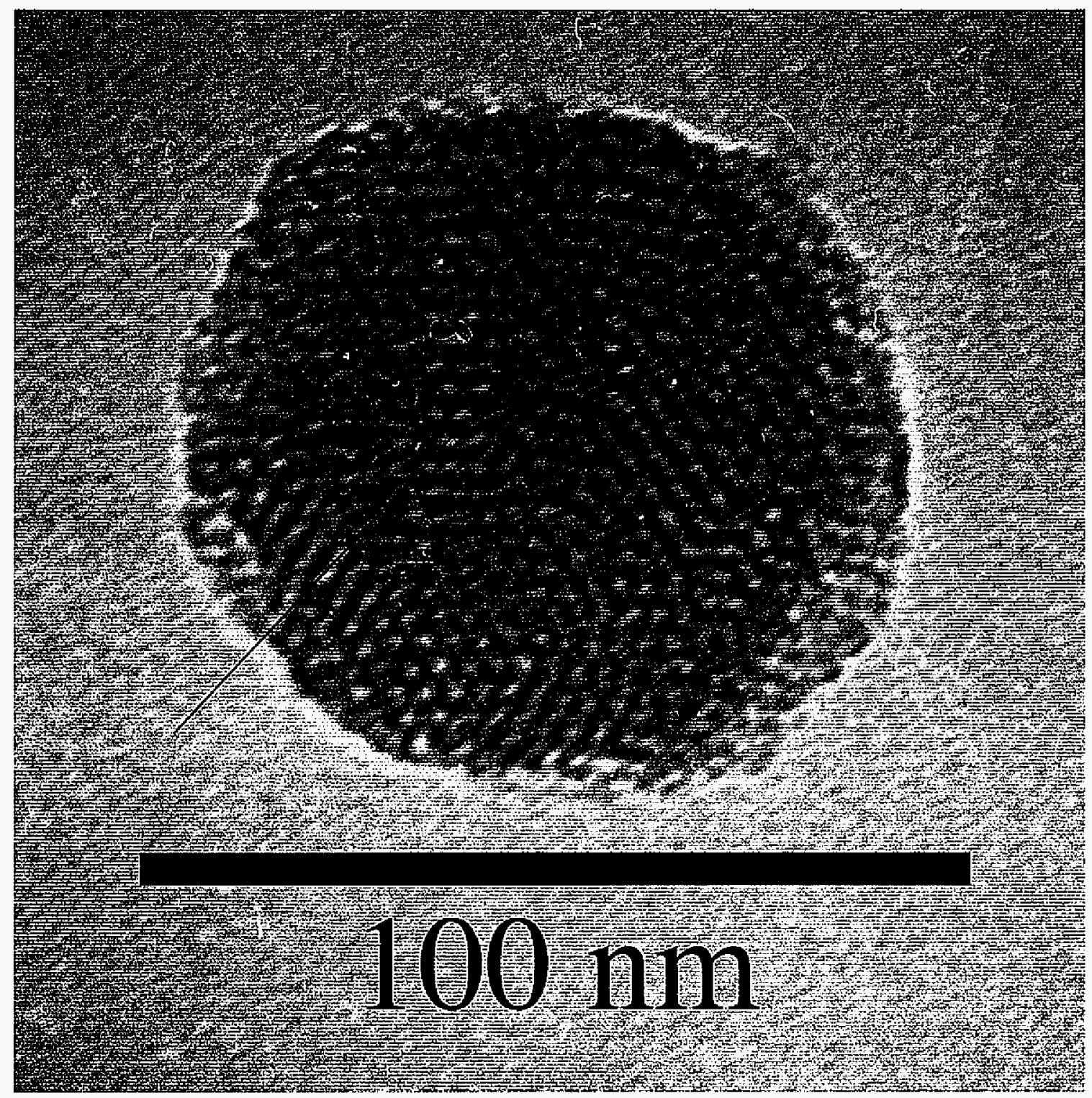


Figure 3.

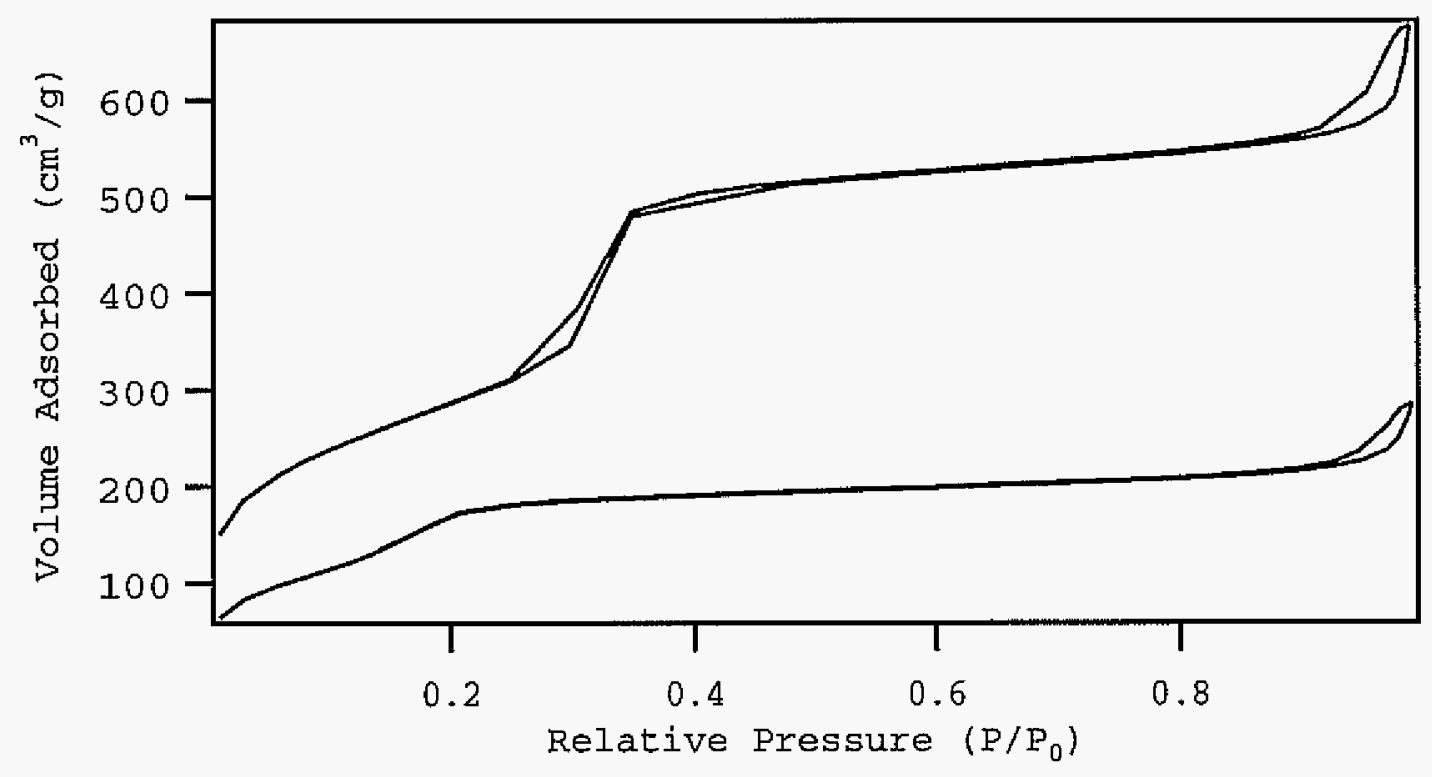


Figure 3b.

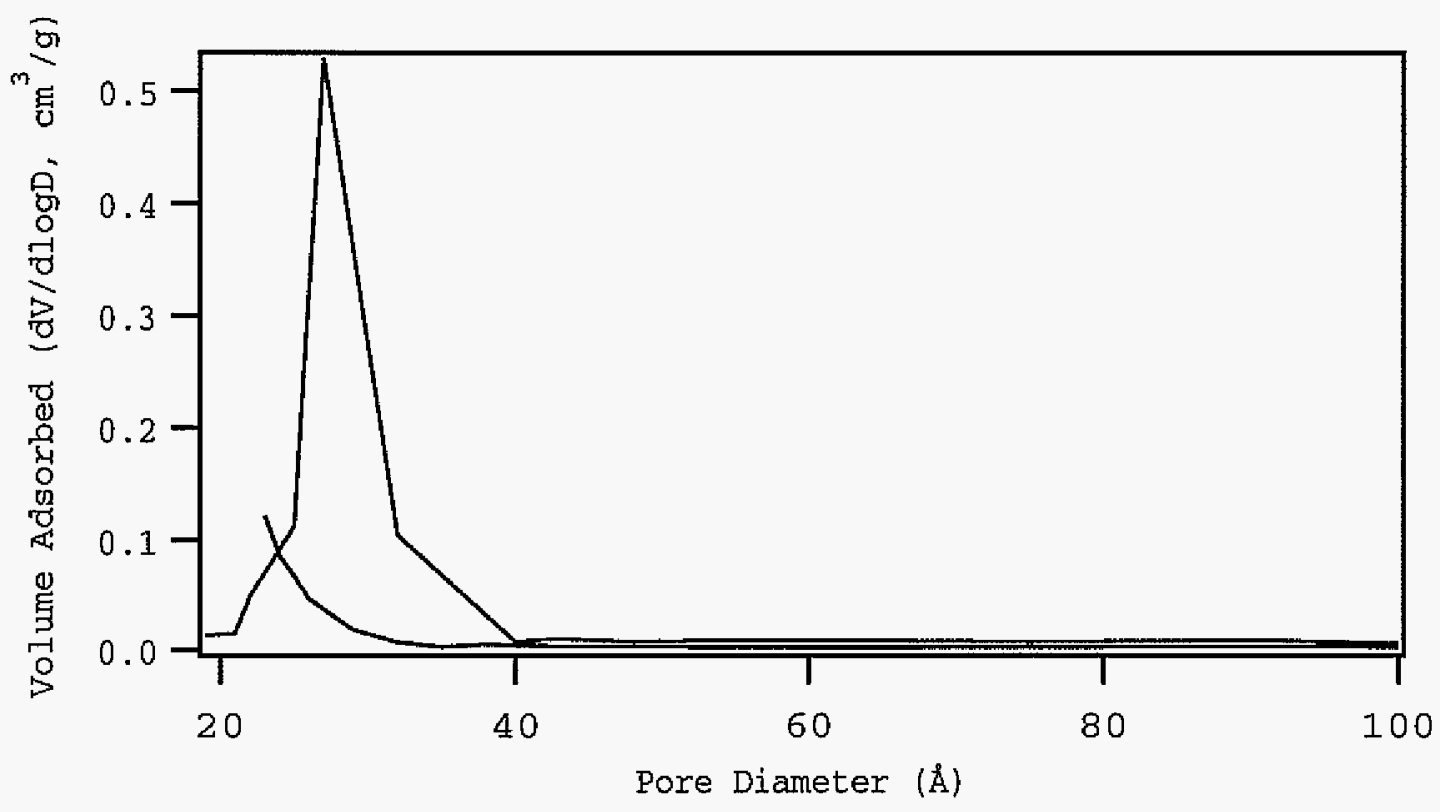


Figure 4.

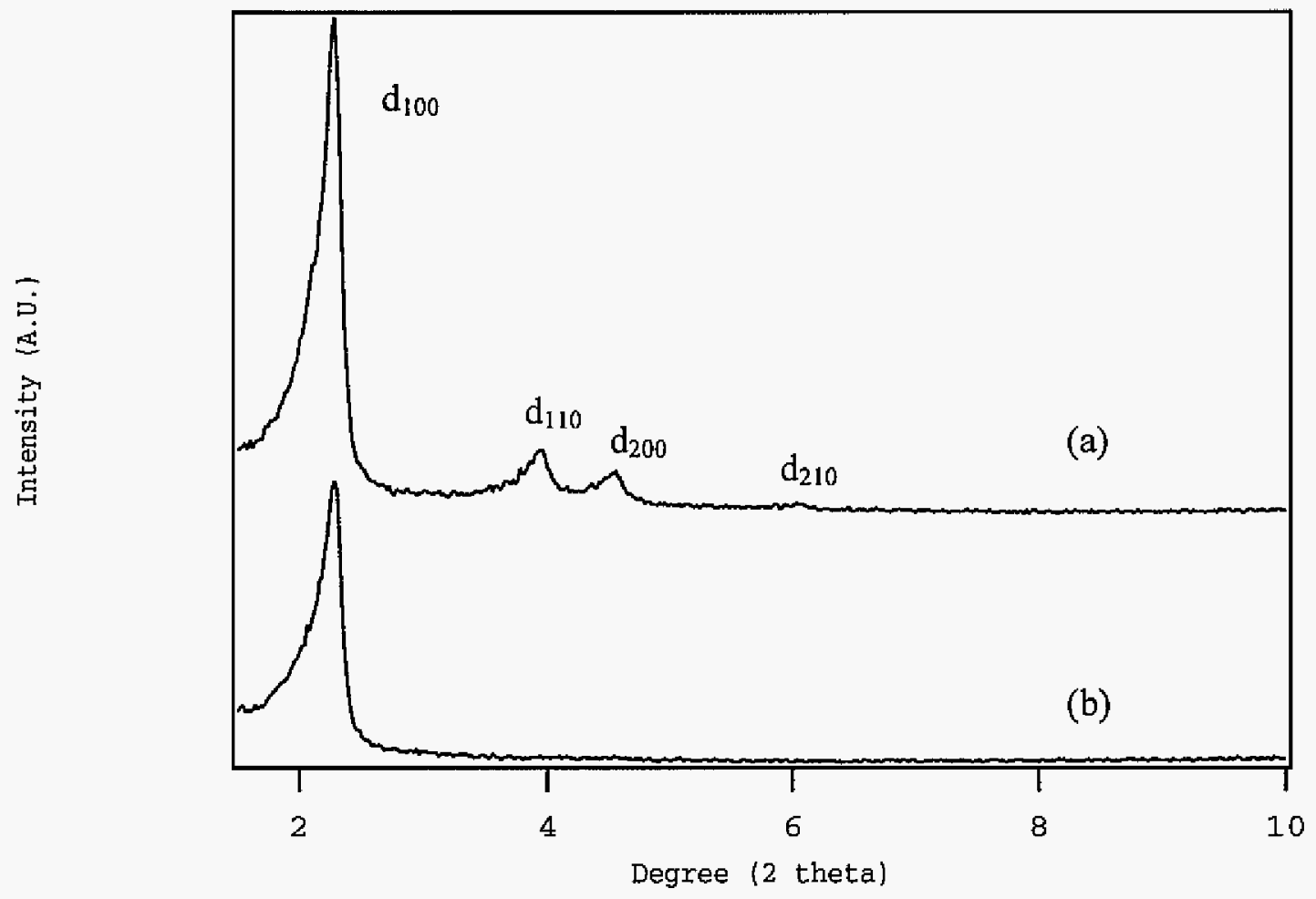


Figure 5.

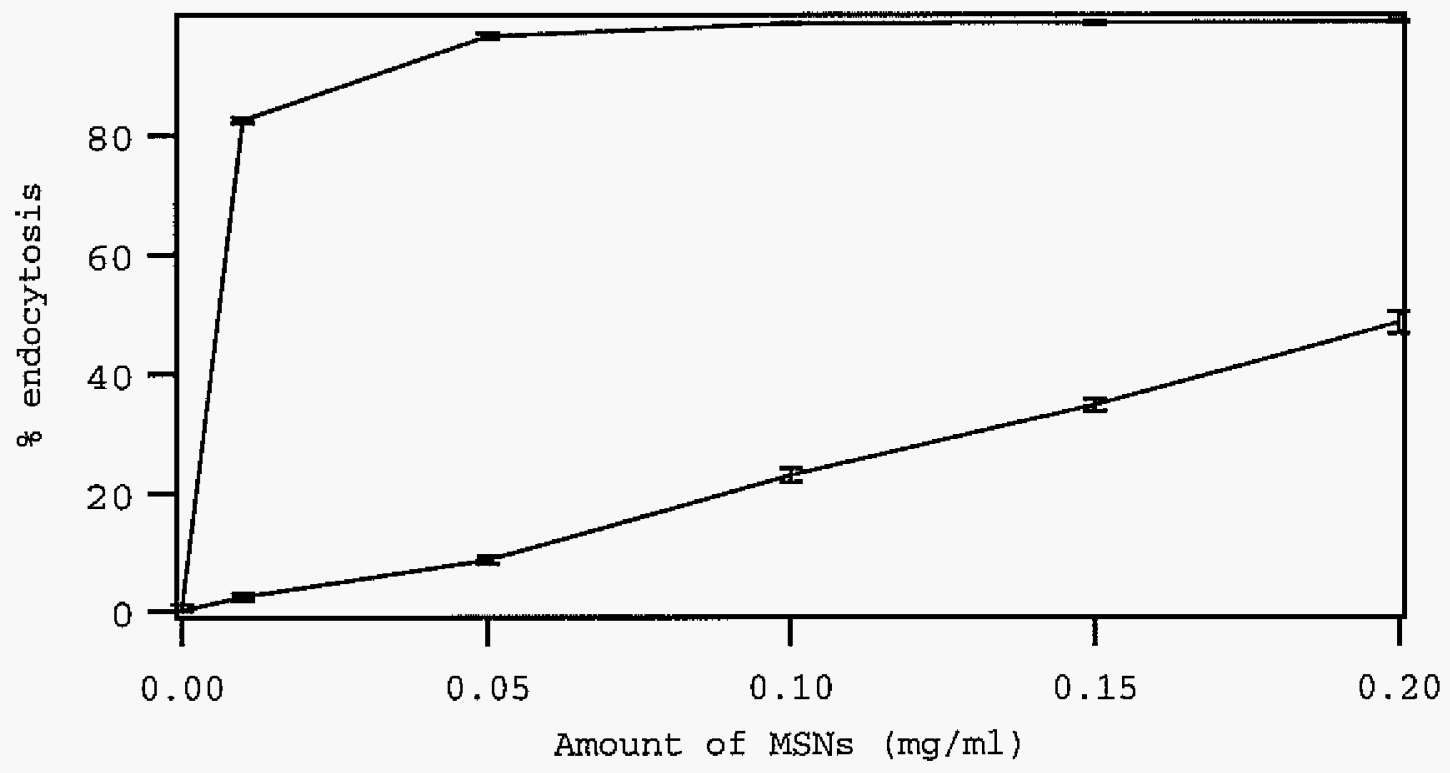


Figure 6 .

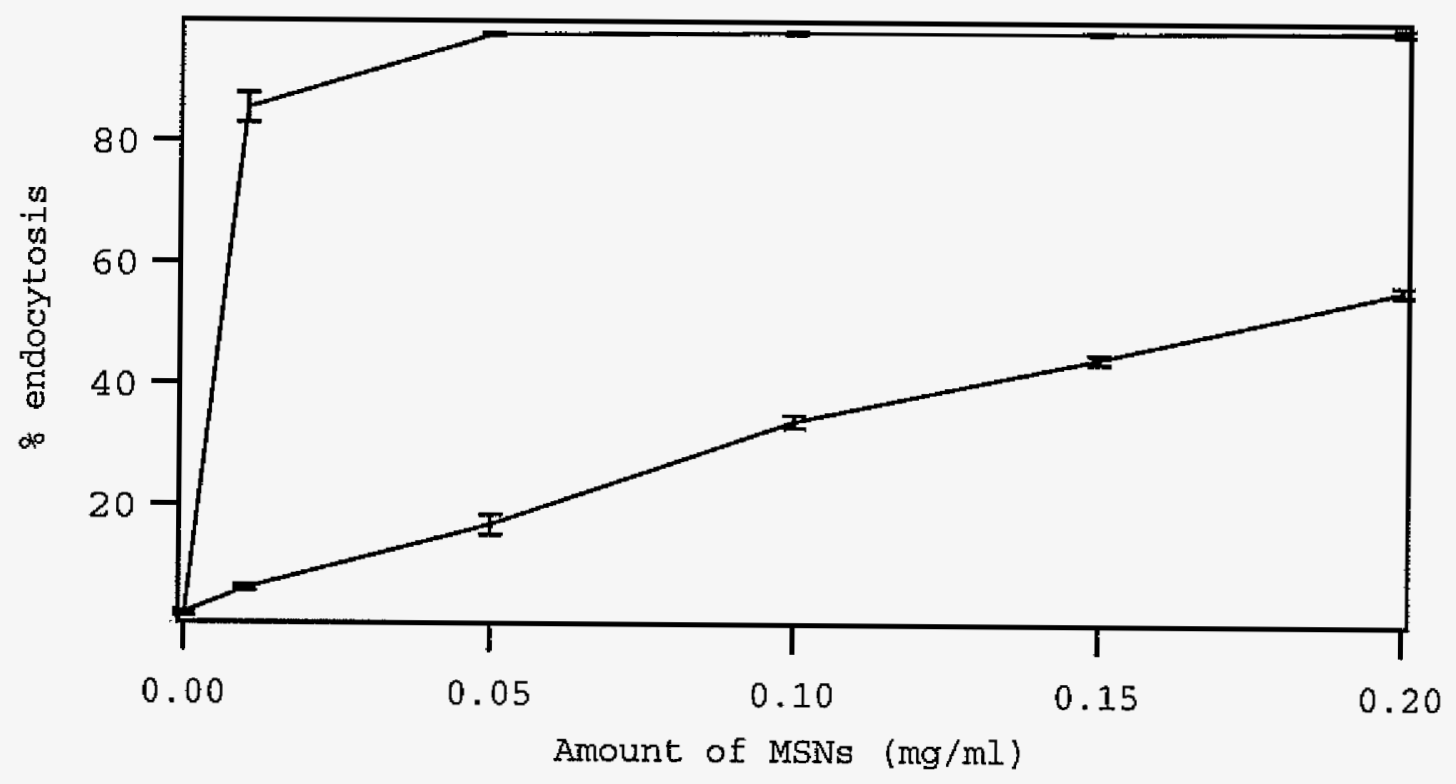


Figure 7.

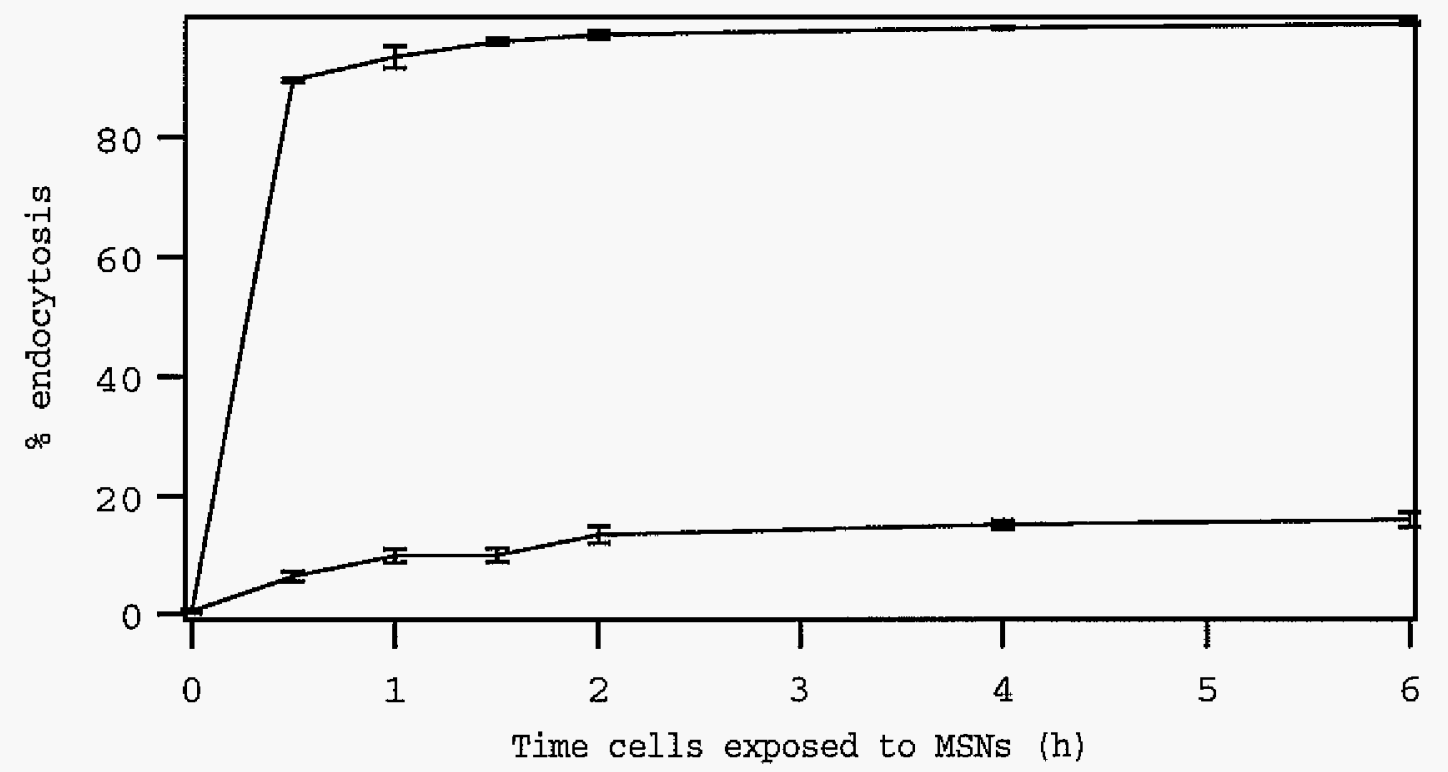


Figure 8.

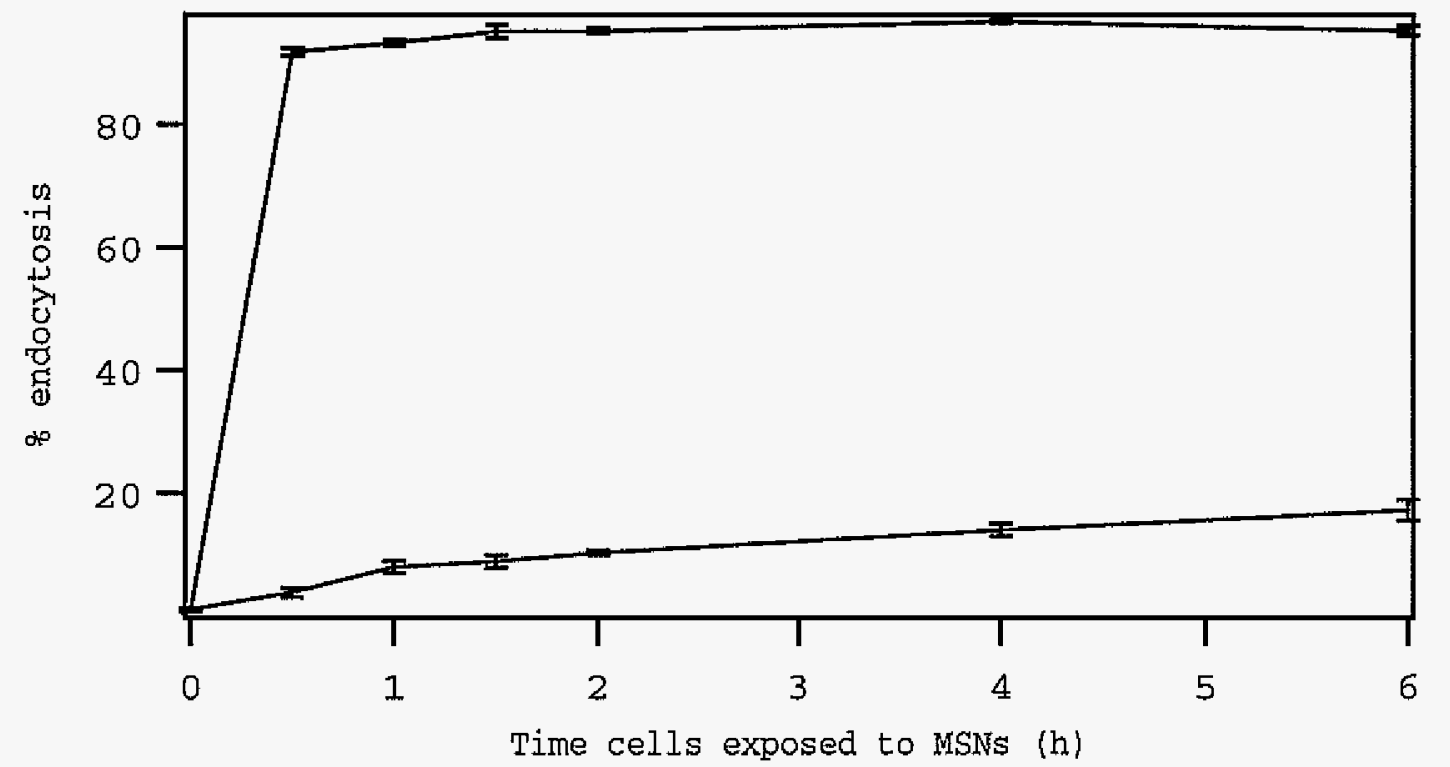


Figure 9.
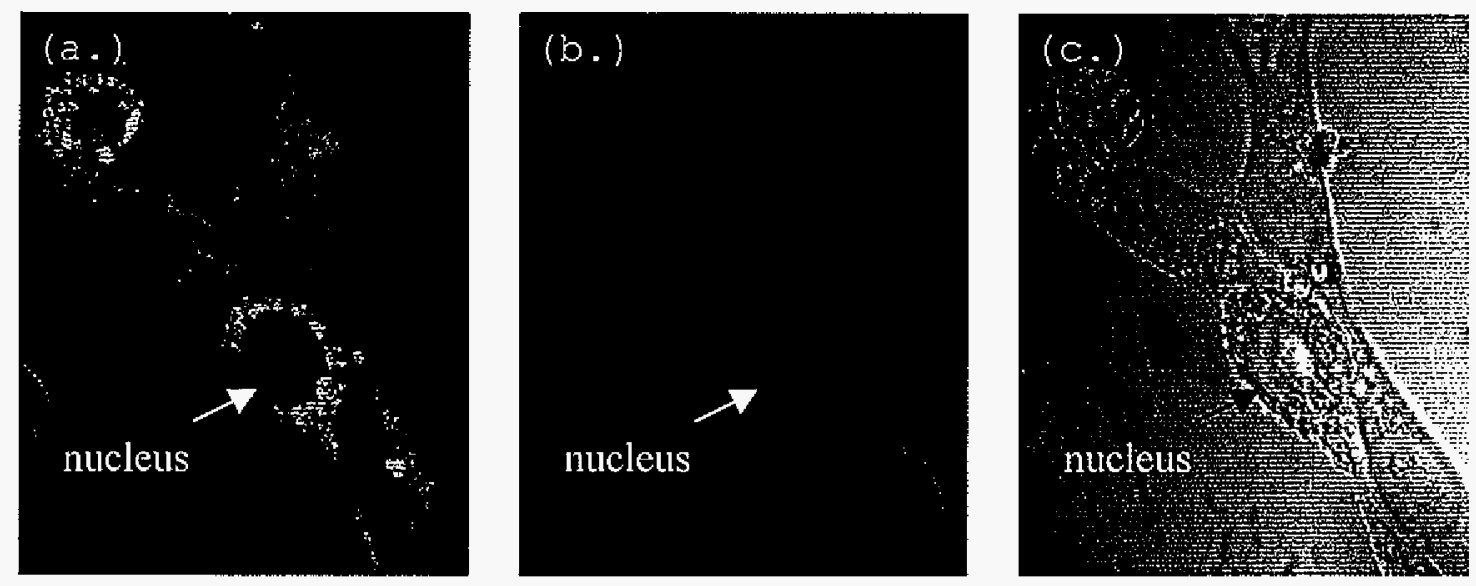
Figure 10.
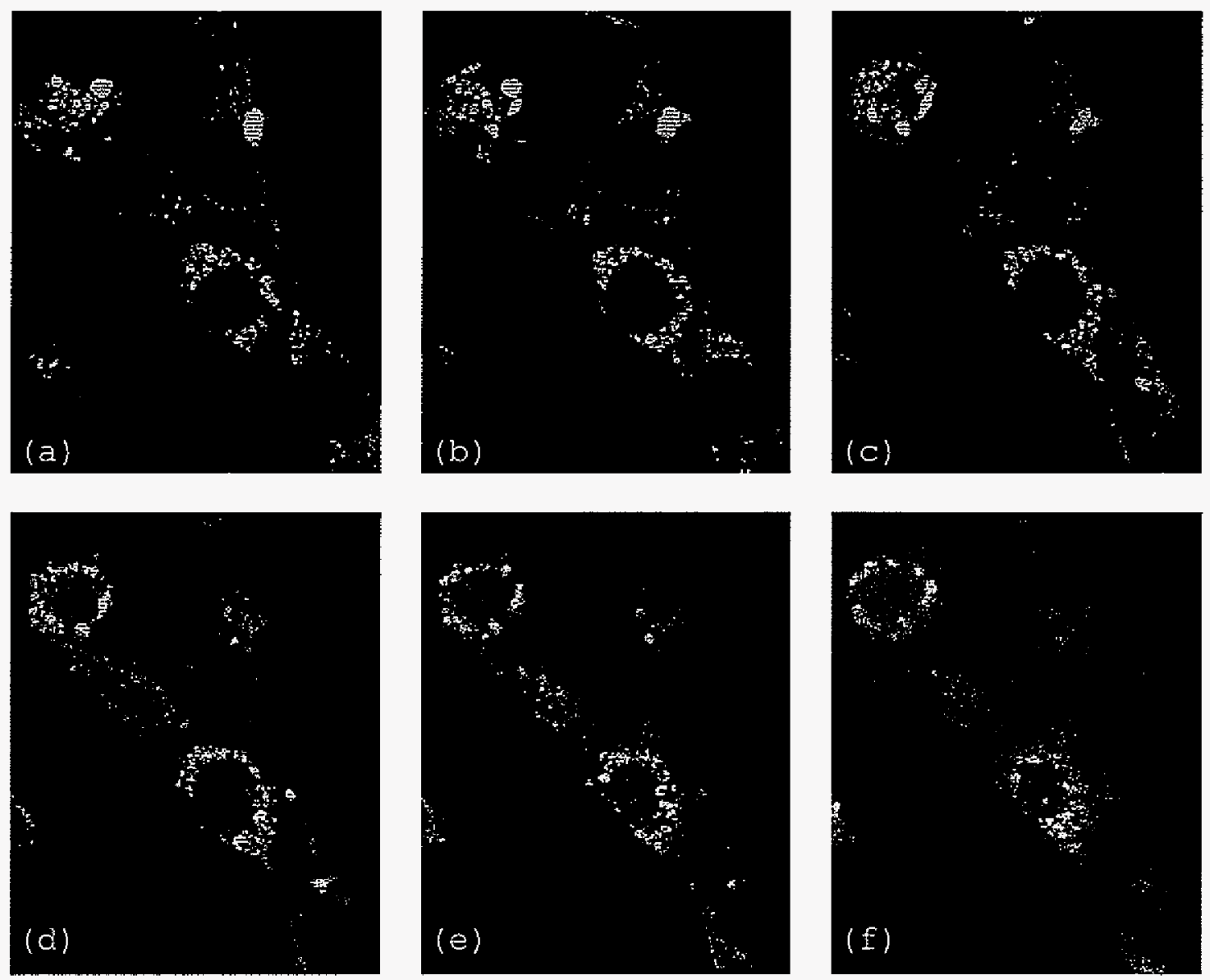
Figure 11.
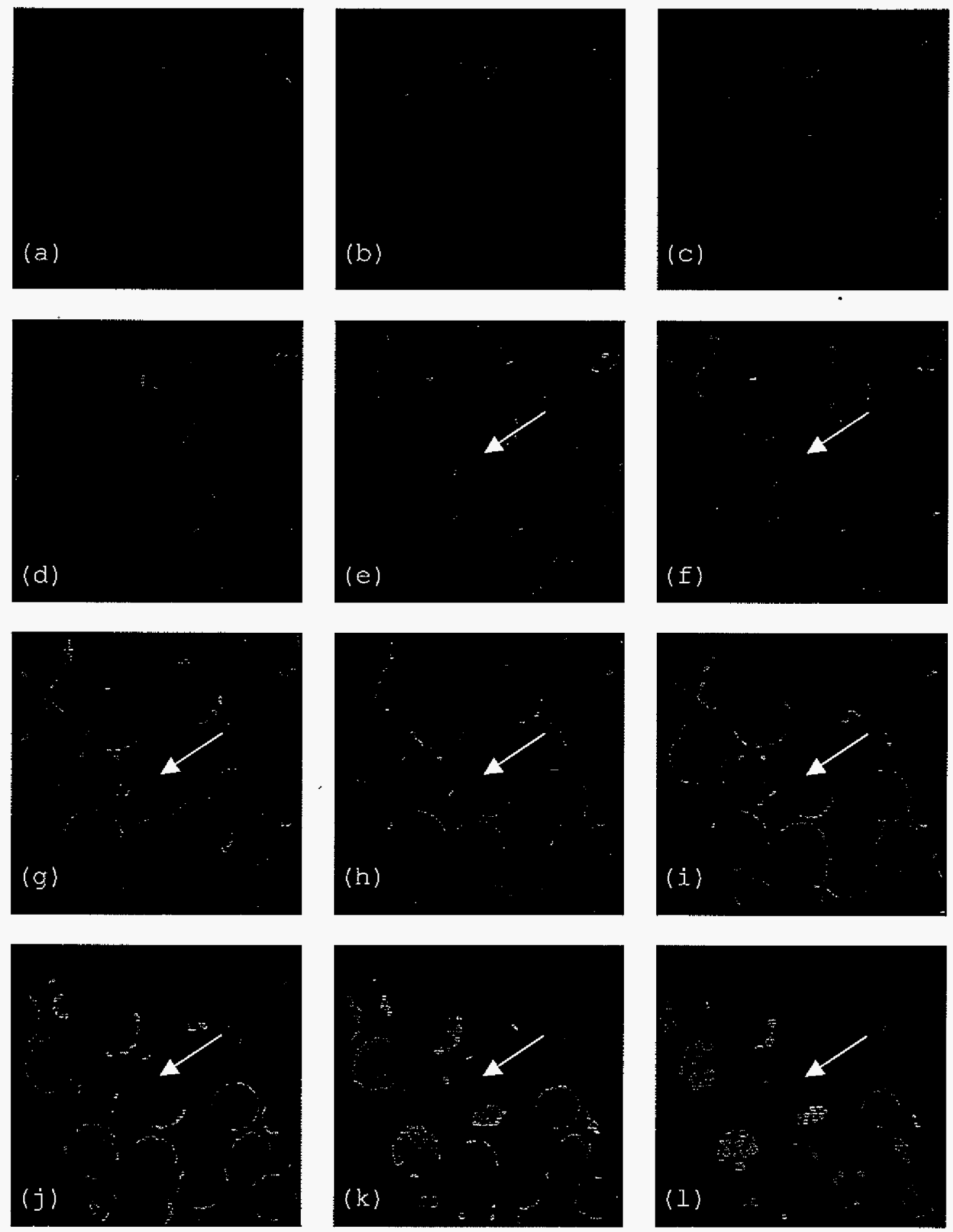


\section{REFERENCES}

(1) Descalzo, A. B.; Marcos, M. D.; Martinez-Manez, R.; Soto, J.; Beltran, D.; Amoros, P. Journal of Materials Chemistry 2005, 15, 2721-2731.

(2) Radu, D. R.; Lai, C.-Y.; Wiench, J. W.; Pruski, M.; Lin, V. S. Y. Journal of the American Chemical Society $2004,126,1640-1641$.

(3) Andersson, J.; Rosenholm, J.; Areva, S.; Linden, M. Chemistry of Materials 2004, 16, 4160-4167.

(4) Mal, N. K.; Fujiwara, M.; Tanaka, Y. Nature (London, United Kingdom) 2003, 421, 350-353.

(5) Ostafin, A. E.; Burgess, J. P.; Mizukami, H. Tissue Engineering and Novel Delivery Systems 2004, 483-503.

(6) Tozuka, Y.; Oguchi, T.; Yamamoto, K. Pharmaceutical Research 2003, 20, 926-930.

(7) Vallet-Regi, M.; Doadrio, J. C.; Doadrio, A. L.; Izquierdo-Barba, I.; Perez-Pariente, J. Solid State Ionics 2004, 172, 435-439.

(8) Lai, C.-Y.; Trewyn, B. G.; Jeftinija, D. M.; Jeftinija, K.; Xu, S.; Jeftinija, S.; Lin, V. S. Y. Journal of the American Chemical Society 2003, 125, $4451-4459$ 
(9) Giri, S.; Trewyn, B. G.; Stellmaker, M. P.; Lin, V. S. Y. Angewandte Chemie, International Edition 2005, 44, $5038-5044$

(10) Radu, D. R.; Lai, C.-Y.; Jeftinija, K.; Rowe, E. W. ; Jeftinija, S.; Lin, V. S. Y. Journal of the American Chemical Society 2004, 126, 13216-13217.

(11) Huang, D.-M.; Hung, Y.; Ko, B.-S.; Hsu, S.-C.; Chen, W.-H.; Chien, C.-L.; Tsai, C.-P.; Kuo, C.-T.; Kang, J.-C.; Yang, C.-S.; Mou, C.-Y.; Chen, Y.-C. FASEB Journal 2005, 19, 2014-2016.

(12) Lin, Y.-S.; Tsai, C.-P.; Huang, H.-Y.; Kuo, C.-T.; Hung, Y.; Huang, D.-M.; Chen, Y.-C.; Mou, C.-Y. Chemistry of Materials 2005, 17, 4570-4573.

(13) Floyd, S.; De Camilli, P. Trends in Cell Biology 1998, $8, \quad 299-301$

(14) Hyun, T. S.; Ross, T. S. Trends in Molecular Medicine 2004, 10, 194-199.

(15) Baluska, F.; Liners, F.; Hlavacka, A.; Schlicht, M.; Van Cutsem, P.; MCCurdy, D. W.; Menzel, D. Protoplasma $2005,225,141-155$.

(16) Baluska, F.; Samaj, J.; Hlavacka, A.; Kendrick-Jones, J.; Volkmann, D. Journal of Experimental Botany 2004, $55,463-473$ 
(17) Dhonukshe, P.; Mathur, J.; Huelskamp, M.; Gadella, T. W. J., Jr. BMC Biology 2005, 3, No pp given.

(18) Etxeberxia, E.; Baroja-Fernandez, E.; Munoz, F. J.; Pozueta-Romero, J. Plant and Cell Physiology 2005, 46, $474-481$

(19) Gross, A.; Kapp, D.; Nielsen, T.; Niehaus, K. New Phytologist 2005, 165, 215-226.

(20) Holstein, S. E. H. Traffic (Oxford, United Kingdom) $2002,3,614-620$

(21) Samaj, J.; Baluska, E.; Voigt, B.; Schlicht, M.; Volkmann, D.; Menzel, D. Plant Physiology 2004, 135, $1150-1161$

(22) Samaj, J.; Read, N. D.; Volkmann, D.; Menzel, D.; Baluska, F. Trends in CeIl Biology 2005, 15, 425-433.

(23) Volkmann, D.; Mori, T.; Tirlapur, U. K.; Konj.g, K.; Fujiwara, T.; Kendrick-Jones, J.; Baluska, F. Cell Biology International 2003, 27, 289-291.

(24) Paciorek, T.; Zazimalova, E.; Ruthardt, N.; Petrasek, J.; Stierhof, Y.-D.; Kleine-Vehn, J.; Morris, D. A.; Emans, N.; Juergens, G.; Geldner, N.; Friml, J. Nature (London, United Kingdom) 2005, 435, 1251-1256.

(25) Zheng, M.; Davidson, F.; Huang, X. Journal of the American Chemical Society 2003, 125, 7790-7791. 
(26) Spangenberg, G.; Osusky, M.; Oliveira, M. M.; Freydl, E.; Nagel, J.; Pais, M. S.; Potrykus, I. Theoretical and Applied Genetics 1990, 80, 577-87. 


\title{
CHAPTER 4. TRANSMISSION ELECTRON MICROSCOPY AND IN VITRO INVESTIGATION OF FLUORESCEIN LOADED, IRON OXIDE NANOPARTICLE CAPPED MESOPOROUS SIIICA NANOPARTICLES
}

\author{
Brian G. Trewyn, Supratim Giri, Michael P. Stellmaker, and \\ Victor S. $-Y$. Lin*
}

Published in Angew. Chem. Int. Ed. 2005, 44, 5038-5044.

\begin{abstract}
Once the synthesis of a controlled-release delivery system based on MCM-41-type mesoporous silica nanorods capped with superparamagnetic iron oxide nanoparticles was completed, the material characterized, and the dosage and kinetics of the antioxidant dependent release; the biological interaction of the material was determined along with TEM measurements. The electron microscopy investigation proved the pore openings of the MSN were indeed blocked by the $\mathrm{Fe}_{3} \mathrm{O}_{4}$ nanoparticles. The biological interaction investigation demonstrated $\mathrm{Fe}_{3} \mathrm{O}_{4}$-capped MSN endocytosis into Hela cells. Not only do the material enter the cells through endocytosis but it seems the fluorescein was released from the pores, most probably
\end{abstract}


caused by disulfide bond reducing molecules, antioxidants. In addition to endocytosis and release, the $\mathrm{Fe}_{3} \mathrm{O}_{4}$-capped MSN propelled the cells across a cuvette upon induction of a magnet force.

\section{INTRODUCTION}

While recent reports on surface-functionalized, superparamagnetic iron oxide nanoparticles have demonstrated their ability in drug/gene delivery, ${ }^{1-3}$ magnetic resonance imaging, ${ }^{4}$ thermal tumor therapy, ${ }^{5}$ and tissue repairing; ${ }^{6}$ there have been very limited reports of a magnetic nanoparticle based controlled-release system.7,8 These controlled-release systems are comprised of magnetic iron oxide cores surrounded by organic or inorganic constituents, and can be affected by magnetic force. However, many of these systems fail to maintain "zero release" prior to desired delivery mainly because of the nature of the drug encapsulation. To the best of our knowledge, no controlled-release delivery systems based on magnetic nanoparticles that are stimuli-responsive and capable of "zero premature release" have been reported.

Surface-functionalized mesoporous silica materials have been demonstrated to be excellent hosts of molecules 
of various sizes, shapes, and functionalities.9-15 Recent reports on the design of capped and gated mesoporous silica derivatives have shown promise in the generation of controlled-release nanodevices. ${ }^{16-19}$ Herein, we report the transmission electron microscopy investigation, endocytosis into cancer cells, and the magnetic force propulsion of cancer cells of a controlled-release delivery system that is based on MCM-41-type mesoporous silica nanorods (MSNs) capped with superparamagnetic iron oxide nanoparticles and is stimuli-responsive and chemically inert to guest molecules entrapped in the matrix.

\section{EXPERIMENTAL}

Hela cell line maintenance: Human cervical cancer (Hela) cell lines were obtained from American Tissue Culture Collection (ATCC) and were maintained using DMEM (Dulbecco's modified Eagle's medium) supplemented with horse serum $\left(10 \frac{\circ}{0}\right)$, L-glutamine $(2.00 \mathrm{mM})$, penicillin (100 U $\left.\mathrm{mL}^{-1}\right)$, streptomycin $\left(100.0 \mathrm{mg} \mathrm{mL} \mathrm{m}^{-1}\right)$, and gentamicin $(1.0 \mathrm{mg}$ $\left.\mathrm{mL}^{-1}\right)$.

Endocytosis of $\mathrm{Fe}_{3} \mathrm{O}_{4}$ capped MSNs in HeLa cells for magnetic force propulsion: Hela cells were seeded onto 6well plates $\left(1 \times 10^{5}\right.$ cells per well with $3.00 \mathrm{~mL}$ growth media) $24 \mathrm{~h}$ prior to the experiment. After $24 \mathrm{~h}$ the wells 
were seeded with $\mathrm{Fe}_{3} \mathrm{O}_{4}$-capped $\mathrm{MSN}$ - in growth media $10.2 \mathrm{mg}$ $\mathrm{mL}^{-1}$ ) in growth media. After $10 \mathrm{~h}$, the media was removed and the cells were washed with fresh growth media. Eollowing, the cells were trypsinized with $0.25 \%$ trypsin. A magnet was used to keep the cells associated with the magnetic nanoparticles stationary while the remaining (nonmagnetic) cells were removed. The cells that took up the $\mathrm{Fe}_{3} \mathrm{O}_{4}$-capped MSNs were centrifuged and resuspended in a solution of $4^{\prime}, 6$-diamidino-2-phenylindole (DAPI, $100.0 \mu \mathrm{g} \mathrm{mL}^{-1}$ ) in PBS $(100.0 \mathrm{mM}, \mathrm{pH} 7.4)$.

Endocytosis of $\mathrm{Fe}_{3} \mathrm{O}_{4}$-capped MSNs in Hela cells for fluorescence confocal examination: HeLa cells were seeded onto 6-well plates with acid cleaned $22 \mathrm{~mm}^{2}$ cover slips on the bottom( $1 \times 10^{5}$ cells per well with $3.00 \mathrm{~mL}$ growth media) $24 \mathrm{~h}$ prior to the experiment. After $24 \mathrm{~h}$ the wells were

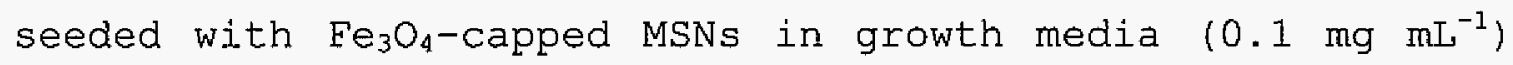
in growth media. After $13 \mathrm{~h}$, the media was removed and the cells were washed with PBS. Following, the cells were incubated with a solution of $\mathrm{PBS}(0.1 \mathrm{M}, \mathrm{pH} 7.4)$ with formaldehyde $\left(3.7 \frac{\circ}{6}\right)$ and DAPI $\left(100.0 \mu \mathrm{g} \mathrm{mL} \mathrm{m}^{-1}\right)$ for $30 \mathrm{~min}$. After incubating the cover slips were laid cell side down on acid cleaned glass slides and adhered with clear fingernail polish. 
Instrumental methods, conditions, and parameters for microscopy measurements: For transmission electron microscopy measurements, a small aliquot was ground with methanol in an agate mortar and pestle. A single drop of this suspension was placed on a lacey carbon coated copper TEM grid and dried in air. The TEM examination was completed on a Philips model CM-30 operated at $300 \mathrm{kV}$ at 69,000-340,000 electron optical magnification.

For fluorescence confocal microscopy measurements, HeLa cells were grown on cover slips as reported above. The fluorescence confocal examinations were completed on a Leica TCS NT confocal microscope with UV, argon, and krypton lasers with excitation wavelengths at $340-458 \mathrm{~nm}$, $488 \mathrm{~nm}$, and $568 \mathrm{~nm}$, respectively.

\section{RESULTS AND DISCUSSION}

Following synthesis, some characterizing, and in vitro release investigation; the uncapped MSN, capped MSN, and iron (III) oxide nanoparticle caps were measured by TEM and the endocytosis of the $\mathrm{Fe}_{3} \mathrm{O}_{4}$-capped MSNs into HeLa cells was investigated.

First, TEM investigation confirmed the rod-shape and the average particle size $(200 \mathrm{x} 80 \mathrm{~nm})$ of the uncapped, acid functional MSN (linker-MSN) (Figure la). Transmission 
electron microscopy measurements also confirmed the irregular, spherical shape and average particle size $(10 \mathrm{~nm}$ diameter) of the 3-aminopropyltriethylsilane functional superparamagnetic iron (III) oxide nanoparticles (APTES$\mathrm{Fe}_{3} \mathrm{O}_{4}$ ) (Figure $\mathrm{Ib}$ ). The $10 \mathrm{~nm}$ average pore diameter was chosen, so the pores would be capped but the APTES-Fe $\mathrm{O}_{4}$ is too large to enter the pores (average diameter $3.0 \mathrm{~nm}$ ). Finally, TEM investigations $\mathrm{Fe}_{3} \mathrm{O}_{4}$-capped MSNs also provided direct evidence of the distribution of $\mathrm{Fe}_{3} \mathrm{O}_{4}$ nanoparticles on the organically functionalized linker-MSN material. The $\mathrm{Fe}_{3} \mathrm{O}_{4}$ nanoparticles are clearly visible as dark areas on the outside edge of the mesopores (Figure 1c). In contrast to the feature observed for $\mathrm{Fe}_{3} \mathrm{O}_{4}$-capped MSNs, the TEM micrograph of the linker MSNs (Figure la) prior to capping with $\mathrm{Fe}_{3} \mathrm{O}_{4}$ nanoparticles showed smooth edges and a good contrast between the mesoporous channels and the silica matrix.

To investigate the endocytosis and biocompatibility of our system, Hela (human cervical cancer) cells $\left(10^{5}\right.$ cells $\mathrm{mL}^{-1}$ ) were incubated overnight with $\mathrm{Fe}_{3} \mathrm{O}_{4}$-capped MSNs $(0.2 \mathrm{mg}$ $\mathrm{mL}^{-1}$ ) to allow the endocytosis of $\mathrm{Fe}_{3} \mathrm{O}_{4}$-capped MSNs. The cells that took up $\mathrm{Fe}_{3} \mathrm{O}_{4}$-capped $\mathrm{MSN}$ s were magnetically separated from those that did not. The isolated cells were 
treated with $0.001 \%$ of $4^{\prime}, 6$-diamidino-2-phenylindole (DAPI) dye in PBS solution $(100.0 \mathrm{~mm}, \mathrm{pH} 7.4)$ and placed in a cuvette. DAPI is known to form blue-fluorescent complexes with natural double-stranded DNA and has been widely used as a fluorescent dye for nucleus staining. These DAPIstained, fluorescent cells were first accumulated to the right side wall of the cuvette by applying an external magnetic field-a commercially available grade $\mathrm{N} 45$ neodymium iron boron magnet. When the magnet was moved to the left side of the cuvette, the blue-fluorescent HeLa cells were clearly seen to move across the cuvette toward the magnet (Figure $3 \mathrm{a}-\mathrm{C}$ ) indicating that the $\mathrm{Fe}_{3} \mathrm{O}_{4}$-capped MSNs were indeed endocytosed by HeLd cells. To further confirm the endocytosis of $\mathrm{Fe}_{3} \mathrm{O}_{4}$-capped MSNs, these HeLa cells were examined by confocal fluorescence microscopy. Green fluorescence was clearly observed within the cell bodies of these HeLa cells upon excitation at 494 nm (Figure 3d), which strongly indicates that the mesopore-encapsulated fluorescein molecules were released inside the cells. A series of fluorescence images of different cross-sections of $\mathrm{Fe}_{3} \mathrm{O}_{4}$-capped MSNs -containing HeLa cells were obtained by changing the focal depth every $1.2 \mathrm{~mm}$ vertically (Figure $4 a-f)$ 
As previously reported by Biaglow et al., cancer cell lines express significant amounts of dihydrolipoic acid (DHLA). ${ }^{20}$ We believe that the efficient intracellular release of fluorescein was triggered by the high intracellular concentration of DHLA. To visualize the locations of the nuclei, the cells were excited at $358 \mathrm{~nm}$ (Figure 3e). The appearance of healthy intact nuclei and the visibility of fully grown, healthy cells by transmission (Figure $3 f$ ) suggested that the $\mathrm{Fe}_{3} \mathrm{O}_{4}$-capped MSNs are biocompatible with Hela cells in vitro under these experimental conditions.

In conclusion, we have confirmed the capping of mesoporous silica nanorods by superparamagnetic iron oxide nanoparticles by transmission electron microscopy. The biocompatibility and efficiency of intracellular delivery of $\mathrm{Fe}_{3} \mathrm{O}_{4}$-capped MSN system with human cervical cancer cells offer promising potential in utilization of this system to investigate various inter- and intracellular chemical/neurochemical communications in vitro. Furthermore, we demonstrated that this stimuli-responsive controlled release delivery system based on mesoporous silica nanorods capped with magnetic nanoparticles had a 
magnetic motor effect when in the presence of an external magnetic effect. 


\section{FIGURE LEGENDS}

Figure 1. Schematic of the stimuli-responsive delivery system ( $\mathrm{Fe}_{3} \mathrm{O}_{4}$-capped MSNs) based on mesoporous silica nanorods capped with superparamagnetic iron oxide nanoparticles. The controlled release mechanism of the system is based on reduction of the disulfide linkage between the $\mathrm{Fe}_{3} \mathrm{O}_{4}$ nanoparticle caps and the linker-MSN hosts by reducing agents such as DHLA.

Figure 2. Transmission electron microscopy micrographs of a) linker MSNs, b) APTMS-coated $\mathrm{Fe}_{3} \mathrm{O}_{4}$ nanoparticles, and c) $\mathrm{Fe}_{3} \mathrm{O}_{4}$-capped magnet MSNs.

Figure 3. a-c) Single frames of digital photographs of HeLa cells with $\mathrm{Fe}_{3} \mathrm{O}_{4}$-capped fluorescein-loaded MSNs traveling across the cuvette, propelled by magnet force. d-f) Fluorescence confocal micrographs of HeLa cells after $10 \mathrm{~h}$ incubation with $\mathrm{Fe}_{3} \mathrm{O}_{4}$-capped fluorescein loaded MSNs: cells excited at $494 \mathrm{~nm}$; e) cells excited in 
the UV region; f) a pseudo-brightfield image, where dark aggregations of $\mathrm{Fe}_{3} \mathrm{O}_{4}$-capped MSNs s can be clearly observed.

Figure 4. Fluorescence confocal micrographs of HeLa cells after $10 \mathrm{~h}$ incubation demonstrating endocytosis of $\mathrm{Fe}_{3} \mathrm{O}_{4}$-capped MSNs $\mathrm{s}(\mathrm{a})-(\mathrm{f})$. Each frame represents a focal point with $1.2 \mu \mathrm{m}$ vertical difference. 
FIGURES

Eigure 1.<smiles>O=C([O-])CCCCC1CCSS1</smiles>

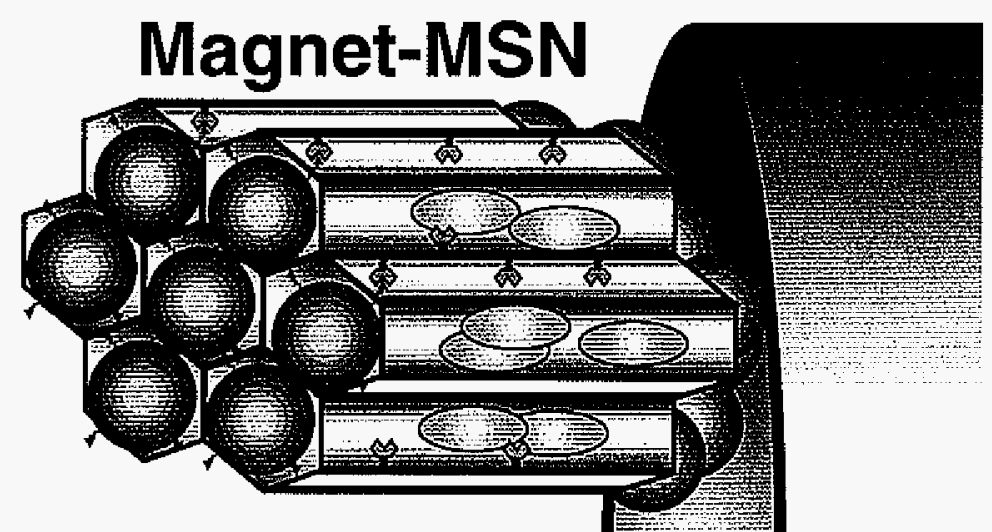

Disulfide Linker Cleavage
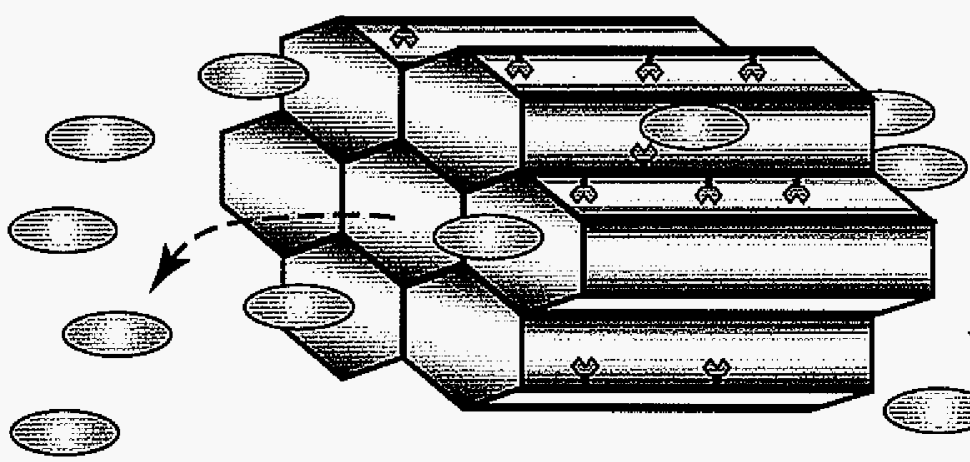
Figure 2 .
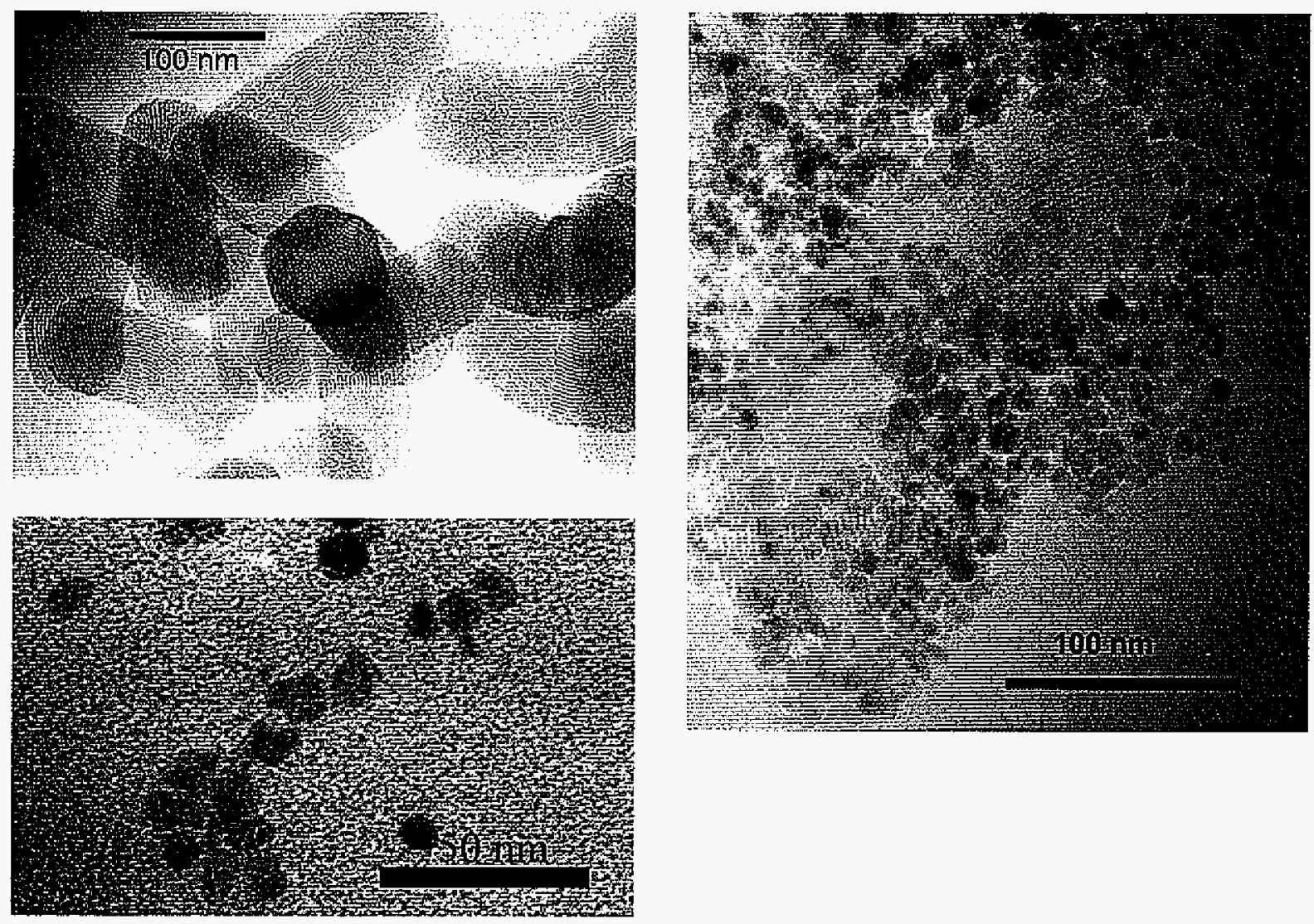
Figure 3.
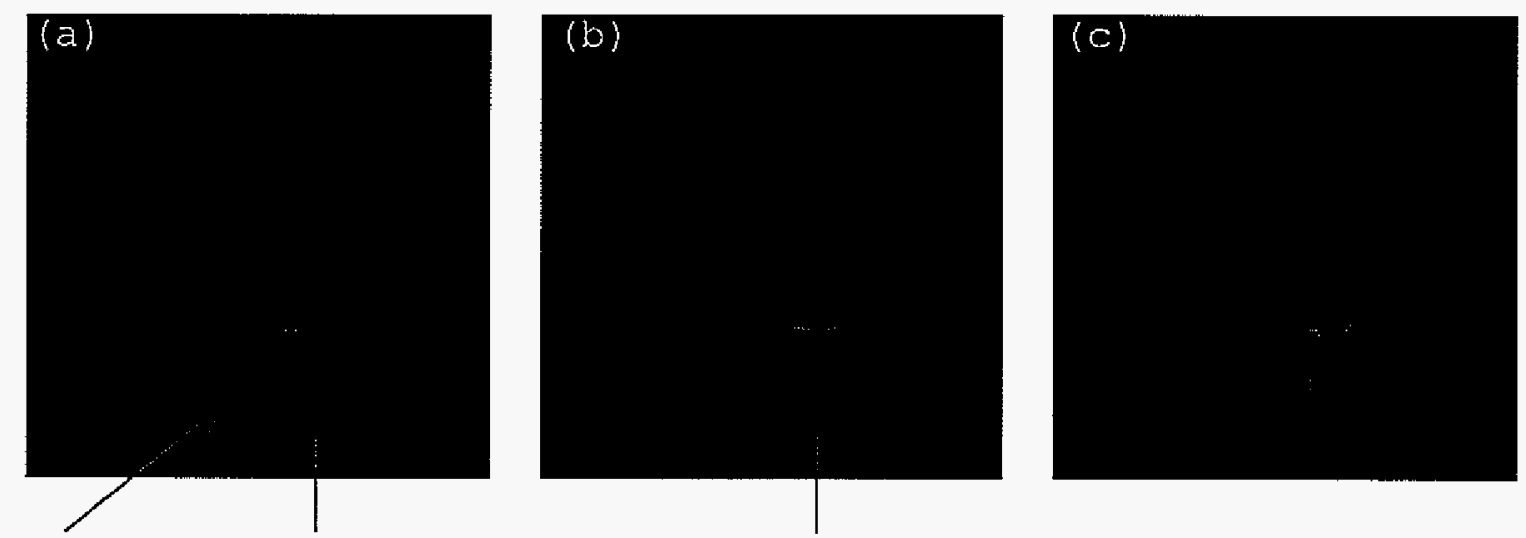

Magnet

Hela Cells

HeLa Cells
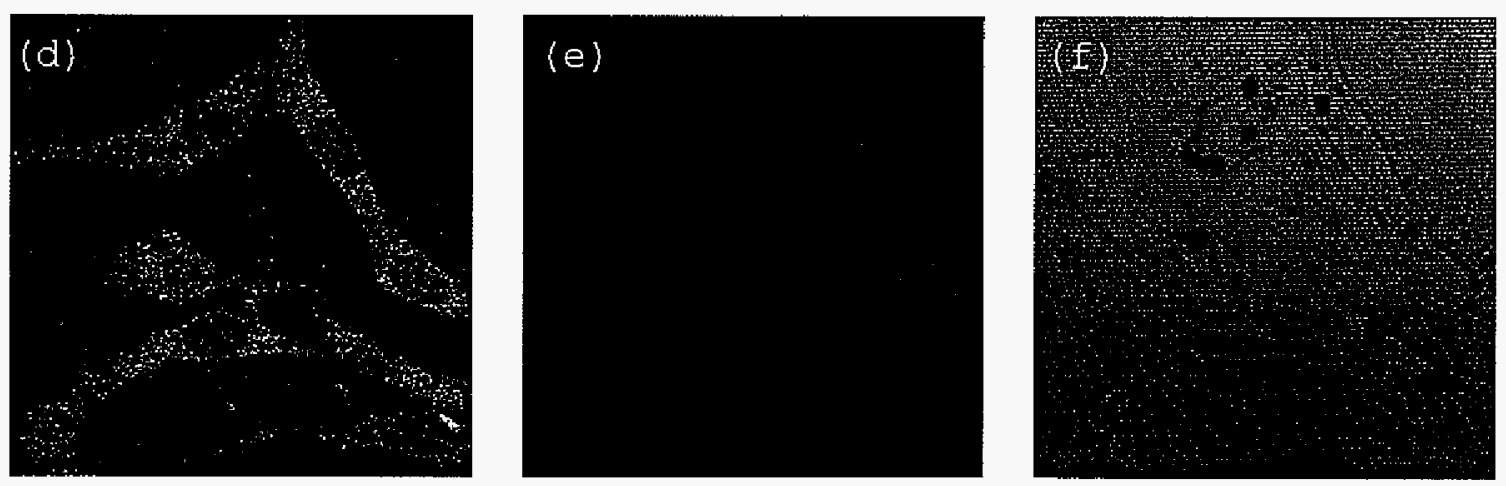
Figure 4.
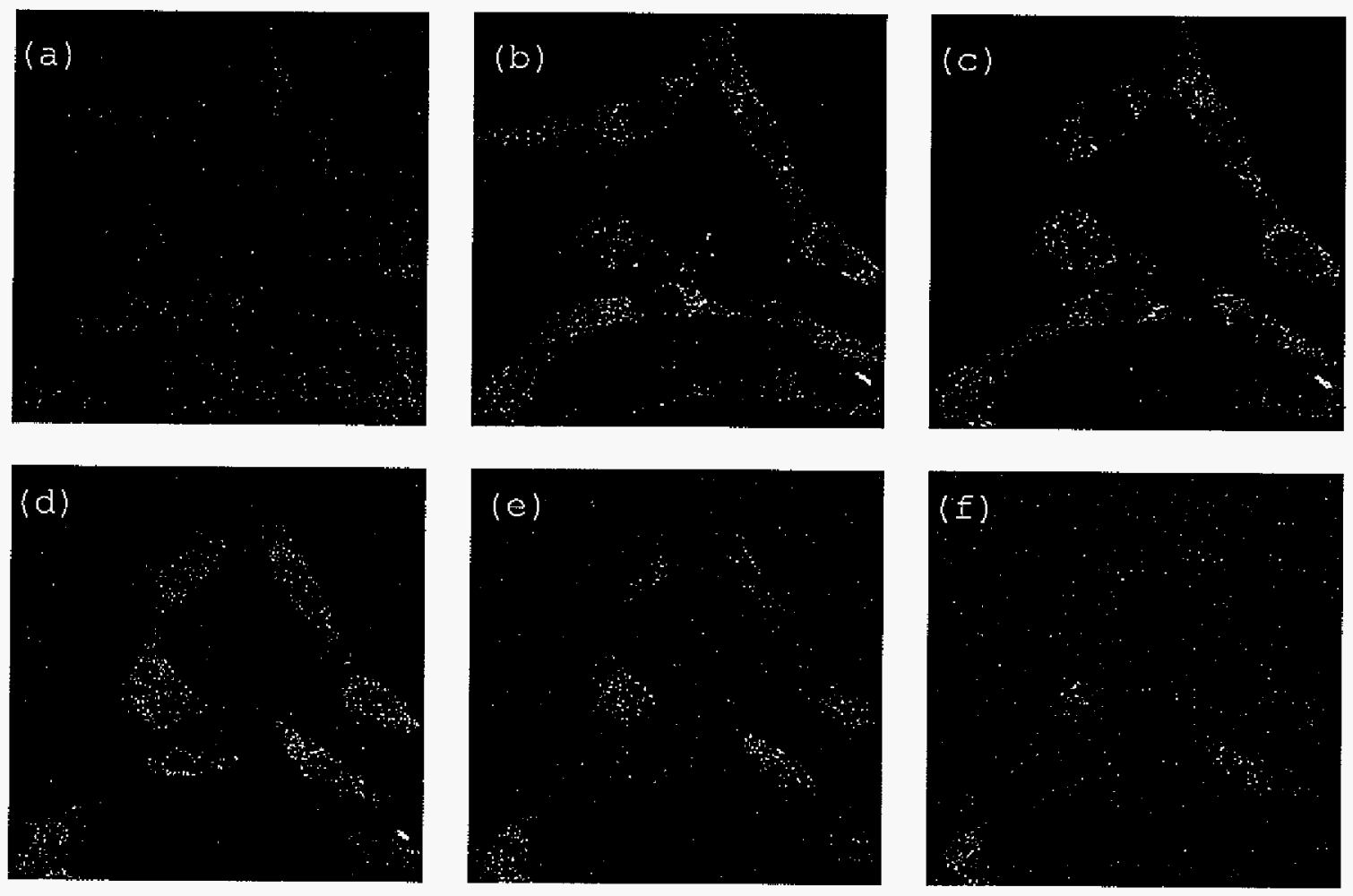


\section{REFERENCES}

(1) Gupta, A. K.; Curtis, A. S. G. Journal of Materials Science: Materials in Medicine 2004, 15, 493-496.

(2) Lubbe, A. S.; Bergemann, C.; Brock, J.; McClure, D. G. Journal of Magnetism and Magnetic Materials 1999, 194, 149-155.

(3) Neuberger, T.; Schoepf, B.; Hofmann, H.; Hofmann, M.; Von Rechenberg, B. Journal of Magnetism and Magnetic Materials $2005,293,483-496$.

(4) Perez, J. M.; Josephson, L.; O'Loughlin, T.; Hogemann, D.; Weissleder, R. Nature biotechnology 2002, 20, 81620.

(5) Jordan, A.; Scholz, R.; Maier-Hauff, K.; Johannsen, M.; Wust, P.; Nadobny, J.; Schirra, H.; Schmidt, H. ; Deger, S.; Loening, S.; Lanksch, W.; Felix, R. Journal of Magnetism and Magnetic Materials 2001, 225, 118126.

(6) Gupta, A. K.; Gupta, M. Biomaterials 2005, 26, 39954021 .

(7) Chattopadhyay, P.; Gupta, R. B. Industrial \& Engineering Chemistry Research 2002, 41, 6049-6058. 
(8) Yoon, T.-J.; Kim, J. S.; Kim, B. G.; Yu, K. N.; Cho, M.-H.; Lee, J.-K. Angewandte Chemie, International Edition 2005, 44, 1068-1071.

(9) Diaz, J. F.; Balkus, K. J., Jr. Journal of Molecular Catalysis B: Enzymatic 1996, 2, 115-126.

(10) Han, Y.-J.; Stucky, G. D.; Butler, A. Journal of the American Chemical Society 1999, 121, 9897-9898.

(11) Munoz, B.; Ramila, A.; Perez-Pariente, J.; Diaz, I.; Vallet-Regi, M. Chemistry of Materials 2003, 15, 500503.

(12) Ramila, A.; Munoz, B.; Perez-Pariente, J.; ValletRegi, M. Journal of Sol-Gel Science and Technology $2003,26,1199-1202$.

(13) Tourne-Peteilh, C.; Brunel, D.; Begu, S.; Chiche, B.; Fajula, F.; Lerner, D. A.; Devoisselle, J.-M. New Journal of Chemistry 2003, 27, 1415-1418.

(14) Vallet-Regi, M.; Doadrio, J. C.; Doadrio, A. I.; Izquierdo-Barba, I.; Perez-Pariente, J. Solid State Ionics $2004,172,435-439$.

(15) Vallet-Regi, M.; Ramila, A.; del Real, R. P.; PerezPariente, J. Chemistry of Materials 2001, 13, 308-311. 
(16) Gruenhagen, J. A.; Lai, C.-Y.; Radu, D. R. ; Lin, V. S. Y.; Yeung, E. S. Applied Spectroscopy 2005, 59, 424431.

(17) Mal, N. K.; Eujiwara, M.; Tanaka, Y. Nature (London, United Kingdom) 2003, 421, 350-353.

(18) Lai, C.-Y.; Trewyn, B. G.; Jeftinija, D. M.; Jeftinija, K.; Xu, S.; Jeftinija, S.; Lin, V. S. Y. Journal of the American Chemical Society 2003, 125, $4451-4459$

(19) Radu, D. R.; Lai, C.-Y.; Jeftinija, K.; Rowe, E. W.; Jeftinija, S.; Lin, V. S. Y. Journal of the American Chemical Society 2004, 126, 13216-13217.

(20) Biaglow, J. E.; Donahue, J.; Tuttle, S.; Held, K.; Chrestensen, C.; Mieyal, J. Analytical biochemistry $2000,281,77-86$ 


\title{
CHAPTER 5. TRANSMISSION ELECTRON MICROSCOPY INVESTIGATION INTO MESOPOROUS MATERIAL AND RELATED STRUCTURES
}

\author{
Brian G. Trewyn and Victor S.-Y. Iin
}

\section{ABSTRACT}

An important characterization technique for the synthesis and application of mesoporous material is transmission electron microscopy. Here we present a survey of some of the mesoporous materials produced in our lab. Included are brief explanations of each project, along with TMM micrographs of the materials.

\section{INTRODUCTION}

Since the invention of the first simple light microscope in 1673 by Antoni van Leeuwenhoek, the field of microscopy has developed incredibly to a point where light is no longer the sole image forming source. Electrons are now used to visualize the details of the microstructural 
characterization of materials. Electron microscopy is simply defined as the science and technology of using a beam of electrons to produce magnified images of specimens. ${ }^{1}$ The invention of the modern day transmission electron microscope (TEM) could not have been made without the work of numerous scientists, many of whom went on to become Nobel laureates. In 1897, J.J. Thomson discovered the electron, work he received the Nobel Prize in Physics for in 1906. Thomson demonstrated that an electron is a particle of very small mass, with a negative charge, and can be deflected by electric and magnetic fields. Prince de Broglie, winner of the Nobel Prize in Physics in 1929, defined the wave nature and wavelength of electrons.

Two individuals are credited with the discovery of the transmission electron microscope in the early 1930s, Max Knoll and Ernst Ruska of the High Voltage Laboratory at the Technological University in Berlin. As part of his student thesis, Ruska built the first operational TEM in 1933. ${ }^{2,3}$ Ruska is also credited with building the first electromagnetic lens suitable for use in an electron microscope to direct the electron beam. ${ }^{4}$ Ruska was awarded the Nobel Prize in Physics in 1986, along with Gerd Binning and Heinrich Rohrer for their work on the design of the 
scanning tunneling microscope. In presenting the award, the Nobel Prize Committee noted the significance of electron microscopes in all areas of science, calling them "one of the most important inventions of the $20^{\text {th }}$ century." The main advantage of using electrons as the imageforming source instead of light is resolution (the ability to distinguish fine detail). The resolving power of a modern light microscope is $200 \mathrm{~nm}$, whereas a TEM can resolve detail to approximately $0.2 \mathrm{~nm}$. Electrons are produced for the imaging beam by an electron gun.

The electron gun is composed of an anode, a wehnelt assembly, and a wire filament (electron source). The three major types of electron gun are tungsten-hairpin filament, lanthanum-hexaboride $\left[\mathrm{LaB}_{6}\right]$ hairpin filament, and the field emission gun. The first two employ thermionic emission, in which the electrons are produced by heating the filament by applying a small voltage differential across the terminals of the filament. The $\mathrm{LaB}_{6}$ gun has several advantages over the tungsten gun. The advantages include a ten-fold increase in beam current and a more narrow point at which the electrons are emitted. The increased beam current is directly related to the beam brightness, while the narrow emission point decreases the energy spread of the emitted 
electron by one-half that of the tungsten-filament gun. Both advantages lead to greater resolution with the $\mathrm{LaB}_{6}$ gun.

The third type of gun, field-emission, gives the best resolution. In high vacuum, electrons are physically drawn off a very finely curved tungsten tip with an applied voltage, The resolution of a field emission gun is improved over a thermionic gun, because of the much greater brightness, and an electron beam of smaller diameter. Finally, a longer lifetime can be expected from a field emission gun over thermionic guns.

After the beam of electrons is formed and passed through the anode, it is controlled by electromagnetic lenses. The beam of electrons passes through the opening in the center and is focused and deflected by magnetic lines of force. These lenses, called pole pieces, concentrate all of the magnetic lines of force in the gap, creating a very powerful lens. All electromagnetic lenses are controlled and focused by varying the electrical current through the lens. In addition to the electromagnetic lens, the electron beam is controlled by apertures. The primary use of these apertures is to limit 
the diameter of the beam and to eliminate stray or widely scattered electrons.

Two lens-aperture separate assemblies are used to control different aspects of specimen imaging. The condenser-lens system controls illumination. The objective lens is the most important and complex lens in a TEM because it is the first magnifying lens. The apertures equipped with the objective lens also control the contrast; the smaller the objective aperture, the greater the contrast. As with many aspects of the TEM, a compromise must be reached between the brightness (condenser assembly) and contrast (objective assembly).

Research in the field of material synthesis, characterization, and application requires transmission electron microscopy measurements to determine size, morphology and porous structure. Reviewers and critics of this area of research require TEM evidence to verify our results and conclusions. The following is a short survey on the work we did on various projects using the TEM. 
All TEMs reported, discussed, and presented in this chapter were measured on a Philips model CM-30 transmission electron microscope operated at an accelerating voltage of $300 \mathrm{kV}$. Sample preparation varied from specimen to specimen .

The solid samples were suspended in water, methanol, or acetone, depending on the hydrophobic or hydrophilic nature of the sample. Following a short sonication the suspensions were placed on an ultrathin carbon film supported by a lacey carbon film on a 400 mesh copper grid via syringe. When the suspendant was water, the grid was placed on a hot plate to expedite the evaporation of the water; the organic suspendants were left at room temperature to evaporate. Some of the specimens presented here necessitated ultramicrotoming for further investigation of the pore structure.

The preparation of ultramicrotomed samples included embedding the samples in EPON epoxy resin using EmBed 812 . The specimens were suspended in the epoxy, centrifuged, and cured for $24 \mathrm{~h}$ at $60{ }^{\circ} \mathrm{C}$ followed by $24 \mathrm{~h}$ at $70{ }^{\circ} \mathrm{C}$. Following the heat treatment, the embedded block was microtomed using a Leica Reichert Ultracut $T$ ultramicrotome 
with a Diatome diamond knife to a thickness of $60-100 \mathrm{~nm}$. Once microtomed, the section was floated on to the same lacey carbon - 400 mesh copper grid. The microtomed samples were also measured on the Philips model CM-30 TEM operating at $300 \mathrm{kV}$. Some ultramicrotomed samples required reduction of the spot size to avoid destruction of the section under the high voltage beam bombardment.

The measurements were recorded on Kodak Electron Image Film so-163. The negatives were then developed by submersion into first Kodak D-19 Professional Developer, followed by Kodak Professional Fixer, for equal amounts of time. All Kodak materials are from the Eastman Kodak Company.

The developed micrographs were then scanned into a computer to get digital images. The Adobe Photoshop software was then used to crop the micrographs to desired size and to accurately add scale bars.

\section{RESULTS AND DISCUSSION}


Transmission electron microscopy investigations began with the synthesis and application of an MCM-41 type mesoporous silica nanosphere-based (MSN) controlled-release delivery system. The MSN was capped with chemically removable cdS nanocrystals to encapsulate several pharmaceutical drug molecules and neurotransmitters inside the mesoporous framework. ${ }^{5}$ Transmission electron micrographs of the uncapped and capped MSN are presented in figure la-d. By using disulfide bond-reducing molecules as release triggers, the stimuli-responsive release profiles of vancomycin- and adenosine triphosphate (ATP)-loaded MSN were studied (Figure le). The biocompatibility and delivery efficiency of the MSN system with astrocytes in vitro were also demonstrated.

The second project presented here is unique in that the material synthesized templated by anionic sodium dodecyl sulfate surfactant. Using a novel method, a mesoporous silica-supported uranyl material $\left(\mathrm{U}_{\mathrm{aqO}}{ }^{2+}-\mathrm{silica}\right)$ were prepared by a co-condensation method under acidic conditions. ${ }^{6}$ An application of this material involved an excitation of aqueous suspensions of $\mathrm{UagO}_{2}{ }^{2+}-$ silica in the visible or near-UV region and photocatalyzing the oxidation of alcohols with $\mathrm{O}_{2}$ (Figure 2a). The material was not MCM- 
41 type; i.e. it had a disordered pore arrangement. The TEM micrographs (Figure $2 \mathrm{~b}$ and 2c) showed a wormhole-like porous structure, which confirmed the observation in the surface sorption BET studies.

Another project, reported in 2003, introduced the development of a synthetic method that can control both the multifunctionalization and morphology of mesoporous organic-inorganic hybrid materials and was reported in 2003. ${ }^{7}$ The morphology can be controlled by introducing different molar ratios of organoalkoxysilane precursors to a base-catalyzed co-condensation of silicate. One example of this morphology control was measured by TEM (Figure 3). By incorporating 12.8 mol응 cyanopropyltriethoxy-silane (CPTES) in the material synthesis, a rod-shaped morphology was observed with an average size of $1 \times 0.2 \mu \mathrm{m}$, in contrast to pure MCM-41, which exhibits irregular spherical shapes. The multifunctionalization of the materials with two organoalkoxysilanes, $\quad 3-[2-(2$-aminoethylamino) ethylamino propyltrimethoxysilane (AEPTMS) and CPTES, demonstrated the incorporation of differing ratios of the two organoalkoxysilanes resulted in spherical particles of differing sizes and degrees of polydispersity. Since all the AEPTMS functionalized materials showed spherical 
morphology, and no rod-shaped particles were formed from the bifunctional material, it was concluded that the presence of AEPTMS precursor in the co-condensation reaction played a crucial role in governing the particle shape.

Calcia-silica materials were prepared via a cocondensation method under basic conditions. The calcium is incorporated into the silica framework, as opposed to discrete calcium oxide crystalline sites. The materials can be utilized as catalysts for the esterification of biomass feedstocks, such as soybean oil and poultry fat, by reaction of the feedstock with catalyst in methanol at elevated temperatures. Biodiesel methyl esters result, and the catalyst may be reused in successive esterification reactions. Three materials were synthesized, each with a different amount of calcium oxide incorporated. The higher calcium oxide content materials catalyzed the esterification of biomass to biodiesel methyl esters with faster conversion rates.

An inorganic-organometallic hybrid material in which a palladium organophosphine complex was integrated into the pore walls of highly ordered microstructured silica (PdPMO) as synthesized by co-condensation. This material 
catalyzed the suzuki coupling reaction of ethyl 4bromobenzoate with phenylboronic acid, and exhibits high recyclability. This material was challenging in that the average pore diameter could not be accurately determined by conventional nitrogen surface sorption analysis, since the average pore diameter was below $20 \AA$. The TEM micrograph was used to determine a pore size of $19 \AA$ by digitally measuring the distance between two parallel lanes of the silica framework (Figure 5a). Another interesting aspect of this material is its biphasic. The material possesses regular, hexagonal parallel pore structure in selected areas (Figure 5a) and, other areas of wormhole pore structure (Figure 5b). Both types of pore structure seem to form within close proximity (Figure 5c). The reason for the biphasic nature of the material is unclear, but a possible contributing factor is that the synthesis includes both aqueous and organic solvents. The organoalkoxysilane is suspended in acetonitrile, while the silane monomer is hydrolyzed in an acidic aqueous phase.

Transmission electron microscopy is an important characterization technique to investigate the synthesis and application of mesoporous material. Here we presented the TEM images and gave short reviews of mesoporous materials 
produced and applied in our lab for use in biological and catalytic systems. 


\section{FIGURE LEGENDS}

Figure 1. Transmission electron micrographs of microtomed amine functional MSN (a and $c$ ) and microtomed CdS nanoparticle capped ATP loaded MSN (b and $d$ ). The first two micrographs. ( $a$ and $b$ ) are orientated so the pores are orthogonal to the electron beam, while the second two micrographs (c and d) are orientated parallel to the electron beam. The mesoporous channel structure of the nanoparticles is visualized with the parallel stripes (a and $\mathbf{b}$ ) and the hexagonally packed light dots (c and d) shown in the micrographs. The labile linker is a reducible disulfide linkage. The blue arrows indicate the aggregation of CdS nanoparticles on the exterior surface of the MSN material. The green arrow indicates an area, which the MSN is capped by the CdS, displayed by light dots packed in a disordered symmetry. An uncapped region is indicated by the red axrow, where the hexagonal arranged pores is readily visible. Schematic representation of the CdS nanoparticle-capped MSN based drug/neurotransmitter delivery system (e). 
Figure 2. Transmission electron micrographs of microtomed mesoporous silica-supported uranyl material synthesized by the co-condensation method (a and b). A schematic representation of the chemical nature inside the pores and the photochemical reaction that is catalyzed by the $\mathrm{U}_{\mathrm{aq}} \mathrm{O}_{2}{ }^{2+}-\mathrm{silica}$ (c) .

Figure 3. Transmission electron micrograph of 3-cyanopropyl functionalized MSN synthesized by the cocondensation method.

Figure 4. Transmission electron micrographs of calciasilica material synthesized by the cocondensation method under basic conditions.

Figure 5. Transmission electron micrographs of the Pd-PMO material synthesized by the co-condensation method under acidic conditions (a-c). The red arrows indicate the hexagonally ordered parallel pores, and the blue arrows indicate the wormhole, disordered pores.

\section{FIGURES}


Figure 1a-d.
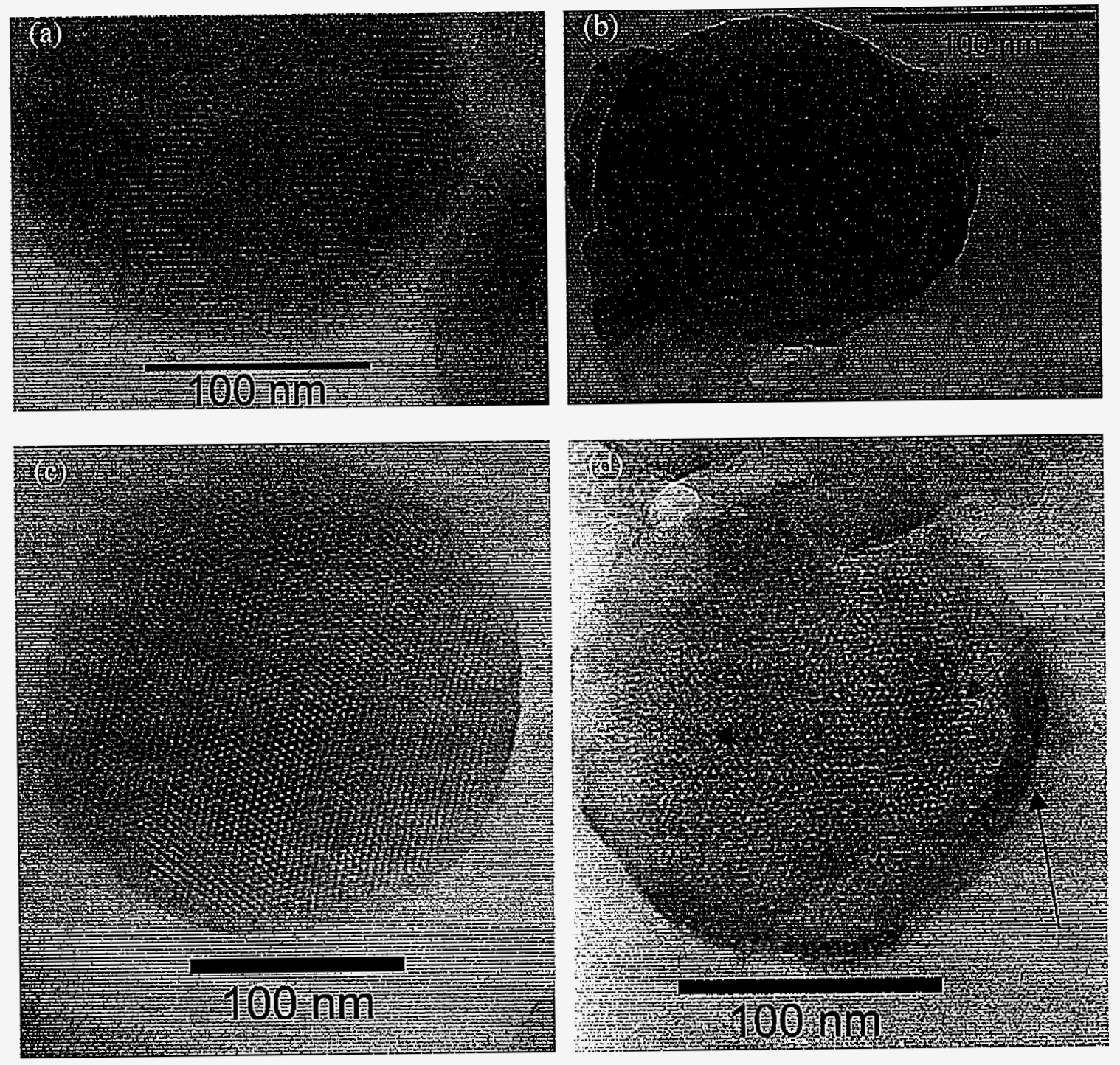
Figure 1e.

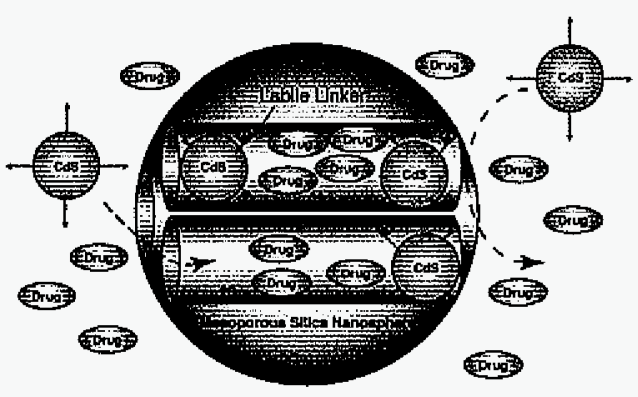

Capping

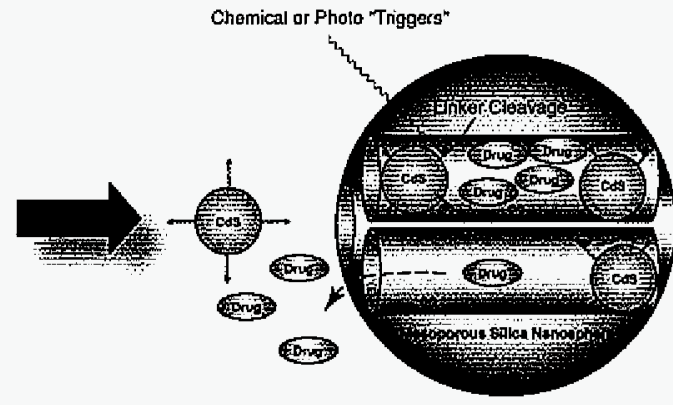

Uncapping 
Figure 2 .

(a) $\left(\mathrm{CH}_{3}\right)_{2} \mathrm{CHOH}+\mathrm{O}_{2} \frac{h v}{\mathrm{U}_{\mathrm{aq}} \mathrm{O}_{2}{ }^{2+} \text { - silica }}\left(\mathrm{CH}_{3}\right)_{2} \mathrm{CO}+\mathrm{H}_{2} \mathrm{O}_{2}$
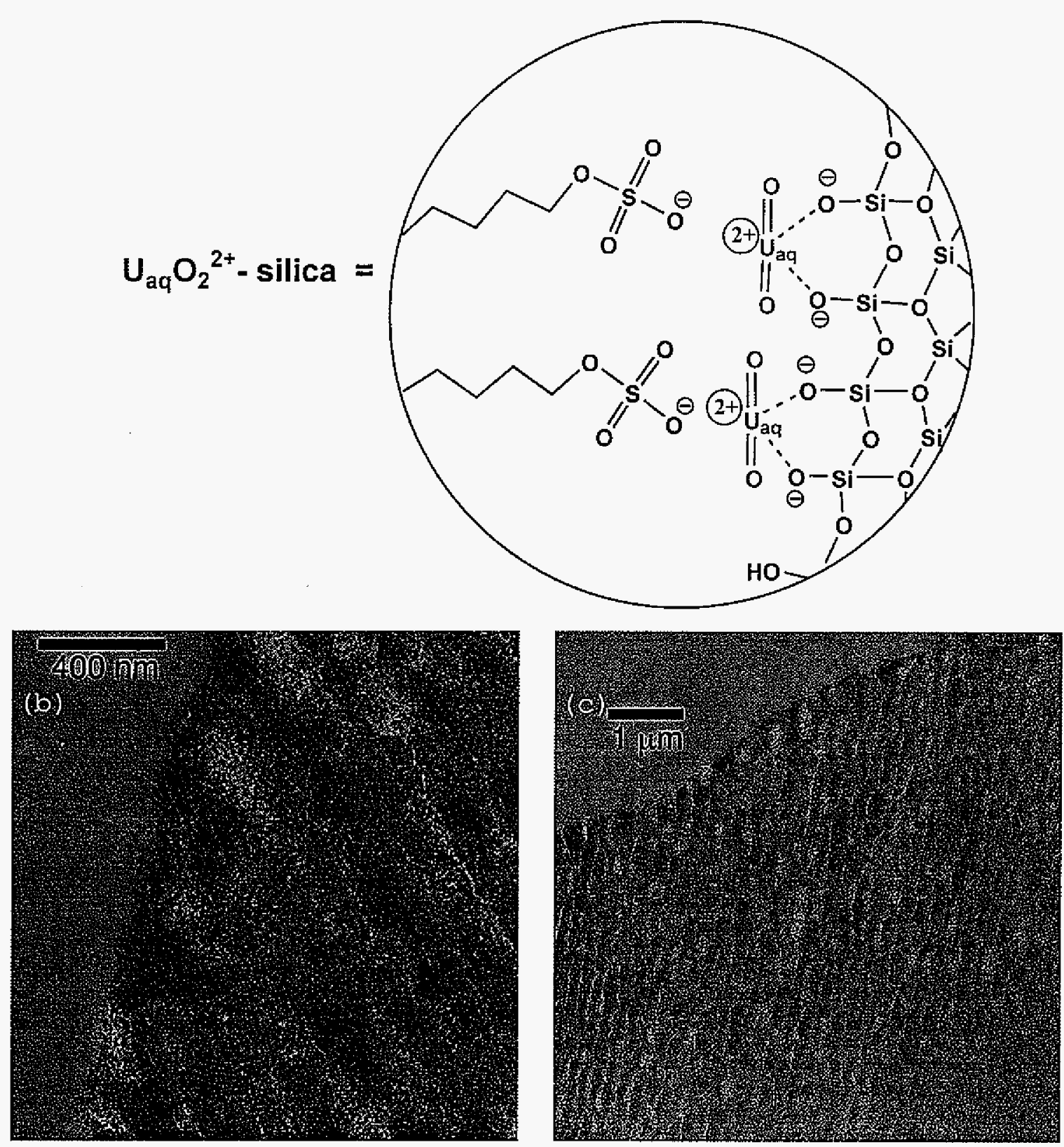
Figure 3.

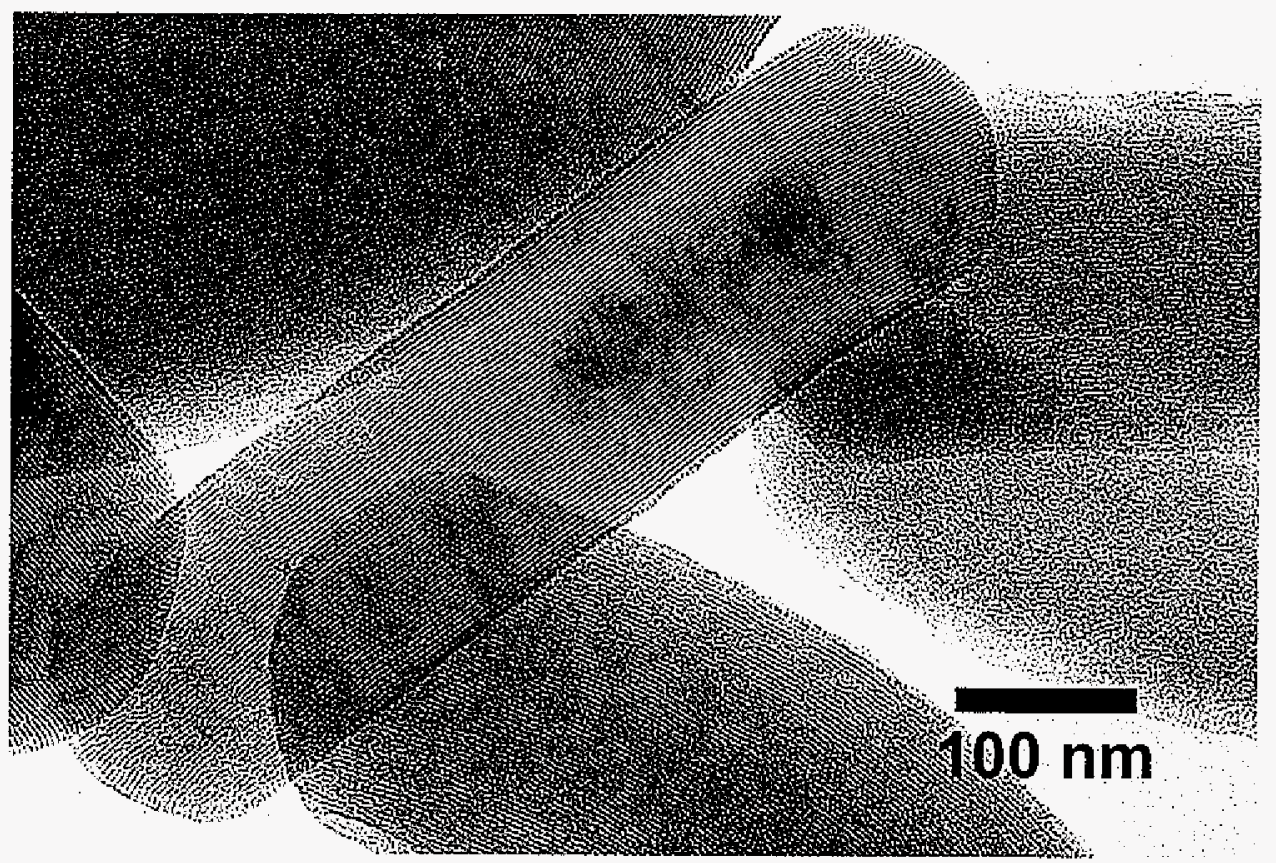


Figure 4 .
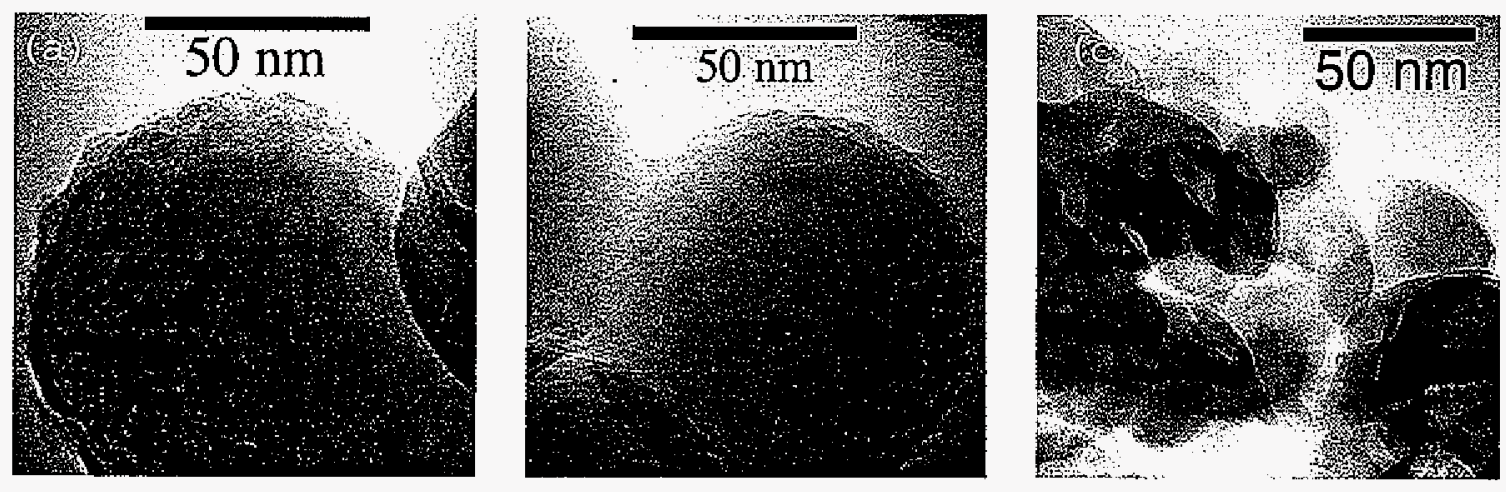
Figure 5.
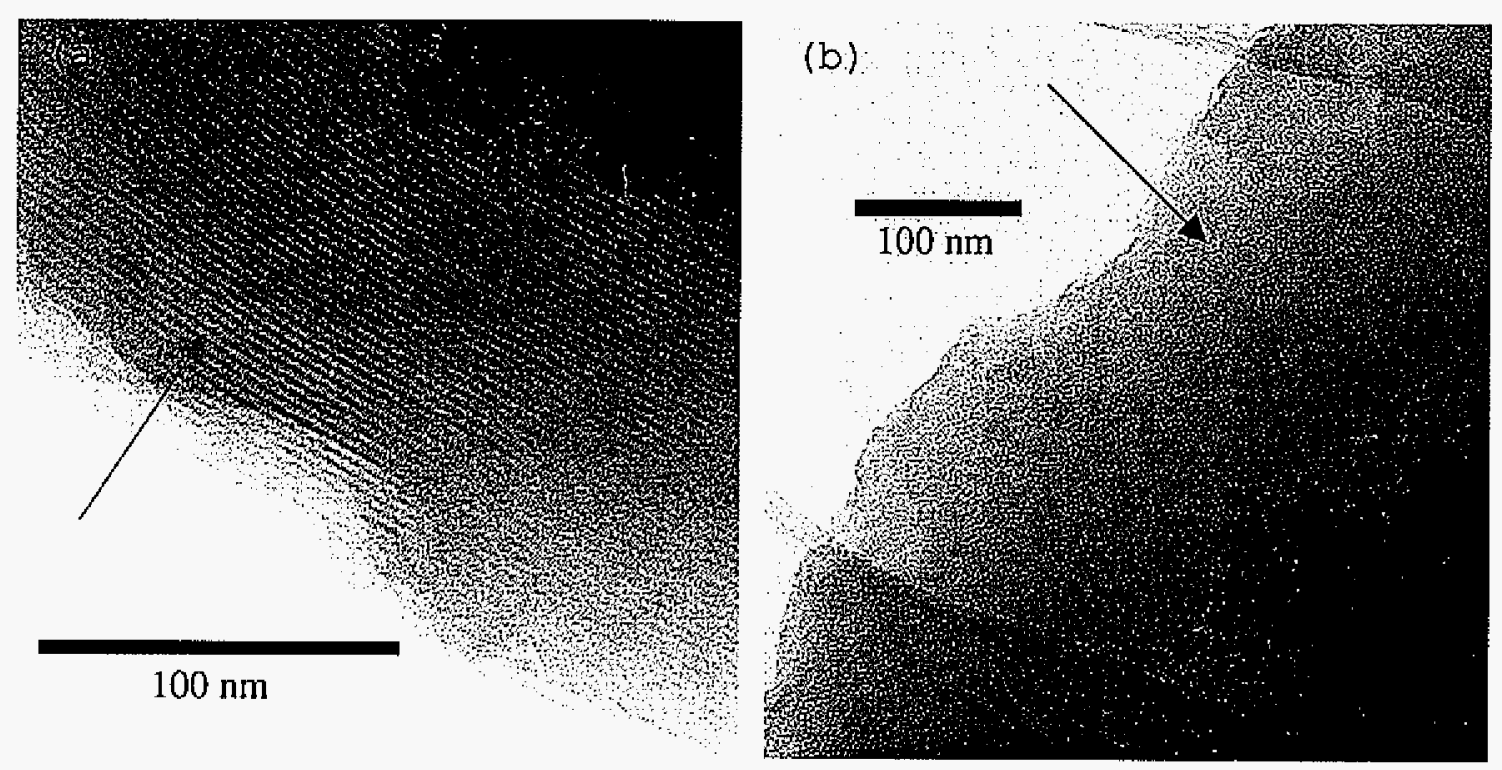

(c)

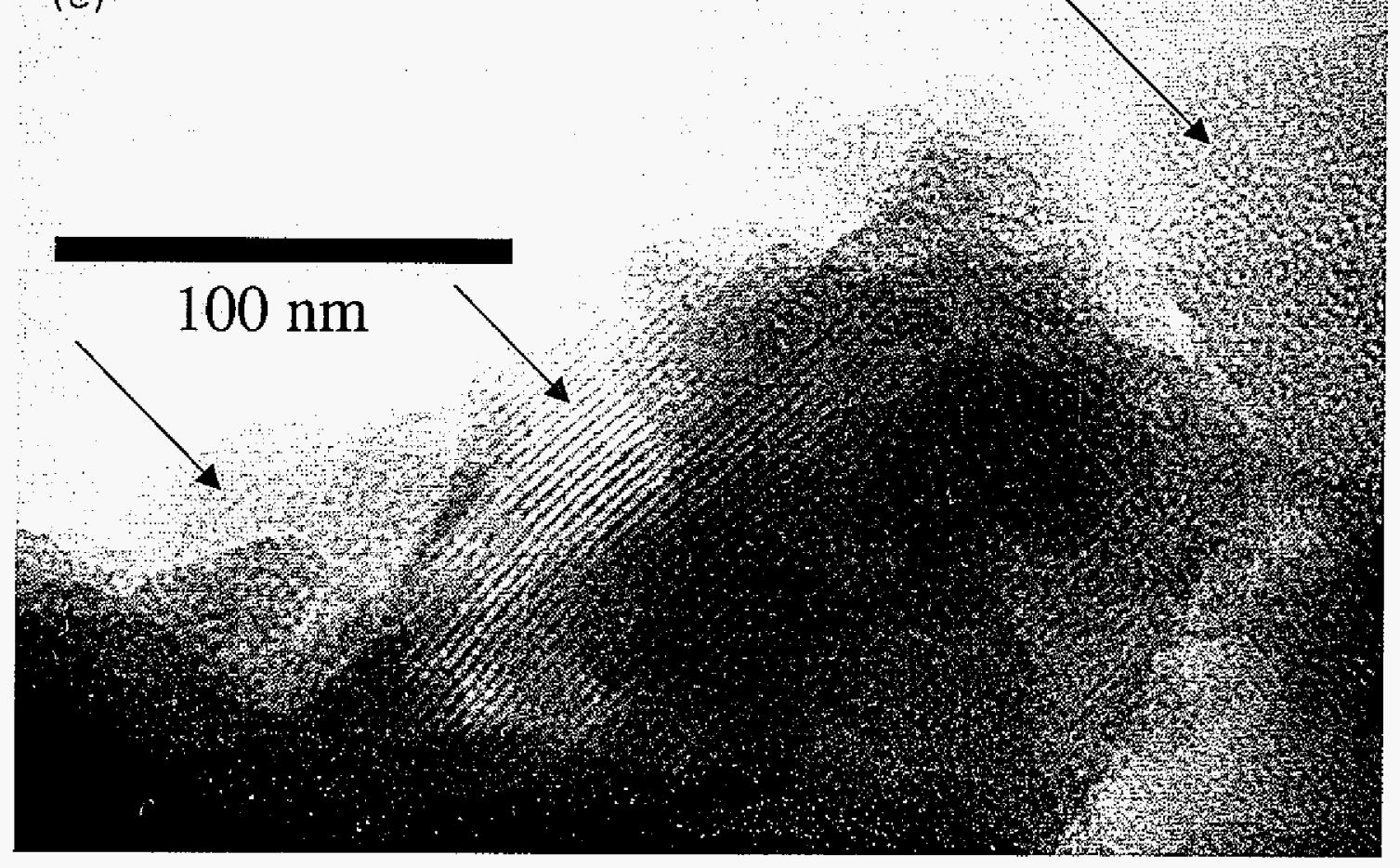




\section{REFERENCES}

(1) Flegler, S. L.; Heckman, J. W., Jr; Klomparens, K. L. Scanning and Transmission Electron Microscopy: An Introduction; Oxford University Press: New York, 1993.

(2) Ruska, E. Zeitschrift fuer Physik 1933, 83, 492-7.

(3) Knol1, M.; Ruska, E. Zeitschrift fuer Physik 1932, 78, $318-39$

(4) Ruska, E. Zeitschrift fuer Physik 1934, 89, 90-128.

(5) Lai, C.-Y.; Trewyn, B. G.; Jeftinija, D. M.; Jeftinija, K.; Xu, S.; Jeftinija, S.; Lin, V. S. Y. Journal of the American Chemical Society 2003, 125, $4451-4459$.

(6) Nieweg, J. A.; Lemma, K.; Trewyn, B. G.; Lin, V. S. Y.; Bakac, A. Inorganic Chemistry 2005, 44, 5641-5648.

(7) Huh, S.; Wiench, J. W.; Trewyn, B. G.; Song, S.; Pruski, M.; Lin, V. S. Y. Chemical Communications (Cambridge, United Kingdom) 2003, 2364-2365. 


\section{CHAPTER 6. GENERAL CONCLUSIONS}

Research into the field of mesoporous materials vast vast and ever expanding field due to the growing number of possible applications available. Mesoporous material exhibits numerous characteristics, including high surface area, varying pore size, large specific pore volume, chemical inertness, and biocompatibility. These materials may be functionalized, loaded with host molecules, capped, and used as controlled release vehicles; functionalized mesoporous materials have also been shown to effectively catalyze various reactions. Examples of both these biological and catalytic applications are reported and discussed within.

First, a series of ionic liquid (IL) containing mesoporous silica nanoparticle materials with various particle morphologies was synthesized. By changing the II template, the pore morphology was tuned from the MCM-41 type of hexagonal mesopores, to rotational moiré type of helical channels, and finally to wormhole-like porous structures. These materials were used as controlled 
release delivery nanodevices to release antibacterial ionic liquids against $E$. coli.

The effect of a specific organosiloxane functional group covalently attached to the exterior of fluorescein doped mesoporous silica nanoparticles on the degree and kinetics of endocytosis into cancer and plant cells was investigated. The kinetics of endocystosis of TEG coated FITC-MSN is significantly quicker, than FITC-MSN as determined by flow cytometry experiments. The fluorescence confocal microscopy investigation showed the endocytosis of TEG coated-FITC MSN into both Hela cells and Tobacco protoplasts.

Once the synthesis of a controlled-release delivery system based on MCM-41-type mesoporous silica nanorods capped with superparamagnetic iron oxide nanoparticles was completed, the material was characterized, and the dosage and kinetics of the antioxidant dependent release was determined; the TEM measurements were recorded and the biological interaction of the material with cancer cells was determined. The electron microscopy investigation proved that the pore openings of the MSN were indeed blocked by the $\mathrm{Fe}_{3} \mathrm{O}_{4}$ nanoparticles. The biological interaction investigation demonstrated $\mathrm{Fe}_{3} \mathrm{O}_{4}$-capped $\mathrm{MSN}$ endocytosis into 
Hela cells. Not only does the material enter the cells through endocytosis; but also it seems the fluorescein was released from the pores, likely caused by cell-producing disulfide bond reducing molecules. Upon endocytosis, the $\mathrm{Fe}_{3} \mathrm{O}_{4}$-capped MSNs were able to propel the cells across a cuvette upon induction of a magnetic force.

Finally, an important aspect of nanostructured material characterization is transmission electron microscopy (TEM) and the importance of a complete TEM investigation was shown for the various materials produced. It was demonstrated that incorporating different functional groups (organic and inorganic) during the synthesis (cocondensation) changes the particle and pore morphologies.

One of the most promising directions of mesoporous material is its fusion with biology and biotechnology. Future possible applications of this material include the intracellular controlled release of drugs and cellular markers from the pores. If the pores can be loaded with highly active anti-cancer drugs and released selectively in cancer cells, then some of the detrimental side effects of the current "shotgun" approach to cancer therapy can be avoided. The pores may similarly be loaded with fluorescent cell markers and released after the mesoporous 
nanoparticles enter the cell. Currently, cells are labeled by endocytosis of ester protected fluorescent tags, and the rate of intracellular diffusion cannot be controlled. If, at a later date, the rate of uncapping of the MSN can be controlled then it may be possible to record some cellular functions that are currently not observable.

In addition to the applications discussed in this dissertation, various other potential applications in microelectronics, sensors, and molecular wires are currently being exploited. These potential research opportunities will continue to expand with the development of new surface and framework modification techniques, pore structure, and composition. 